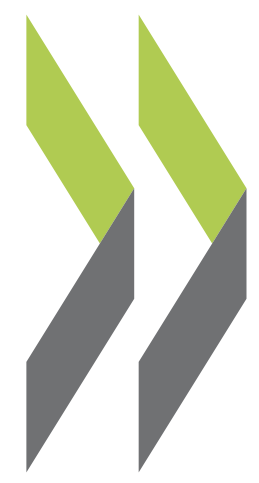

OECD Economics Department Working Papers No. 1402

\author{
The global income \\ distribution for high-income \\ countries
}

Mikkel Hermansen 
Organisation de Coopération et de Développement Économiques

Organisation for Economic Co-operation and Development

13-Jul-2017

ECONOMICS DEPARTMENT

English - Or. English

THE GLOBAL INCOME DISTRIBUTION FOR HIGH-INCOME COUNTRIES

ECONOMICS DEPARTMENT WORKING PAPERS No. 1402

By Mikkel Hermansen

OECD Working Papers should not be reported as representing the official views of the OECD or of its member countries. The opinions expressed and arguments employed are those of the author(s).

Authorised for publication by Christian Kastrop, Director, Policy Studies Branch, Economics Department.

All Economics Department Working Papers are available at www.oecd.org/eco/workingpapers.

JT03417352

Complete document available on OLIS in its original format

This document, as well as any data and map included herein, are without prejudice to the status of or sovereignty over any territory, to the delimitation of international frontiers and boundaries and to the name of any territory, city or area. 
OECD Working Papers should not be reported as representing the official views of the OECD or of its member countries. The opinions expressed and arguments employed are those of the author(s).

Working Papers describe preliminary results or research in progress by the author(s) and are published to stimulate discussion on a broad range of issues on which the OECD works.

Comments on Working Papers are welcomed, and may be sent to OECD Economics Department, 2 rue André Pascal, 75775 Paris Cedex 16, France, or by e-mail to eco.contact@oecd.org.

All Economics Department Working Papers are available at www.oecd.org/eco/workingpapers.

This document and any map included herein are without prejudice to the status of or sovereignty over any territory, to the delimitation of international frontiers and boundaries and to the name of any territory, city or area.

The statistical data for Israel are supplied by and under the responsibility of the relevant Israeli authorities. The use of such data by the OECD is without prejudice to the status of the Golan Heights, East Jerusalem and Israeli settlements in the West Bank under the terms of international law.

Latvia was not an OECD member at the time of preparation of this publication. Accordingly, Latvia does not appear in the list of OECD members and is not included in the zone aggregates.

(C) OECD (2017)

You can copy, download or print OECD content for your own use, and you can include excerpts from OECD publications, databases and multimedia products in your own documents, presentations, blogs, websites and teaching materials, provided that suitable acknowledgment of OECD as source and copyright owner is given. All requests for commercial use and translation rights should be submitted to rights@oecd.org 


\section{ABSTRACT/RESUMÉ The Global Income Distribution for High-Income Countries}

This paper presents the global income distribution between all individuals living in the developed world. Global inequality for the group of high-income countries, as measured by the Gini coefficient, stands at 37 in 2013 and has increased by almost 3 Gini points since the mid-1990s. This was mainly driven by top $10 \%$ incomes growing more than middle and lower incomes and the bottom $10 \%$ falling behind. Rising inequality within the United States drives almost half of the inequality increase among high-income countries, a combination of a sizeable rise in inequality and a population share around a third in the sample. The broad global middle in high-income countries, located from the $10^{\text {th }}$ to the $90^{\text {th }}$ percentile, experienced strikingly similar disposable income growth, but at a very slow annualised rate around $0.5 \%$. Robustness analyses show that this low-growth result is sensitive to declining real incomes in Japan and that scaling micro-based incomes to national accounts means, to include in-kind transfers such as healthcare and educational services, lifts measured household income growth substantially. Finally, the paper delivers a methodological contribution by decomposing the global growth incidence curve into within- and between-country components, allowing for a more granular assessment of the development than is possible by decomposing inequality indices. The decomposition shows that between-country income differences contributed little to growing inequality in the group of high-income countries.

JEL codes: D31, D63, F60

Keywords: Global inequality, high-income countries, income distribution, between-country inequality.

$* * * * * * * * * *$

\section{La distribution mondiale des revenus dans les pays à haut revenu}

Ce document présente la distribution mondiale des revenus entre tous les individus qui vivent dans des pays développés. Les inégalités globales au sein du groupe des pays à haut revenu, mesurées par le coefficient de Gini, s'établissaient à 37 en 2013 et ont augmenté de près de 3 points depuis le milieu des années 90. Cette évolution résulte principalement d'une progression des revenus de la tranche des $10 \%$ des individus les plus aisés qui a été plus forte que celle des titulaires de revenus intermédiaires et faibles, tandis que la tranche des $10 \%$ les plus pauvres accuse un retard. L'aggravation des inégalités aux États-Unis génère près de la moitié de la hausse des inégalités dans les pays à haut revenu, car ce pays cumule une forte montée des inégalités et une population qui représente un tiers de l'échantillon. La tranche médiane des habitants des pays à haut revenu, qui se situe entre le $10^{\mathrm{e}}$ et le $90^{\mathrm{e}}$ centile, a enregistré une croissance étonnamment similaire de son revenu disponible, mais à un taux annualisé très faible de l'ordre de $0.5 \%$. Les analyses de robustesse montrent que ce résultat de faible croissance est sensible au recul des revenus réels au Japon et que la transposition des revenus au niveau des ménages dans les comptes nationaux, de façon à inclure les transferts en nature tels que les soins de santé et les services éducatifs, fait sensiblement augmenter la mesure de la progression du revenu des ménages. Enfin, ce document apporte une contribution méthodologique en décomposant la courbe d'incidence de la croissance mondiale en composantes nationale et internationale, ce qui permet d'aboutir à une évaluation plus détaillée du développement que la décomposition des indices d'inégalités. Cette décomposition révèle que les différences de revenus entre pays ont peu contribué à l'aggravation des inégalités dans le groupe des pays à haut revenu.

Codes JEL: D31, D63, F60

Mots-clés : Inégalités globales, pays à haut revenu, distribution du revenu, inégalités entre pays. 


\section{TABLE OF CONTENTS}

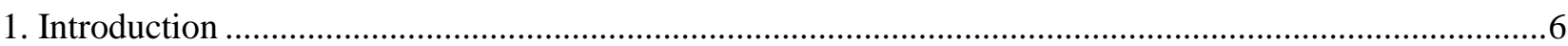

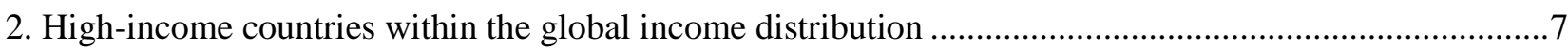

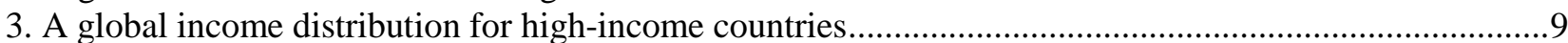

3.1 Data for high-income countries from the OECD Income distribution Database...............................

3.2 Inequality measures of the global income distribution for high-income countries ..........................11

4. The trend in the global income distribution for high-income countries .................................................14

4.1 Rising inequality and slow-growing middle-class incomes .......................................................... 14

4.2 Decomposing the global growth incidence curve into within- and between-countries components 18

4.3 The role of rising market income inequality ...............................................................................

4.4 Country movements: best and worst performance in the global income distribution for high-

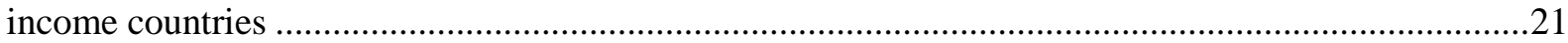

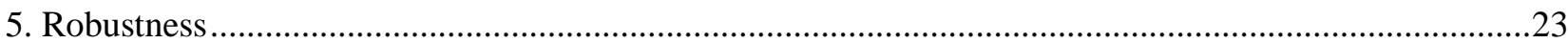

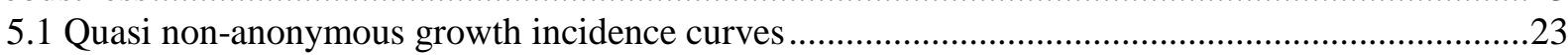

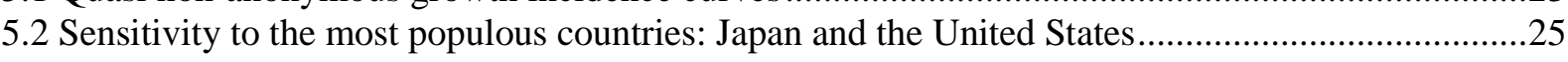

5.3 Scaling incomes to comply with national accounts means and adding social transfers in-kind ......26

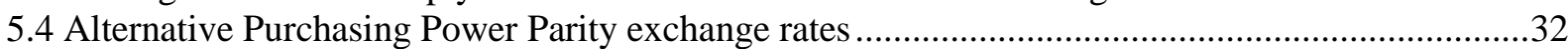

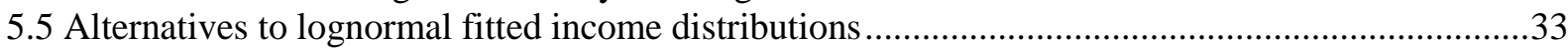

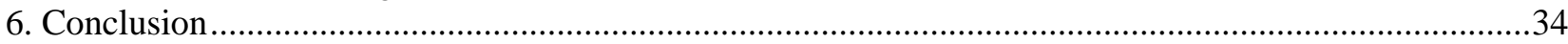

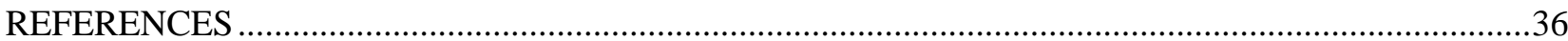

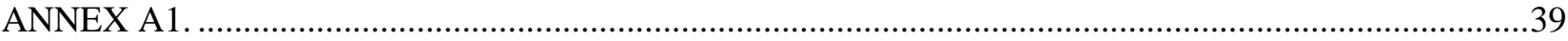

\section{Tables}

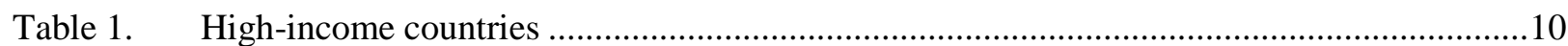

Table 2. Global income distribution for high-income countries.......................................................12

Table 3. The trend in the global household disposable income distribution for high-income countries15

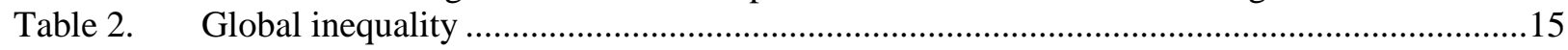

Table 4. Household income adjustments to national account measures ............................................28

Table 5. Inequality trends for household incomes adjusted to national accounts means....................31

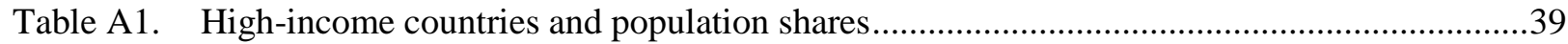

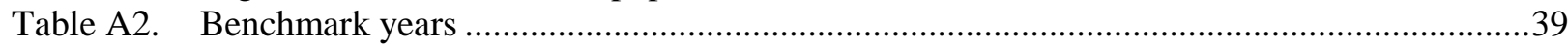

\section{Figures}

Figure 1. High-income countries within the global income distribution ..........................................

Figure 2. The composition of the global income distribution for high-income countries.....................13

Figure 3. More unequal global income distribution for high-income countries, mainly

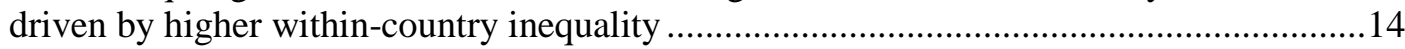

Figure 4. Global growth incidence curve for high-income countries..............................................17

Figure 5. Decomposing the global growth incidence curve for high-income countries into

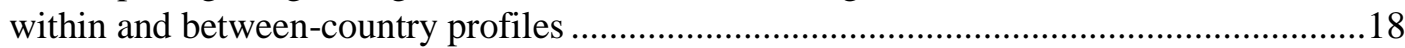

Figure 6. Global growth incidence curve for high-income countries: household market incomes for the working-age population .......................................................................2

Figure 7. Movements of selected countries within the global income distribution for high-income countries 
Figure 8. Quasi non-anonymous global growth incidence curves for high-income countries .........24

Figure 9. The weight of United States and Japan in the global growth incidence curve

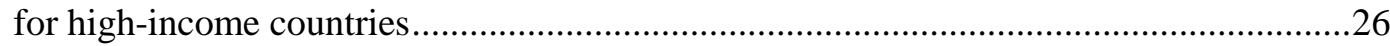

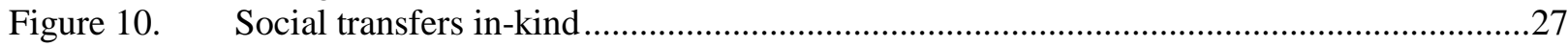

Figure 11. Growth incidence curves for incomes scaled to national accounts measures.....................32

Figure 12. Robustness to the choice of baseyear PPP: Global growth incidence curve for high- income countries .............................................................................................3

Figure 13. Robustness to lognormal fitted income distribution: Global growth incidence curve for high-income countries ......................................................................................34

Figure A1. Density of high-income countries' global income distribution: OECD Income Distribution data vs Lakner-Milanovic data ........................................................................4

Figure.A2. The global income distribution for high-income countries based on decile

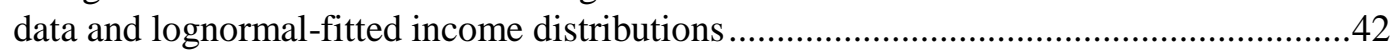

Figure A3. Composition of the global income distribution for 17 high-income countries ..................43

Figure A4. Decomposing the global growth incidence curve for high-income countries into within and between-country profiles: subperiods .............................................................4

Figure A5. Decomposing the global growth incidence curve from Lakner and Milanovic (2016) into within and between-country components ....................................................45

Figure A6. Movements of individual countries within the global income distribution for

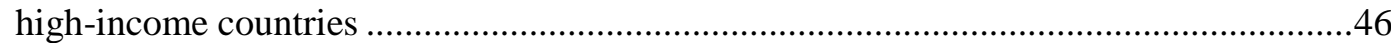

Figure A7. Quasi non-anonymous global growth incidence curves for high-income countries..........48

Figure A8. Micro-based household incomes versus national account means...................................49

Figure A9. Position within global income distribution for high-income countries for different

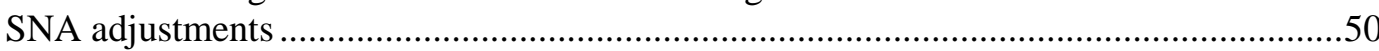




\title{
THE GLOBAL INCOME DISTRIBUTION FOR HIGH-INCOME COUNTRIES
}

\author{
By Mikkel Hermansen ${ }^{1}$
}

\section{Introduction}

1. The distribution of household incomes is usually analysed among individuals within a country, whereas inequality between countries is quantified in terms of differences in GDP per capita or average incomes. The analysis of the global income distribution is one way of combining the within-country and between-countries approaches in a coherent framework. The global income distribution refers to the distribution of incomes between all individuals in the world, irrespective of their country of residence. ${ }^{2}$ This perspective has received growing attention (see Milanovic, 2016; Lakner and Milanovic, 2016; Anand and Segal, 2015; Hammar and Waldenström, 2017), driven by renewed interest in globalisation and rising factor mobility, not least for drawing international migration implications.

2. The global income distribution approach has been used to analyse the global impact of fast growing large emerging economies such as China and India, showing in a nutshell that income convergence has driven down inequalities between countries, more than offsetting rising income inequalities within countries, hence resulting in declining global world-level inequalities (Lakner and Milanovic, 2016). For developing countries, Ravallion (2014) applied the concept to show that global inequality for the developing world as a whole has declined from the 1980s to 2010; an outcome of falling between-country inequality, partly mitigated by slowly increasing within-country inequality. Income inequality for the European Union as a whole has also been analysed, for instance by Frederiksen (2012). But the global inequality approach has not yet been used in the context of advanced countries. The purpose of this paper is therefore to analyse global inequality for the developed world as a whole, encompassing high-income countries as defined by the World Bank.

3. Income inequality has become a key concern for policy makers in many high-income countries and its potential link to globalisation has recently attracted renewed attention (e.g. Autor et al., 2013; OECD, 2017a). In this respect, the global inequality perspective can bring new insights for a number of reasons:

- First of all, globalisation may have expanded the relevant reference group for inequality assessment beyond national borders. Although people tend to compare their living standards to the people they see around them, digitalisation and the ICT revolution has greatly enhanced the scope for cross-border comparison and enlarged awareness of living standards around the world, especially among advanced and highly integrated economies.

- Secondly, some of the key drivers that have been identified to cause rising inequality are global forces and common trends not restricted by national borders; foremost technological

1. The author is member of the Economics Department of the OECD. He would like to thank OECD colleagues Carlotta Balestra, Orsetta Causa, Alain de Serres, Michael Förster, Jean-Marc Fournier, Horacio Levy, Marco Mira D’Ercole, Jon Pareliussen, Nicolas Ruiz and Céline Thevenot for useful comments and suggestions. He also thanks Amelia Godber for editorial assistance. The views expressed in this paper are those of the author and do not necessarily reflect those of the OECD and its member countries.

2. With a slight abuse of terminology, the paper associates the term "global income distribution" with the concept of constructing a combined income distribution for a set of countries, e.g. high-income countries. As a result, global need not reflect the world level. 
development and its diffusion through international trade and global value chains, but also weaker worker wage bargaining power and rising top incomes. Furthermore, the digitisation of routine tasks is putting pressure on many middle-income jobs hence driving a rise in job polarisation, which more broadly has led to growing concern of a shrinking middle class. However, little is known about the global middle class in high-income countries - defined according to household incomes across borders. This group has been identified as the principal laggards in the world income distribution over the recent decades (Lakner and Milanovic, 2016). But how is the state of the middle class among high-income countries as a whole, when leaving out the rest of the world?

- Finally, in the current juncture, with renewed focus on the potential downsides of globalisation in advanced countries, the global income distribution for high-income countries can provide a clear visualisation of opportunities and challenges of economic integration across similar countries, and point to specific policy challenges for both global and domestic policies.

4. The paper delivers three main contributions to the literature on global income distributions. First, it studies the global income distribution for high-income countries as a whole. Although less than a fifth of the world population lives in high-income countries, they generate almost half of world output, justifying a new perspective on the development in the distribution of those material goods. Second, the paper offers a methodological innovation by decomposing the global growth incidence curve into a within- and between country component, allowing for a more granular assessment of the development than is possible by relying on decomposable inequality indices. To our knowledge this decomposition has not been applied before in the context of the global income distribution. Finally, the paper relies on household income data from the OECD Income Distribution Database, a novelty in a field that has usually relied on data from the World Bank or the Luxembourg Income Study (e.g. Bourguignon, 2011; Anand and Segal, 2015; Lakner and Milanovic, 2016). Focusing on high-income countries only also allows for a robustness analysis that explores the role of in-kind transfers, such as healthcare and educational services, by adjusting micro-based household incomes to national accounts aggregates that covers spending on social transfers in-kind.

5. The paper is organised as follows: Section 2 briefly outlines the position of high-income countries within the world income distribution compiled by Lakner and Milanovic (2016). Section 3 presents the data and describes the global income distribution for high-income countries in 2013, the latest available year. Section 4 studies the development in global inequality among high-income countries from the mid-1990s to 2013, including the role of within-country inequality and market incomes as the main drivers of rising inequality. Section 5 offers a number of robustness checks and Section 6 concludes.

\section{High-income countries within the world income distribution}

6. Income inequality between individuals at the world level is to a large extent driven by differences in average incomes between countries. Nearly all people living in high-income countries, that is countries with a GNI per capita above USD 12,476 according to the World Bank classification (December 2016), are placed at the very top of the world income distribution estimated by Lakner and Milanovic (2016; Figure 1, Panel A). A typical resident in a high-income country obtained an annual household disposable income of between USD 10,000-20,000 in 2008 (measured in 2005 PPP), while the majority of the world population, not living in a high-income country, received much lower annual incomes of less than USD 3,000. Most poor people living in rich countries thus have better material living standards than the majority of people living in poor countries. Moreover, those with very high incomes in 
poor countries are few in numbers and only make up a tiny part of the top of the world income distribution. $^{3}$

Figure 1. High-income countries within the world income distribution

A. World household income distribution, 2008

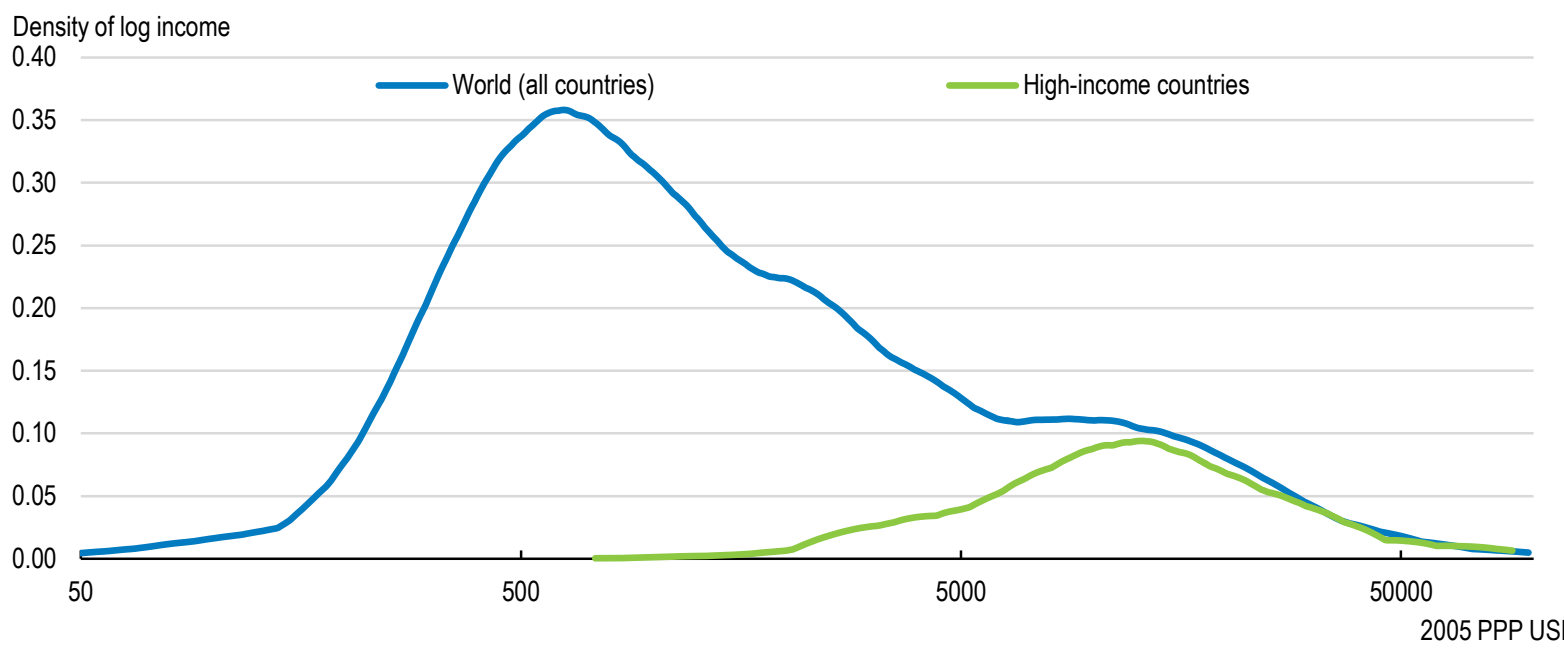

B. Global growth incidence curve, 1988-2008

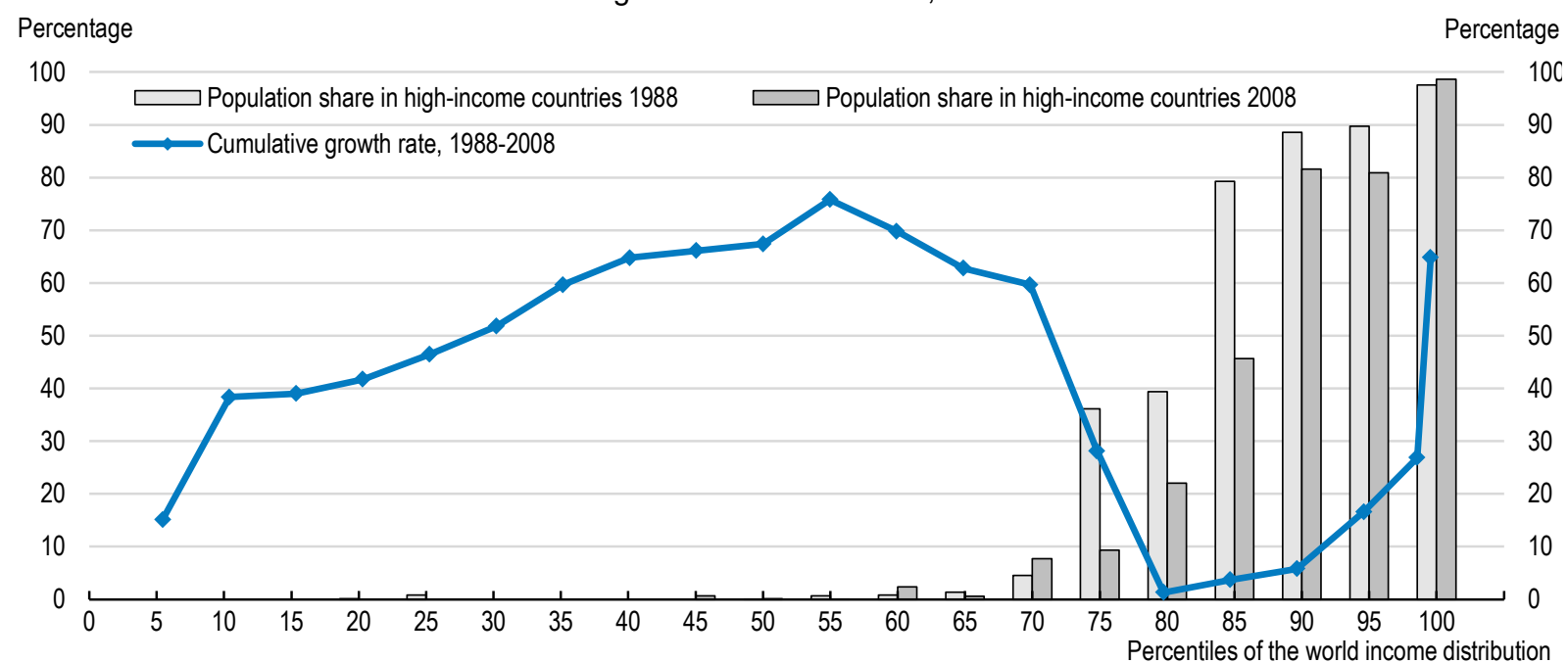

Note: Panel A shows estimated kernel densities based on log mean household disposable incomes (or consumption) by decile for 121 countries of which 38 countries are high-income countries according to the World Bank classification (see text). Panel B shows the (anonymous) global growth incidence curve between 1988 and 2008 . The bars indicate the population share, within each ventile of the world income distribution, living in high-income countries in 1988 and 2008, respectively. See Lakner and Milanovic (2016) for details.

Source: Author's calculations based on data from Lakner and Milanovic (2016).

7. Recently the world income distribution has attracted much attention due to the striking reshuffling of household incomes from the late 1980s to the late 2000s shown by Lakner and Milanovic (2016) and reproduced in Figure 1, Panel B (also referred to as "the elephant curve"). The middle of the

3. This is subject to the usual caveat that top incomes are generally not captured by household income surveys. 
world income distribution, roughly from the $35^{\text {th }}$ to the $70^{\text {th }}$ percentile, experienced remarkable cumulative income growth close to $70 \%$ over two decades (corresponding to an average annual growth rate close to $3 \%$ ), albeit starting from an income level below or near absolute poverty. This development was predominantly driven by Asia and China in particular. The world top 1\%, mainly residing in the United States, reached similar growth rates as the emerging global middle class. This is also remarkable considering that it benefited a category of households whose initial income levels were already at a higher level than every other category at the start of the period. Finally, income growth has been the lowest for the upper quarter of the world income distribution, excluding the very top: from the $80^{\text {th }}$ to the $90^{\text {th }}$ percentile incomes grew by less than $10 \%$ over two decades.

8. The upper quarter of the distribution primarily consists of households from high-income countries, but this composition has changed significantly over time (Figure 1, Panel B). The bars show that $80 \%$ of the ventile ${ }^{4}$ around the $85^{\text {th }}$ percentile of the world income distribution for 1988 is comprised by people from high-income countries (of which around half are from Italy, France, Germany and the United States). In contrast, within the same ventile of the 2008 world income distribution only around $45 \%$ lived in high-income countries (China now covers close to $20 \%$ and Russia $10 \%$ of this ventile). The share varies because the global growth incidence curve illustrated in Figure 1, Panel B is anonymous in the sense that it is based on a different set of countries and ignores the composition of the ventiles of the world income distribution in 1988 and 2008. ${ }^{5}$ Lakner and Milanovic (2016) address this caveat by also constructing quasi non-anonymous growth incidence curves, i.e. they fix the position of country-deciles in the world income distribution to be the same in the initial and terminal year to avoid the effect of reranking (see Bourguignon, 2011). The overall shape turns out to be similar to the anonymous growth curve, but the upper quarter now performs better and no parts of the quasi non-anonymous growth incidence curve display cumulative income growth below $20 \%$ between 1988 and 2008.

\section{A global income distribution for high-income countries}

\subsection{Data for high-income countries from the OECD Income distribution Database}

9. The relatively weak income growth in the upper quarter of the global income distribution, except at the very top, warrants further investigation. This section presents a corresponding global income distribution for high-income countries only, in order to shed more light on income inequality and income growth within and between developed countries. It relies on household income statistics from the OECD Income Distribution Database (IDD, see oe.cd/idd). This has several advantages compared to the world income distribution assembled by Lakner and Milanovic (2016) presented above, which is primarily based on data from PovcalNet compiled by the World Bank. Firstly, the IDD is developed to monitor income distributions across OECD countries and therefore it is better tailored to study high-income countries. Secondly, the method of data collection aims to maximize international comparability as well as intertemporal consistency of the data. ${ }^{6}$ The IDD gathers a number of standardised indicators under the form of semi-aggregated tabulations (e.g. mean income by deciles applied in this study) based on national sources, deemed to be most representative for most countries, drawing on the experience of country experts with knowledge of the specificities of the national sources. Finally, household disposable incomes in the IDD can be broken down into its main components, which facilities further investigation of e.g. the role of

4. The global growth incidence curve is constructed by dividing the world population into groups of $5 \%$ (ventiles), except for the top for which the top $1 \%$ is separated out.

5. The world income distribution for 1988 is based on 75 countries, while 121 countries are used to construct the 2008 world income distribution (see Lakner and Milanovic, 2016).

6. This is achieved through a common set of protocols and statistical conventions based on internationally agreed statistical standards. See Gasparini and Tornarolli (2015) for a review of the database. 
market incomes (see Section 4). The main disadvantage of the IDD is that as a result of the data collection process, the data available for analysis are no longer the original micro datasets but average incomes by deciles generated from the microdata. ${ }^{7}$ Moreover, the indicators from the IDD are based on household income surveys for most countries and thus suffer from underreporting of top incomes, which implies underestimation of the true inequality levels, also at the global level.

10. The set of high-income countries in this study is selected according to the most recent World Bank classification. 79 countries pass the threshold of GNI per capita above USD 12,476 (December 2016). Combined they represent $16.4 \%$ of the world population in 2013, but generates almost half of world GDP and GNI (Table 1). However, more than 30 high-income countries have a population of less than 0.5 million people, implying a very close correspondence between the total population living in OECD countries and the total population living in high-income countries. ${ }^{8}$ As a result, the 34 high-income countries included in the IDD cover 91\% of the population living in all high-income countries in 2013. Unfortunately, long time-series dating back to the mid-1990s are only available for 17 high-income countries in the IDD. ${ }^{9}$ Among these are the most populous countries (for instance all G7 countries are included), which ensures that more than $70 \%$ of the total population living in high-income countries, and jointly generating more than $40 \%$ of world GDP, can be analysed across time (Table 1). Table A1 in the Annex provides a list of the specific countries included in the two samples and their population shares.

Table 1. High-income countries

\begin{tabular}{lccc} 
& & \multicolumn{2}{c}{ OECD Income Distribution Database } \\
\cline { 3 - 4 } & $\begin{array}{c}\text { All high-income } \\
\text { countries, 2013 }\end{array}$ & $\begin{array}{c}\text { Sample for 2013 or latest } \\
\text { available year }\end{array}$ & $\begin{array}{c}\text { Sample available from } \\
\text { mid-1990s to 2013 }\end{array}$ \\
\hline Number of countries & 79 & 34 & 17 \\
Share of world (\%) & 16.4 & 14.9 & 12.4 \\
Population & 47.9 & 42.8 & 44.0 \\
GDP (2011 PPP) & 49.3 & 44.1 & 44.5 \\
GNI (2011 PPP) & & & 72.1 \\
Share of high-income countries (\%) & 100 & 91.1 & 77.7 \\
Population & 100 & 89.4 & 77.4 \\
GDP (2011 PPP) & 100 & 89.4 & \\
GNI (2011 PPP) & & & \\
\hline
\end{tabular}

1. Averages across 1995-2013 reported.

Note: The World Bank classification of high-income countries from December 2016 is applied. More than 30 of the 79 high-income countries have a population of less than 0.5 million people. See Tables A1 and A2 in the Annex for details on country and year coverage.

Source: World Development Indicators, World Bank; OECD Income distribution Database.

11. Before turning to a characterisation of the global income distribution for high-income countries, two technical remarks are necessary. One is that household income statistics from the IDD assumes economies of scale within households, implying that incomes have been equivalised by scaling total

7. The world income distribution constructed by Lakner and Milanovic (2016) is also based on mean household incomes by deciles. For computing Gini indices, grouped data by deciles generally give results close to those based on micro-data (Davies and Shorrocks, 1989).

8. Mexico and Turkey are OECD countries, but not high-income countries. Lithuania is included in the IDD and in this study as the only non-OECD, but high-income country.

9. The series contain a break around 2011 for most countries (update of the terms of reference). This is addressed by scaling incomes for each decile by the ratio of the corresponding deciles in a year for which the series before and after the break overlap. The series applied for analysis of the latest available year, based on the sample of 34 countries, are used without any adjustment, which implies small differences between figures reported for Japan and United States in 2013 in Tables 2 and 3 below. 
household income by the square root of the number of household members. ${ }^{10}$ In contrast, the world income distribution constructed by Lakner and Milanovic (2016) does not assume any economies of scale within households, but applies household income per capita (scaling by the actual number of household members). This generates a difference in the level of household disposable incomes (see Figure A1 in the Annex for a comparison of density plots from the two data sources); the implications of this difference for income growth rates are however unclear a priori. Finally, the equivalised household income figures are deflated by national consumer price indices and measured in constant PPPs for private consumption with base year 2010 for comparison across countries (see e.g. Anand and Segal, 2015 for a discussion of the use of PPPs).

12. The second remark is that as mentioned above the data from the IDD are only available in semiaggregate form, in particular by mean household disposable incomes by income deciles. It is straightforward to construct a global income distribution for high-income countries by weighting each country-decile data point by $10 \%$ of the country's population and aggregating across countries. Based on this distribution inequality indices and growth incidence curves can easily be computed. However, more detailed characterisation of individual countries' position and movements over time within the global income distribution for high-income countries is not feasible without any prior disaggregation of the data. For instance, a country-decile data point for the United States represents more than 30 million people, larger than the total population in many of the smaller countries included in the analysis. Therefore, the available 10 data points for each country and year are fitted to a lognormal distribution before aggregating across countries. ${ }^{11,12}$ This adjustment ensures a more smooth and realistic allocation of countries across the global income distribution for high-income countries. ${ }^{13}$ Figure A2 in the Annex illustrates the global income distribution for high-income countries with and without the fitting of lognormal distributions. Section 5 provides robustness checks of the chosen disaggregation procedure.

\subsection{Inequality measures of the global income distribution for high-income countries}

13. Inequality metrics and average incomes for high-income countries are presented in Table 2. The Gini index is found to be around 37, which is relatively high and higher than the inequality level within the vast majority of high-income countries, roughly corresponding to the inequality level observed in Israel and Estonia. However, the high-income country Gini index is lower than the Gini index in Chile (46.5) and the United States (39.4) and much lower than the Gini index around 70 estimated for the world income distribution (Lakner and Milanovic, 2016). Nonetheless, it should be no surprise that selecting a set of

10. The use of equivalised household incomes is in line with the recommendations in e.g. The Canberra Group Handbook on Household Income Statistics (UNECE, 2011).

11. The "ungroup" command in the DASP package (Abdelkrim and Duclos, 2007) is used to disaggregate each country-year income distribution. The number of data points is set so each observation approximately represents 5,000 individuals, but with a lower limit of at least 100 observations per country-year. The adjustment procedure suggested by Shorrocks and Wan (2008) is applied to ensure consistency between the (raw) decile data and the estimated lognormal distribution.

12. Chotikapanich et al. (1997) and Pinkovskiy and Sala-i-Martin (2009) take a similar approach and assume household incomes to follow a lognormal distribution. Other parametric and nonparametric procedures have also been applied in the literature. See e.g. Pinkovskiy (2013) for a discussion and Minoiu and Reddy (2014) for Monte Carlo simulations with an application to poverty assessment.

13. For instance, the United States is present in all ventiles of the global income distribution for high-income countries based on the disaggregated data (see Figure 2). This would not have been the case if the global income distribution for high-income countries had been constructed directly from country-decile data. In that case, the United States would be present in the second and fourth ventile, but not in the third ventile. Such gaps are obviously not realistic and become problematic when working with a fairly low number of countries. 
homogenous countries yields a combined inequality level not much different from the country-specific levels observed across the homogeneous set.

Table 2. The global household disposable income distribution for high-income countries

2013 or latest available year, based on 34 high-income countries

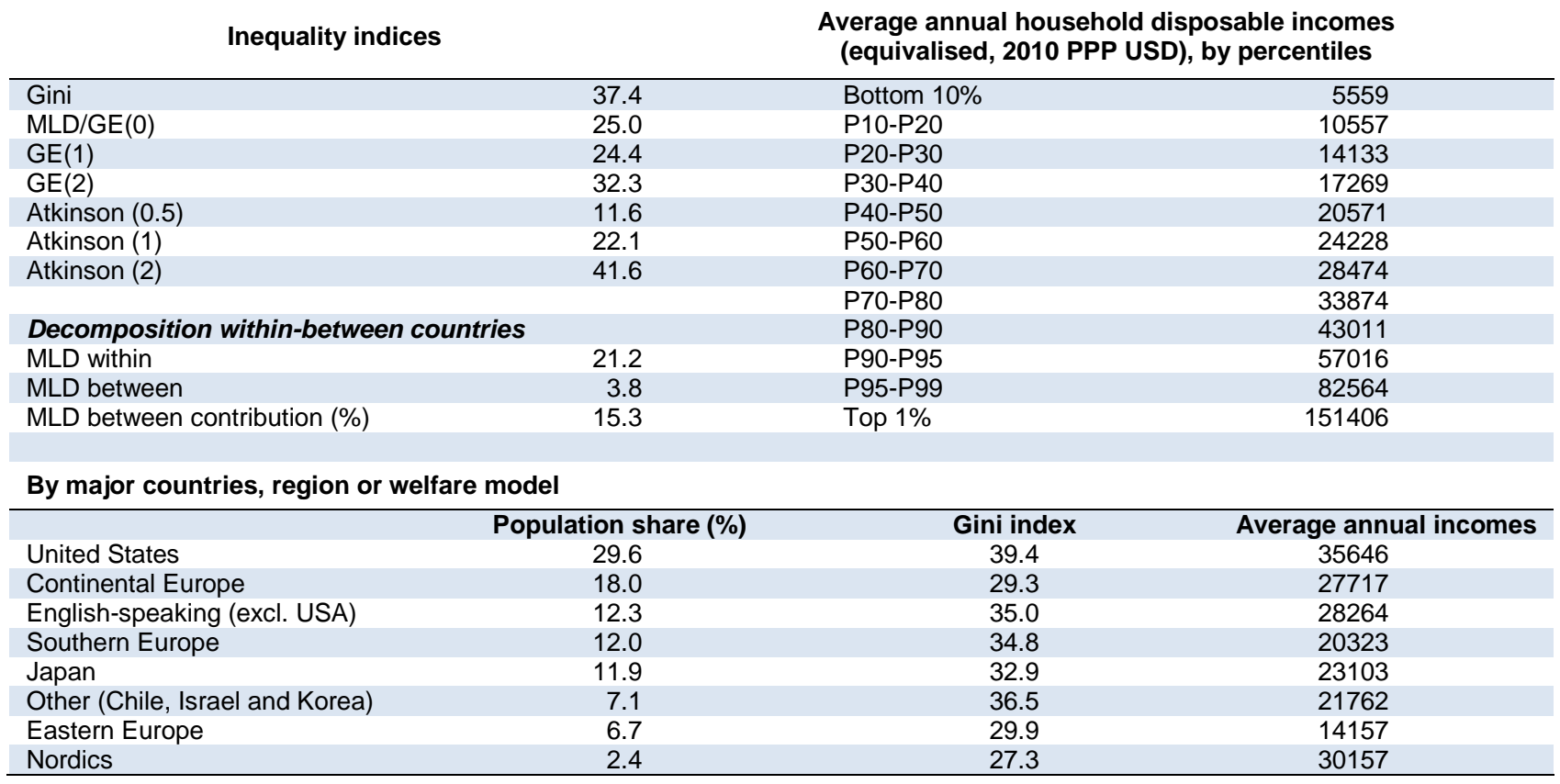

Note: The income distribution for each country, available in the form of mean incomes by deciles, has been fitted to a lognormal distribution (see text). See Tables A1 and A2 in the Annex for country and year coverage.

Source: Author's calculations based on the OECD Income Distribution Database.

14. The Gini index is not decomposable into within- and between-country inequality. Instead, the mean log deviation (MLD) inequality index can be used to provide a clear interpretation of the withincountry component (Anand and Segal, 2015). ${ }^{14}$ The MLD shows that differences in average household incomes between high-income countries only account for around 15\% of global high-income country inequality, while $85 \%$ is caused by inequality within countries. In other words, a population-weighted average of inequality in each country comprises $85 \%$ of global inequality across populations living in highincome countries. This is rather striking, given non-trivial differences in average income levels across countries. Although the group of high-income countries is fairly homogeneous, at least relative to middleand lower-income countries, average incomes still differ substantially as can be seen by tentatively grouping countries by regions and welfare models (Table 2). ${ }^{15}$ For instance, average household disposable income in Eastern Europe is around USD 14,000, less than half of average incomes in the United States and the Nordics. The substantial differences in population sizes across countries should however be kept in mind, especially the United States covering almost $30 \%$ of the population used for the analysis (Table A1

14. The MLD inequality index takes the value 0 when everyone has the same income (perfect equality) and takes positive values as incomes become more unequally distributed, approaching infinity if one person has all income (complete inequality). It is also known as the Theil L index and is more sensitive to inequality in the bottom range of the distribution than e.g. the Gini index. Formally, the MLD is defined as the average across individuals of the logarithm of the ratio of mean household income to household income.

15. The grouping is inspired by the political science literature on welfare models (Esping-Andersen, 1990; Ferrera, 1996; Ferger, 2007), but is nonetheless ad hoc and only used for illustration. 
in the Annex). Finally, cross-country differences in average incomes do not account for differences in public in-kind transfers (e.g. healthcare and educational services) since the micro-based data source only includes cash transfers. ${ }^{16}$ It is, however, not obvious if including in-kind transfers would increase or decrease between-country inequality, for instance such transfers are sizeable in the Nordics, but play a minor role in the United States. The robustness section provides some illustrative computations by combining micro-data sources with national account measures of social transfers in-kind (Section 5.5).

15. The location of major countries, regions and countries with similar welfare models within the global income distribution for high-income countries is further illustrated in Figure 2. Almost all subgroups are present in all ventiles, i.e. in groups of 5\% of the combined population in high-income countries, emphasising the relatively high degree of homogeneity. Although the United States has the highest average income (Table 2) and composes more than half of the top 5\%, it also makes up more than $30 \%$ of the bottom 5\% due to the high level of inequality within the United States and poverty in particular. Japan, English-speaking countries (excluding the United States) and Continental European countries are more equally spread across the global income distribution of high-income countries, while Eastern European and to a lower extent Southern European countries are more concentrated at the bottom.

Figure 2. The composition of the global income distribution for high-income countries

Household disposable incomes 2013, based on 34 high-income countries By major countries, regions or welfare model

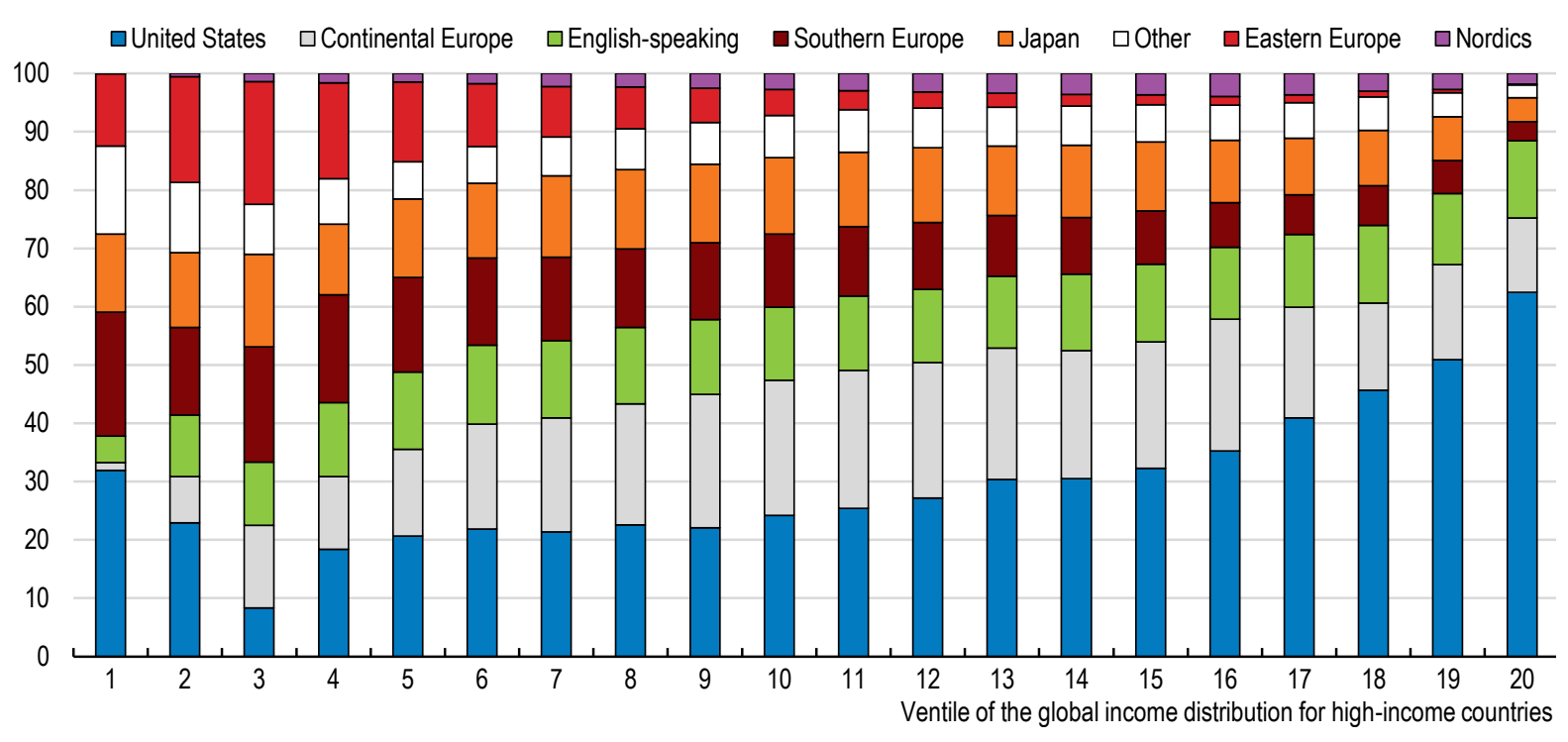

Note: Based on 34 high-income countries (see Table 1) and using lognormal-fitted income distributions at the country level (see text). Continental Europe refer to Austria, Belgium, France, Germany, Luxembourg, the Netherlands and Switzerland; English-speaking countries refer to Australia, Canada, Ireland, New Zealand and the United Kingdom; Southern Europe refer to Greece, Italy, Portugal and Spain; Other refer to Chile, Israel and Korea; Eastern Europe refer to Czech Republic, Estonia, Hungary, Latvia, Lithuania, Poland, Slovak Republic and Slovenia; Nordics refer to Denmark, Finland, Iceland, Norway and Sweden.

Source: Author's calculations based on the OECD Income Distribution Database.

16. The IDD also includes quasi-cash transfers given for a specific purpose (e.g. the Supplemental Nutrition Assistance Program in the United States). 


\section{The trend in the global income distribution for high-income countries}

\subsection{Rising inequality and slow-growing middle-class incomes}

16. From the mid-1990s to 2013 global inequality for high-income countries is estimated to have increased by around 2.7 Gini points (Figure 3; Table 3). This assessment, and the trend analysis in the rest of the paper, are based on the smaller set of 17 high-income countries with long-time series available in the IDD (Table 1) and for instance exclude all the Eastern European countries used in Section 3. Figure 3 shows that the increase in global inequality took place in two separate phases, first from the mid-1990s to mid-2000s after which the global Gini for high-income countries stabilised until it rose even more from 2010 to 2013 in the context of the crisis. Although these numbers should be taken with caution and small changes not exaggerated, the timing of the increase appears to contrast with the timing of the broad upward trend in inequality observed within high-income countries. Since the mid-1980s inequality has increased in the majority of OECD countries, on average across countries by around 3 Gini points (OECD, 2015a), not far from the increase in global inequality among high-income countries since the mid-1990s. However, the bulk of the increase within countries took place during the 1980s and 1990s and since the mid-2000s within-country inequality has not changed much on average across OECD countries (OECD, 2017b, Chapter 2).

Figure 3. Inequality among high-income countries has risen, mainly driven by higher within-country inequality

1995-2013, based on 17 high-income countries

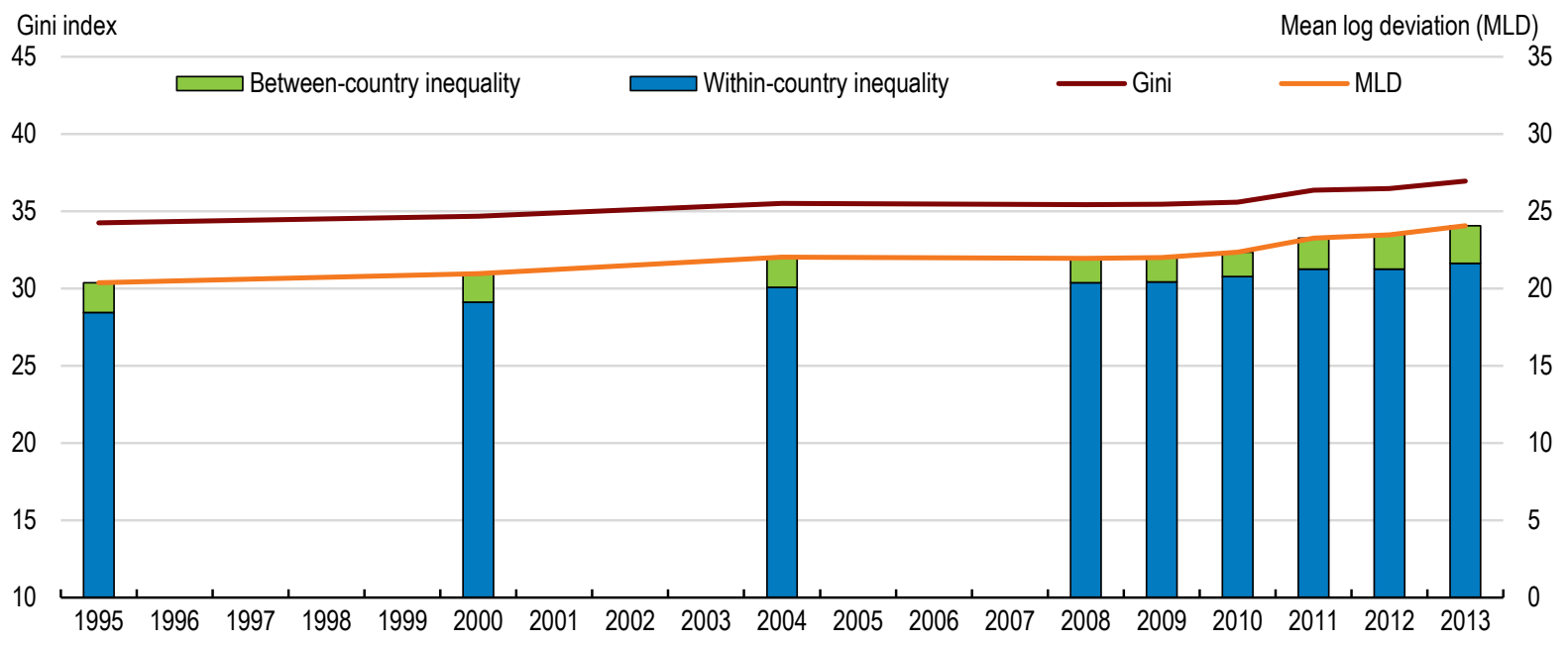

Note: Between and within-country inequality components refer to the decomposition of the mean log deviation (MLD) inequality measure. See Tables A1 and A2 in the Annex for country and year coverage.

Source: Author's calculations based on the OECD Income Distribution Database.

17. The increase in global inequality for high-income countries from 2010 onwards may be explained by the differential impact of the crisis and varying duration of the great recession across high-income countries. This is to some extent confirmed by the split into within- and between-country inequality available for the MLD measure, showing that more than half of the increase from 2010 to 2013 is caused by rising differences in average incomes between high-income countries (Figure 3; Table 3). However, the crisis followed a period of slight convergence across countries prior to 2010 thus leaving the shares of within- and between-country inequality almost unchanged in 2013 compared to the mid-1990s. 
ECO/WKP(2017)34

Table 3. The trend in the global household disposable income distribution for high-income countries

Household disposable incomes 1995-2013, based on 17 high-income countries

\begin{tabular}{|c|c|c|c|c|c|c|c|c|}
\hline \multirow{3}{*}{ Inequality indices } & \multicolumn{6}{|c|}{ Benchmark year } & \multicolumn{2}{|c|}{ Change (\%-point, \%) } \\
\hline & \multirow[t]{2}{*}{1995} & \multirow[t]{2}{*}{2000} & \multirow[t]{2}{*}{2004} & \multirow[t]{2}{*}{2008} & \multirow[t]{2}{*}{2010} & \multirow[t]{2}{*}{2013} & \multirow[t]{2}{*}{ 1995-2013 } & \multirow[t]{2}{*}{ 2004-2013 } \\
\hline & & & & & & & & \\
\hline Gini & 34.3 & 34.7 & 35.5 & 35.4 & 35.6 & 36.9 & 2.7 & 1.4 \\
\hline MLD/GE(0) & 20.4 & 21.0 & 22.0 & 21.9 & 22.3 & 24.0 & 3.7 & 2.0 \\
\hline $\mathrm{GE}(1)$ & 20.1 & 20.6 & 22.1 & 21.7 & 21.9 & 24.2 & 4.1 & 2.1 \\
\hline $\mathrm{GE}(2)$ & 25.2 & 25.9 & 29.1 & 27.9 & 27.8 & 33.0 & 7.8 & 3.9 \\
\hline Atkinson (0.5) & 9.6 & 9.8 & 10.4 & 10.3 & 10.4 & 11.3 & 1.7 & 0.9 \\
\hline Atkinson (1) & 18.4 & 18.9 & 19.8 & 19.7 & 20.0 & 21.4 & 3.0 & 1.6 \\
\hline Atkinson (2) & 34.6 & 35.6 & 36.7 & 36.9 & 37.9 & 39.6 & 5.0 & 2.9 \\
\hline \multicolumn{9}{|c|}{ Gini indices by major countries, regions or welfare model ${ }^{1}$} \\
\hline United States & 35.9 & 35.5 & 37.9 & 37.7 & 37.9 & 39.8 & 3.8 & 1.9 \\
\hline Continental Europe & 27.4 & 27.6 & 28.6 & 28.9 & 29.1 & 29.1 & 1.8 & 0.5 \\
\hline Japan & 32.2 & 33.9 & 32.0 & 33.3 & 33.3 & 32.8 & 0.6 & 0.7 \\
\hline English-speaking & 32.2 & 33.7 & 32.6 & 33.7 & 33.7 & 34.2 & 2.0 & 1.6 \\
\hline Southern Europe & 33.8 & 33.3 & 33.3 & 32.0 & 32.8 & 34.3 & 0.5 & 1.0 \\
\hline Nordics & 23.0 & 25.1 & 25.4 & 26.2 & 26.5 & 27.5 & 4.5 & 2.1 \\
\hline Other (Israel) & 33.1 & 33.9 & 37.7 & 37.6 & 37.4 & 36.4 & 3.2 & -1.3 \\
\hline \multicolumn{9}{|c|}{ Decomposition within-between countries } \\
\hline MLD within & 18.4 & 19.1 & 20.1 & 20.3 & 20.7 & 21.6 & 3.2 & 1.5 \\
\hline MLD between & 1.9 & 1.8 & 1.9 & 1.6 & 1.6 & 2.4 & 0.5 & 0.5 \\
\hline MLD between contribution (\%) & 9.4 & 8.8 & 8.8 & 7.3 & 7.1 & 10.1 & 0.7 & 1.4 \\
\hline \multicolumn{9}{|l|}{ Polarisation indices ${ }^{2}$} \\
\hline FW & 14.6 & 14.8 & 14.9 & 15.0 & 15.1 & 15.5 & 0.9 & 0.6 \\
\hline $\operatorname{DER}(0.5)$ & 21.5 & 21.7 & 22.0 & 21.9 & 22.0 & 22.5 & 1.0 & 0.5 \\
\hline DER (1) & 16.3 & 16.4 & 16.7 & 16.6 & 16.5 & 17.1 & 0.7 & 0.3 \\
\hline \multicolumn{9}{|c|}{ Average annual household disposable incomes (equivalised, 2010 PPP USD), by percentiles } \\
\hline Bottom 10\% & 6701 & 7005 & 7006 & 6988 & 6685 & 6555 & -2.2 & -6.4 \\
\hline P10-P20 & 11488 & 12223 & 12595 & 12657 & 12444 & 12265 & 6.8 & -2.6 \\
\hline P20-P30 & 14794 & 15767 & 16104 & 16240 & 16048 & 15802 & 6.8 & -1.9 \\
\hline P30-P40 & 17725 & 18900 & 19277 & 19462 & 19288 & 18982 & 7.1 & -1.5 \\
\hline P40-P50 & 20716 & 22126 & 22517 & 22797 & 22619 & 22325 & 7.8 & -0.9 \\
\hline P50-P60 & 24021 & 25722 & 26109 & 26535 & 26324 & 26135 & 8.8 & 0.1 \\
\hline P60-P70 & 27890 & 29967 & 30382 & 30927 & 30725 & 30616 & 9.8 & 0.8 \\
\hline P70-P80 & 33020 & 35480 & 36087 & 36719 & 36532 & 36488 & 10.5 & 1.1 \\
\hline P80-P90 & 41259 & 44599 & 45850 & 46521 & 46375 & 46495 & 12.7 & 1.4 \\
\hline P90-P95 & 53194 & 57662 & 59947 & 60930 & 60854 & 61544 & 15.7 & 2.7 \\
\hline P95-P99 & 74270 & 80775 & 86564 & 86434 & 85383 & 91562 & 23.3 & 5.8 \\
\hline Top 1\% & 127408 & 138258 & 156177 & 151681 & 148748 & 171186 & 34.4 & 9.6 \\
\hline \multicolumn{9}{|c|}{ Average annual household disposable incomes by major countries, regions or welfare model } \\
\hline United States & 32595 & 35560 & 36939 & 36173 & 35593 & 37072 & 13.7 & 0.4 \\
\hline Continental Europe & 24186 & 25911 & 26678 & 27152 & 27589 & 27208 & 12.5 & 2.0 \\
\hline Japan & 27068 & 25907 & 24406 & 23902 & 23485 & 22912 & -15.4 & -6.1 \\
\hline English-speaking & 20757 & 23641 & 25752 & 28580 & 28298 & 28933 & 39.4 & 12.3 \\
\hline Southern Europe & 20942 & 23016 & 24002 & 24186 & 23398 & 20922 & -0.1 & -12.8 \\
\hline Nordics & 20464 & 23335 & 25328 & 28198 & 28979 & 30221 & 47.7 & 19.3 \\
\hline Other (Israel) & 14342 & 16307 & 16371 & 17871 & 18429 & 19835 & 38.3 & 21.2 \\
\hline
\end{tabular}

1. Continental Europe refer to France, Germany, Luxembourg and the Netherlands; English-speaking countries refer to Australia, Canada, New Zealand and the United Kingdom; Southern Europe refer to Greece and Italy; Nordics refer to Denmark, Finland, Norway and Sweden; Other refers to Israel.

2. FW: Foster and Wolfson (2010) bipolarisation index. DER: Duclos et al. (2004) polarisation index based on identificationalienation framework.

Note: The income distribution for each country, available in the form of mean incomes by deciles, has been fitted to a lognormal distribution (see text). See Tables A1 and A2 in the Annex for country and year coverage.

Source: Author's calculations based on the OECD Income Distribution Database. 


\section{ECO/WKP(2017)34}

18. Turning to the global growth incidence curve for high-income countries can shed more light on which parts of the global distribution drive the rise in inequality (Figure 4, Panel A). The curve relates each percentile of the global household disposable income distribution for high-income countries in 2013 to the same percentile in 1995, ignoring compositional changes within percentiles. ${ }^{17}$ The growth incidence curve points to two reasons behind the rise in global inequality: i) incomes at the top grew more than middle and lower incomes and ii) incomes at the bottom fell behind, with the poorest even becoming poorer in real terms. Between these two extremes, and including an impressive share of almost $80 \%$ of the total population in high-income countries, household incomes grew by around 10\%, corresponding to a relatively low average annual growth rate near $0.5 \%$. To be sure, the figure shows that incomes at the top $5 \%$ of the global income distribution for high-income countries in 2013 were 20-30\% higher than incomes at the top 5\% in 1995. But the top 5\% need not reflect the same people or the same countries. In a similar way, the figure should not be taken as an indication of the average development across countries. In particular, the result of no growth or declining real incomes by up to $10 \%$ for the bottom $10 \%$ of the global income distribution for high-income countries is too a large extent driven by the United States and Japan, whereas an unweighted average across the 17 OECD countries shows positive income growth for the bottom 10\% (OECD, 2017a).

19. The 2008-09 financial crisis greatly affected most high-income countries. This becomes particularly visible by splitting the global growth incidence curve into sub-periods. From the mid-2000s to 2013 only the top $10 \%$ of the global income distribution for high-income countries experienced positive real income growth, while the bulk of household disposable incomes in 2013 remained at the same level as a decade earlier (Figure 4, Panel B). However, within the two decades before and after the mid-2000s the global growth incidence curves have similar profiles, differing only in levels. Zooming into the decade around the crisis again reveals impressive homogeneity among the middle $80 \%$ during the different phases of the crisis (Figure 4, Panel C). ${ }^{18}$ In contrast, the top of the distribution experienced substantial income fluctuations over the crisis.

20. In sum, global inequality for high-income countries has risen, both because the rich have become richer and the poor poorer. As a result the spread in incomes has increased, which may point to greater polarisation. The typical incidence of polarisation would be for more people to concentrate at the top and bottom, implying a declining middle class; a current concern in many advanced countries. The increase in polarisation at the global level for high-income countries is however moderate according to two popular polarisation indices (Table 3). The bipolarisation measure suggested by Foster and Wolfson (2010) increased from 14.6 to 15.5 during 1995-2013, while the more general polarisation measure by Duclos et al. (2004) shows an increase of similar magnitude. ${ }^{19}$

17. See Figure A3 in the Annex for an illustration of the country composition by ventiles in 1995 and 2013.

18. It would have been more obvious and interesting to split the period before and after 2007 instead of 2008 , but this is not possible due to missing data for many countries in 2007 (see Table A2, Panel B in the Annex).

19. The polarisation assessment is suggestive only, given the semi-aggregate nature of the data and underreporting of top incomes. 
Figure 4. Global growth incidence curves for high-income countries

Cumulative growth rates for household disposable incomes, based on 17 high-income countries
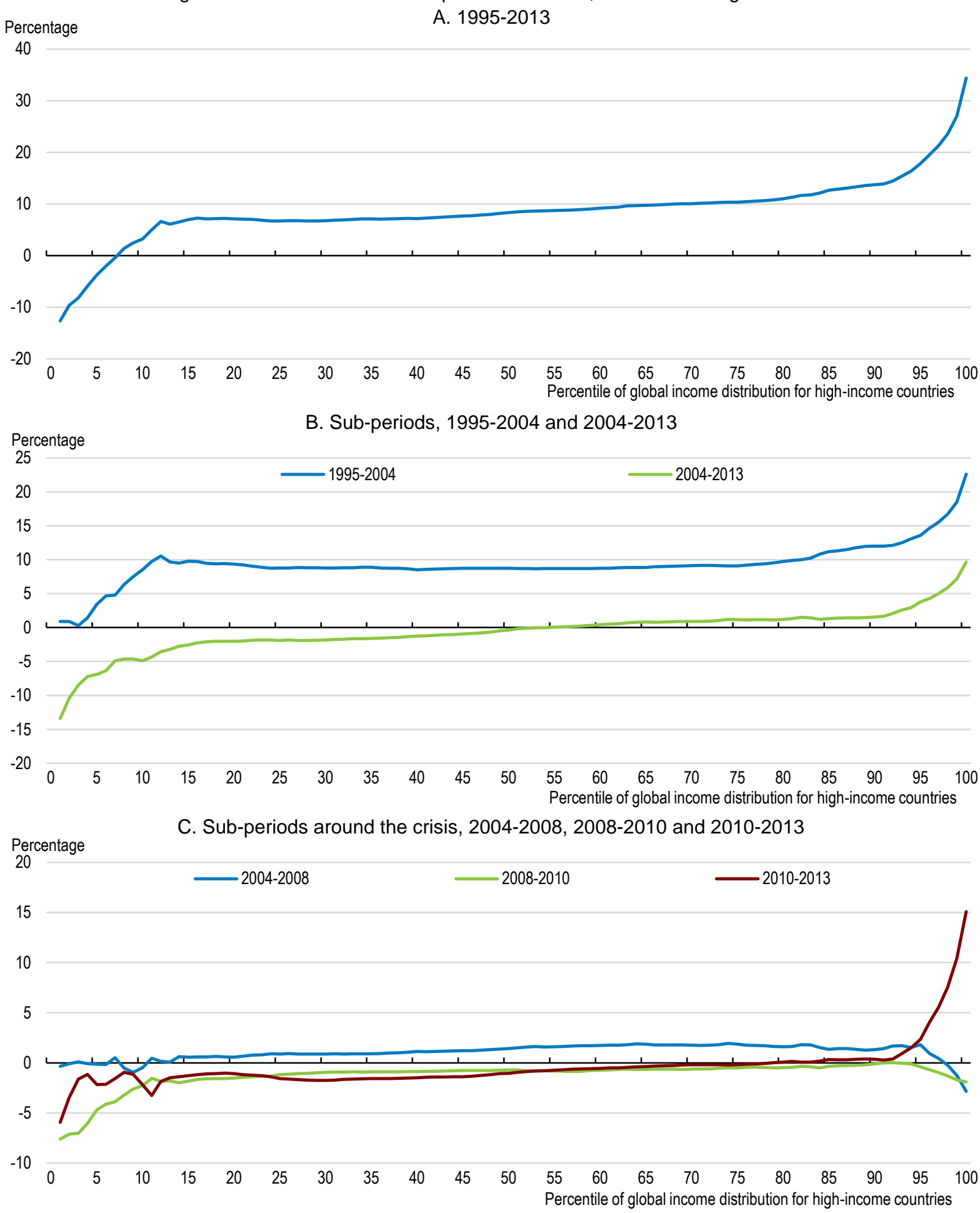

Note: See Tables A1 and A2 in the Annex for country and year coverage.

Source: Author's calculations based on the OECD Income Distribution Database. 


\subsection{Decomposing the global growth incidence curve into within-and between-countries components}

21. The MLD inequality index indicated that most of the increase in global inequality for highincome countries was driven by rising within-country inequality (Table 3). A related decomposition is possible by means of the global growth incidence curve; with the advantage that it does not rely on a particular inequality measure and can provide information on the underlying variation of the within- and between-country components across the distribution. This decomposition is shown in Figure $5:{ }^{20}$

Figure 5. Decomposing the global growth incidence curve for high-income countries into within and betweencountry profiles

Log change in household disposable incomes from 1995 to 2013, based on 17 high-income countries

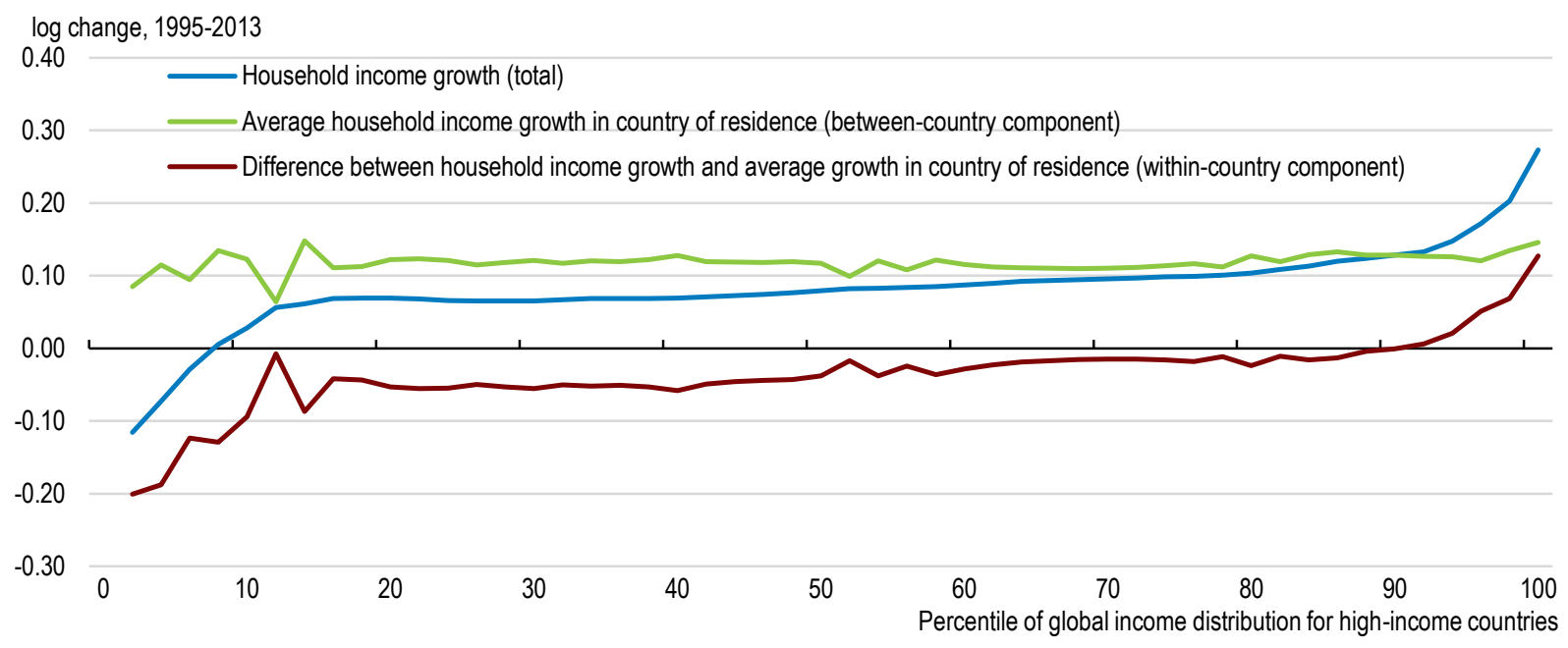

Note: Based on 17 high-income countries. See Tables A1 and A2 in the Annex for country and year coverage.

Source: Author's calculations based on the OECD Income Distribution Database.

- Firstly, the figure replicates the global growth incidence curve for high-income countries from Figure 3, now referred to as total growth in household disposable incomes (the blue line). To ensure additivity of the decomposition the curve now relates log household disposable income at each percentile of the global income distribution for high-income countries in 2013 to log household disposable income for the same percentile in 1995, still ignoring compositional changes within percentiles.

- Secondly, a between-country global growth incidence curve (the green line) is constructed in a similar way by replacing all household incomes with the average household income in each household's country of residence, but maintaining the ordering of households according to their actual incomes used to construct the global income distribution in 1995 and 2013, respectively. For example, in 1995 , households at the $20^{\text {th }}$ percentile of the global income distribution for highincome countries lived in countries with average annual household disposable incomes of USD 25,300 ; in 2013, households at the $20^{\text {th }}$ percentile of the global distribution lived in countries with average household disposable incomes of USD 28,600, corresponding to an 0.12 increase of log average incomes as illustrated by the green line.

20. See Song et al. (2015) for a similar application to illustrate wage growth within and between firms in the United States. 
- Finally, a within-country growth incidence curve (the maroon line) is constructed based on the residual income measure, i.e. actual household disposable incomes less average incomes in each household's country of residence, and again averaged across all households within percentiles of the 1995 and 2013 distribution, respectively. For example, in 1995, households at the $20^{\text {th }}$ percentile on average obtained log household disposable incomes 0.67 less than log average household disposable incomes in their country of residence. By 2013 this difference had increased to 0.72 at the $20^{\text {th }}$ percentile. The within-country growth incidence curve illustrates the difference of -0.05 . Note that by construction the within-country growth incidence curve equals the difference between the total and the between-country growth incidence curves. ${ }^{21}$

22. The within- and between-country growth incidence curves can be interpreted in the same way as the total growth incidence curve. An upward sloping curve, implying higher income growth among more affluent households, points to increasing inequality of the respective component. Figure 5 visually confirms that changing relative differences in average incomes between countries had little impact on global inequality between the mid-1990s and 2013 as can be seen from the almost flat between-country growth incidence curve. In contrast, the profile of the within-country growth incidence curve mimics the total curve very closely, thus accounting for the bulk of the rise in global inequality among high-income countries. Further examination of sub-periods reveals that the between-country curve was flat from the mid-1990s to 2004, but slightly downward-sloping prior to the crisis followed by a slightly upward-sloping curve in the period after the crisis (see Figure A4 in the Annex).

23. The decomposition applied to the world income distribution is included in the Annex (Figure A5) as an additional illustration of the methodology. The within- and between-country components have been computed using the data put together and made available by Lakner and Milanovic (2016). In this case, the between-country curve tends to follow the shape of the global growth incidence curve and shows a downward-sloping tendency, thus signalling a decline in between-country inequality, while the withincountry curve is somewhat upward-sloping, disclosing the counter-acting effect of rising within-country inequality mitigating the decline in world inequality. However, the within-country curve also shows that households from the $25^{\text {th }}$ to the $40^{\text {th }}$ percentile of the world income distribution enjoyed income growth similar to or above the average income growth in their country of residence, while households from the $40^{\text {th }}$ to the $70^{\text {th }}$ percentile experienced the opposite. The methodology presented above thus allows for identifying more granular information on the development in global inequality and complements the simple within-between decomposition available from the MLD index.

\subsection{The role of rising market income inequality}

24. The micro-based household disposable incomes are comprised of market incomes plus cash transfers less direct income taxes. A key question is to what extent household market incomes drive the rise in global inequality for high-income countries and what role changes in tax and transfer systems at the country-level may have had at the global level? To shed light on this, Figure 6 presents a corresponding global growth incidence curve for high-income countries based on household market incomes. The curve is shown for working-age populations only (individuals aged 18-65). The reason is that mean income figures by deciles, including market incomes, in the IDD are reported only for households ranked by household disposable incomes. Ideally households should be ranked by market incomes when analysing the (global) market income distribution. However, so-called re-ranking of households mostly takes place for pensioners with close to zero market incomes and significant disposable incomes from pension transfers. By focusing on the working-age population, the ranking of households by market incomes are generally close to the ranking by disposable incomes (Causa and Hermansen, forthcoming).

21. The overall average log change of the within-country curve is zero, while the total and between-country curves have identical average log changes across their respective distributions. 
Figure 6. Global growth incidence curves for high-income countries: household market incomes for the working-age population

Cumulative growth rates for household market incomes, based on 16 high-income countries

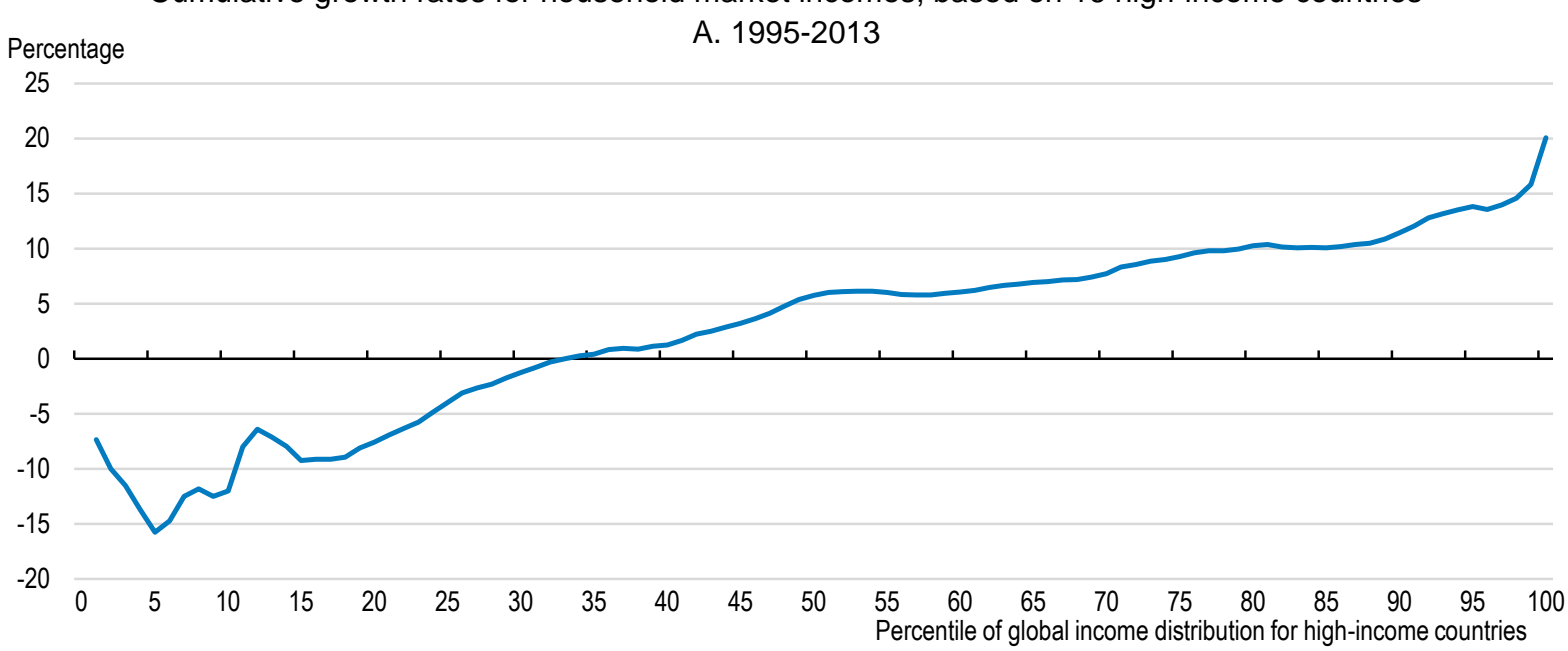

B. Subperiods, 1995-2004 and 2004-2013

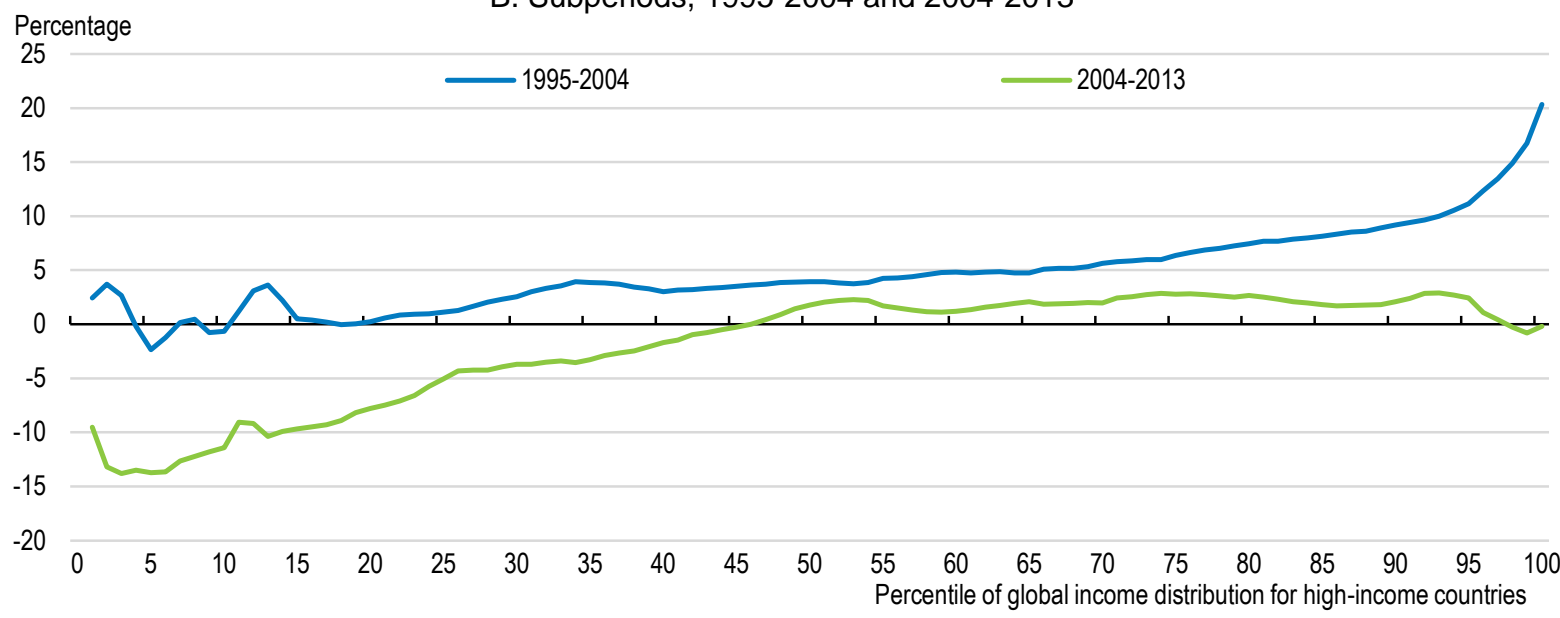

C. Subperiods around the crisis, 2004-2008, 2008-2010 and 2010-2013

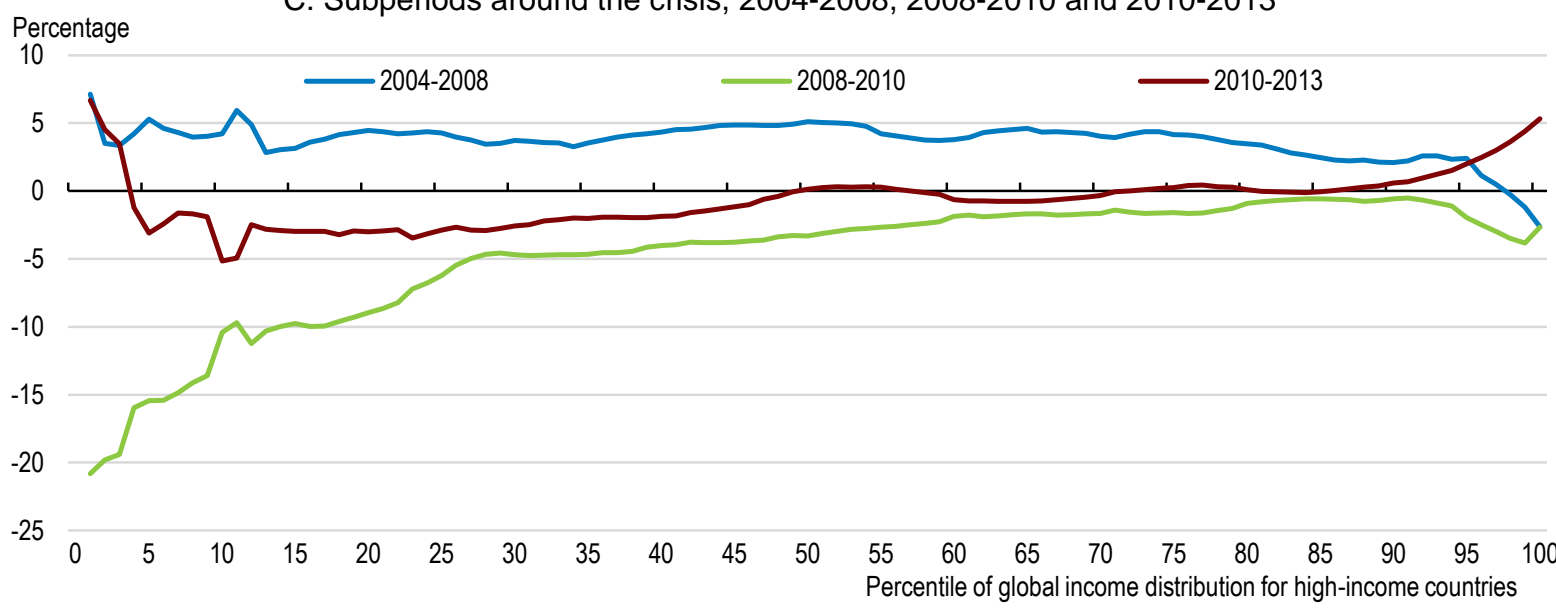

Note: Based on 16 high-income countries (complete series not available for the United Kingdom). See Tables A1 and A2 in the Annex for country and year coverage. The working-age population include households with a household head aged 18-64.

Source: Author's calculations based on the OECD Income Distribution Database. 
25. Global market income inequality in high-income countries also increased from the mid-1990s to 2013 (Figure 6, Panel A): household market incomes in the upper half increased by 5-20\%, while the entire lowest third experienced falling real market incomes. Compared to the corresponding curve for disposable incomes for the total populations (Figure 4), the market income curve is strongly upward sloping almost everywhere. There was thus no stable broad middle group experiencing similar growth in market incomes, which indicates a more widespread source of increasing global market income inequality across highincome countries, for instance in line with skill-biased technological change (see e.g. Acemoglu 2002; OECD, 2011). The increase of the Gini coefficient is around 3 points (from 41.2 to 44.2), which is close to the rise of 2.7 points for the disposable income Gini (covering the full population). In general market incomes are more volatile, which can also be seen from Figure 6.

26. With this caveat in mind, Figure 6, Panel $\mathrm{C}$ indicates that during the upswing and into the first years of the crisis, global market income inequality for high-income countries actually decreased (corresponding to around 0.7 Gini point) as can be seen from the slightly downward sloping growth incidence curve for 2004-2008. However, the decline is likely to reflect a timing difference in the impact of the crisis across the market income distribution, with affluent households being immediately affected through falling capital incomes and labour incomes for lower-income households being affected later due to lags in the adjustment of firm's employment or labour hording. In sum, market incomes appear to have been the main driver of the rise in global inequality in household disposable incomes for high-income countries, with national tax and transfer systems only marginally offsetting the increase, even though they have continued to play an important stabilising role. However, this is only indicative evidence and relies on a comparison of different populations; more formal analysis would require additional data for market incomes to overcome the re-ranking issue.

\subsection{Country movements: best and worst performance in the global income distribution for high-income countries}

27. As a final perspective on household income growth in high-income countries, this subsection turns to individual country performance to single out up- and downward movements within the global income distribution for high-income countries. The income concept is household disposable incomes for the full populations as in the main part of the paper. Country movements can be visualised in a simple way by relating the position of a household within the national income distribution to the corresponding position within the global income distribution for each year. This is illustrated in Figure 7 for selected countries and selected years (see Figure A6 in the Annex for the remaining 11 high-income countries). ${ }^{22}$

28. For instance, households in Germany with incomes around the $50^{\text {th }}$ percentile of the German household disposable income distribution are also placed around the $50^{\text {th }}$ percentile in the global income distribution for high-income countries, which holds for all the years illustrated in Figure 7, Panel A. In fact, this is roughly the case for the entire German income distribution, as can be seen from the lines close resemblance to the 45-degree line. In other words, Germany works well as a "representative country" for all high-income countries combined, at least in terms of the household disposable income distribution. The same can be said for France and the Netherlands (Figure A6). Like Germany, the United States did not move much between 1995 and 2013 within the global income distribution (Figure 7, Panel F), but the curves for the United States display a weak S-shape. This reflects greater income dispersion in the United States and their dominance among the globally most affluent households, for instance the $70^{\text {th }}$ percentile in the American income distribution are placed higher at the $80^{\text {th }}$ percentile in the global income distribution for high-income countries.

22. The lowest- and highest-income households in each country tend to be located in the bottom and the top of the global income distribution for high-income countries. While this may be the case at the extremes in each country, the log-normal fitting of the data probably exaggerates this pattern. 
Figure 7. Movements of selected countries within the global income distribution for high-income countries

Household disposable incomes 1995-2013, based on 17 high-income countries

A. Germany

Percentile of the global distribution for high-income countries

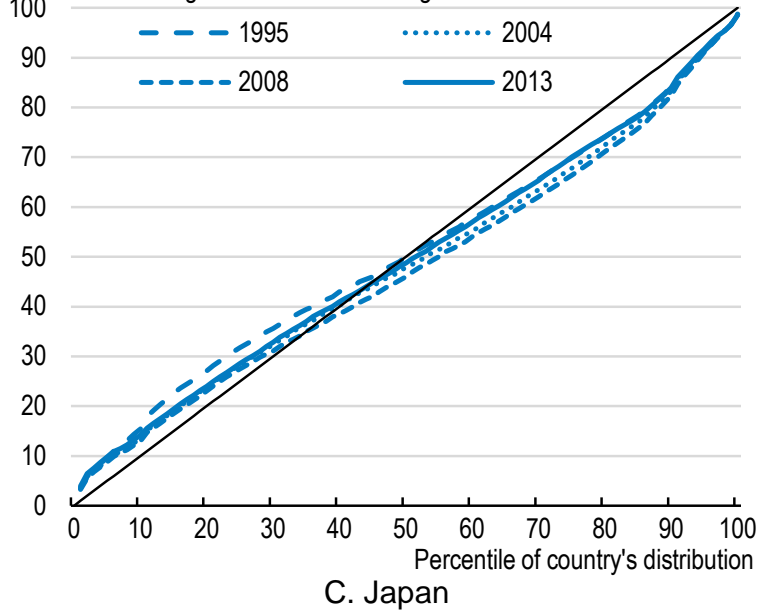

Percentile of the global distribution for high-income countries

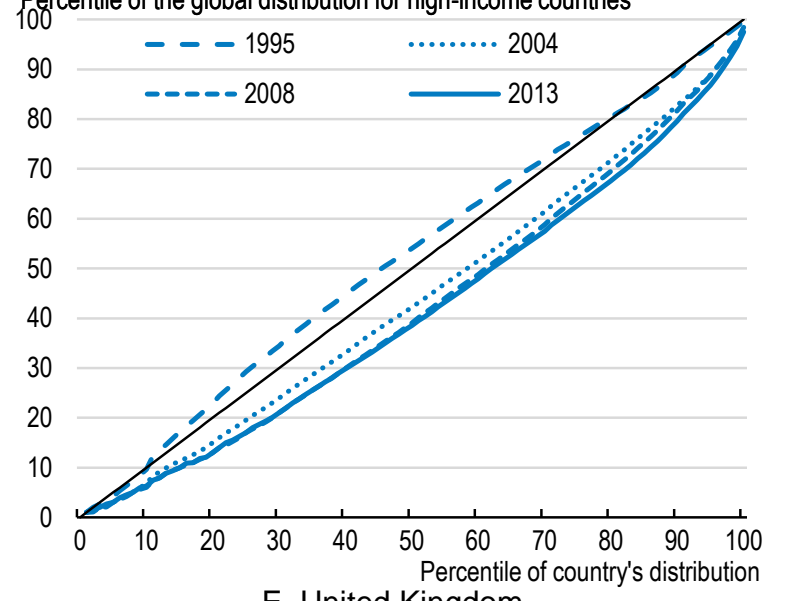

E. United Kingdom

Percentile of the global distribution for high-income countries

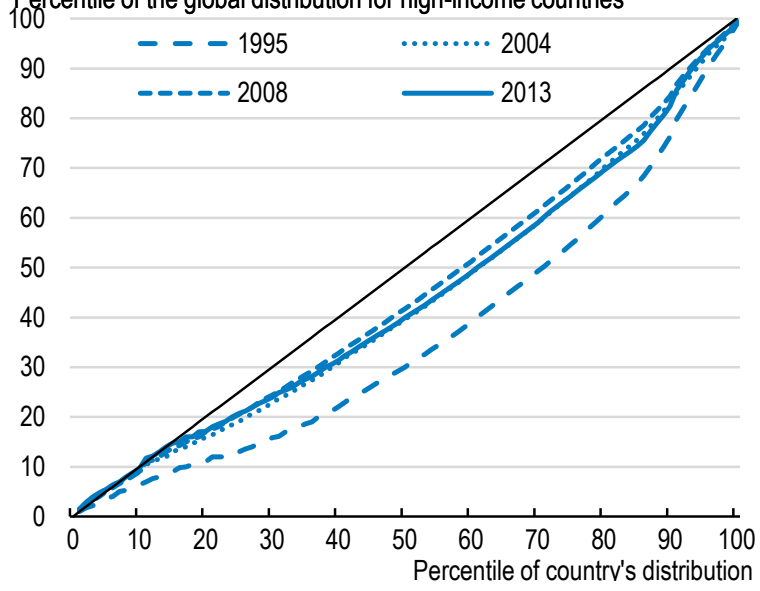

B. Greece

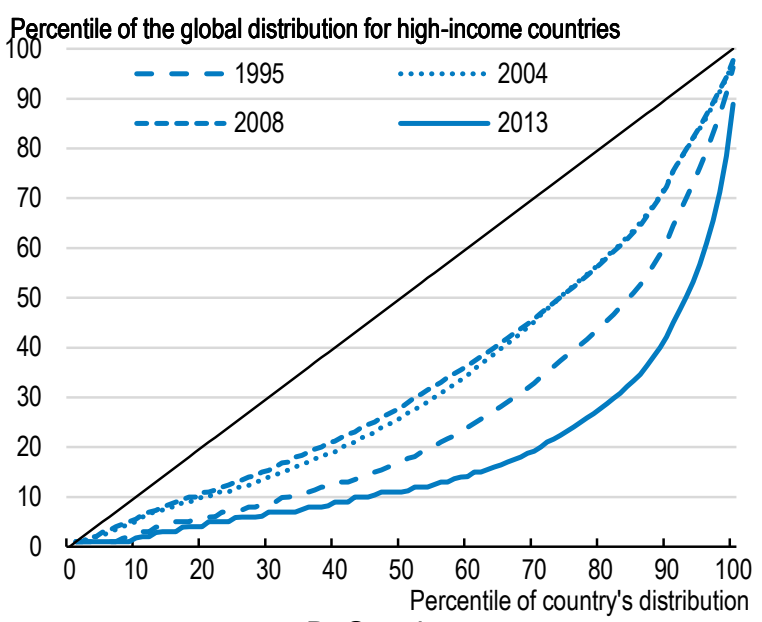

D. Sweden

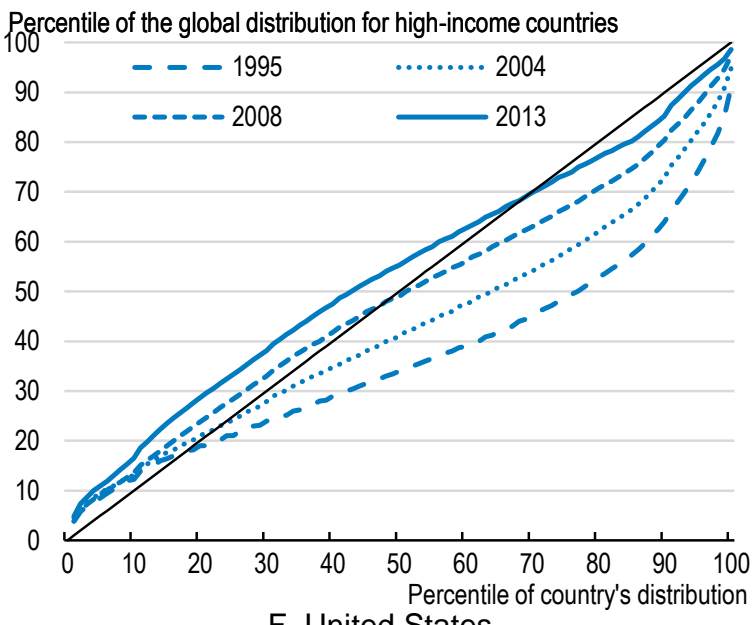

F. United States

Percentile of the global distribution for high-income countries

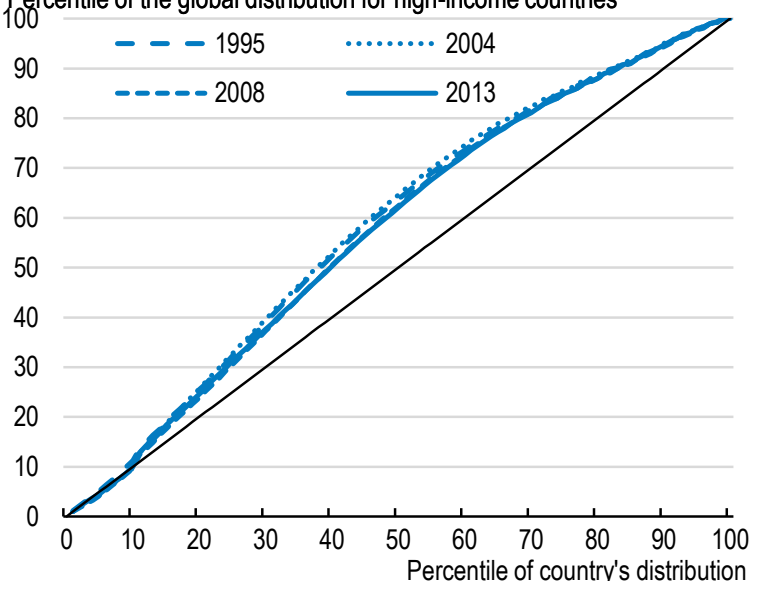

Note: Years shown refer to the global income distribution for high-income countries, for some countries the nearest available year is applied, see Table A2. See Figure A6 in the Annex for the remaining 11 countries.

Source: Author's calculations based on the OECD Income Distribution Database. 
29. Greece, which experienced a deep downturn from the outset of the crisis and has been going through a prolonged recession, does not surprisingly take a great downward step within the global income distribution for high-income countries from 2008 to 2013 (Figure 7, Panel B). However, this followed a strong upward movement from 1995 to 2004. Japan has also experienced a remarkable downwards movement from slightly above the 45-degree line almost everywhere in 1995 to significantly below in 2013. This is to a large extent a result of terms-of-trade losses, reducing purchasing power and thus real household disposable income growth, and rising corporate savings (OECD, 2015b).

30. Sweden has experienced strong GDP growth over the past two decades, which has lifted household incomes and resulted in a strong upward movement from 1995 to 2013 within the global income distribution for high-income countries (Figure 7, Panel D). The United Kingdom also experienced a substantial upward movement from the mid-1990s to 2008, after which relatively weaker household income growth during the crisis implied a slight reversal for the 2013 curve (Figure 7, Panel E). Among the best-performing countries improving their position from the mid-1990s to 2013 are also Australia, Canada, Finland, Israel, New Zealand and Norway (Figure A6). The fact that more countries moves up than down is a result of differences in countries' population sizes. Because Japan represents $16 \%$ of the total population for the combined 17 high-income countries, its strong downward movement necessarily has to be matched by upward movement of a similar amount of people.

\section{Robustness}

31. The construction and analysis of a global income distribution for high-income countries necessarily rests on a number of strong assumptions. To test the sensitivity of the results presented above, this section presents robustness analysis in five areas: i) quasi non-anonymous growth incidence curves are constructed to assess the importance of income mobility (re-ranking) across high-income countries, ii) sensitivity to the exclusion of the two most populous countries, Japan and the United States, iii) scaling household incomes to comply with national accounts means and adding social transfers in-kind, iv) alternatives to 2010 as PPP base year, v) alternatives to log-normal fitting of country-decile data.

\subsection{Quasi non-anonymous growth incidence curves}

32. The (anonymous) growth incidence curves presented above provide a clear link between the development in relative inequality, for instance quantified by the Gini, and household income growth. The slope of the growth incidence curve shows in what way the income distribution has become more or less equal, for instance by disclosing a decline in real incomes at the very bottom. Yet, from a welfare perspective income mobility also matters, in particular whether the same households are stuck at the bottom of the distribution for several years or the low-income state tends to be temporary. Such re-ranking effects can be assessed by fixing the position of households and constructing non-anonymous growth incidence curves (Bourguignon, 2011). Unfortunately, this requires access to the micro-data and is thus not feasible for the exercise in this paper. But a "quasi" non-anonymous growth incidence curve that fixes the position of country-deciles can be constructed to show the influence of mobility among country-deciles. This is useful for assessing e.g. whether the poorest country-decile in 1995 was also the poorest countrydecile in 2013, i.e. experienced the lowest income growth across all country-deciles. 
Figure 8. Quasi non-anonymous global growth incidence curves for high-income countries

Household disposable incomes 1995-2013, based on 17 high-income countries

A. Cumulative growth rates by country-deciles and quasi non-anonymous growth incidence curve

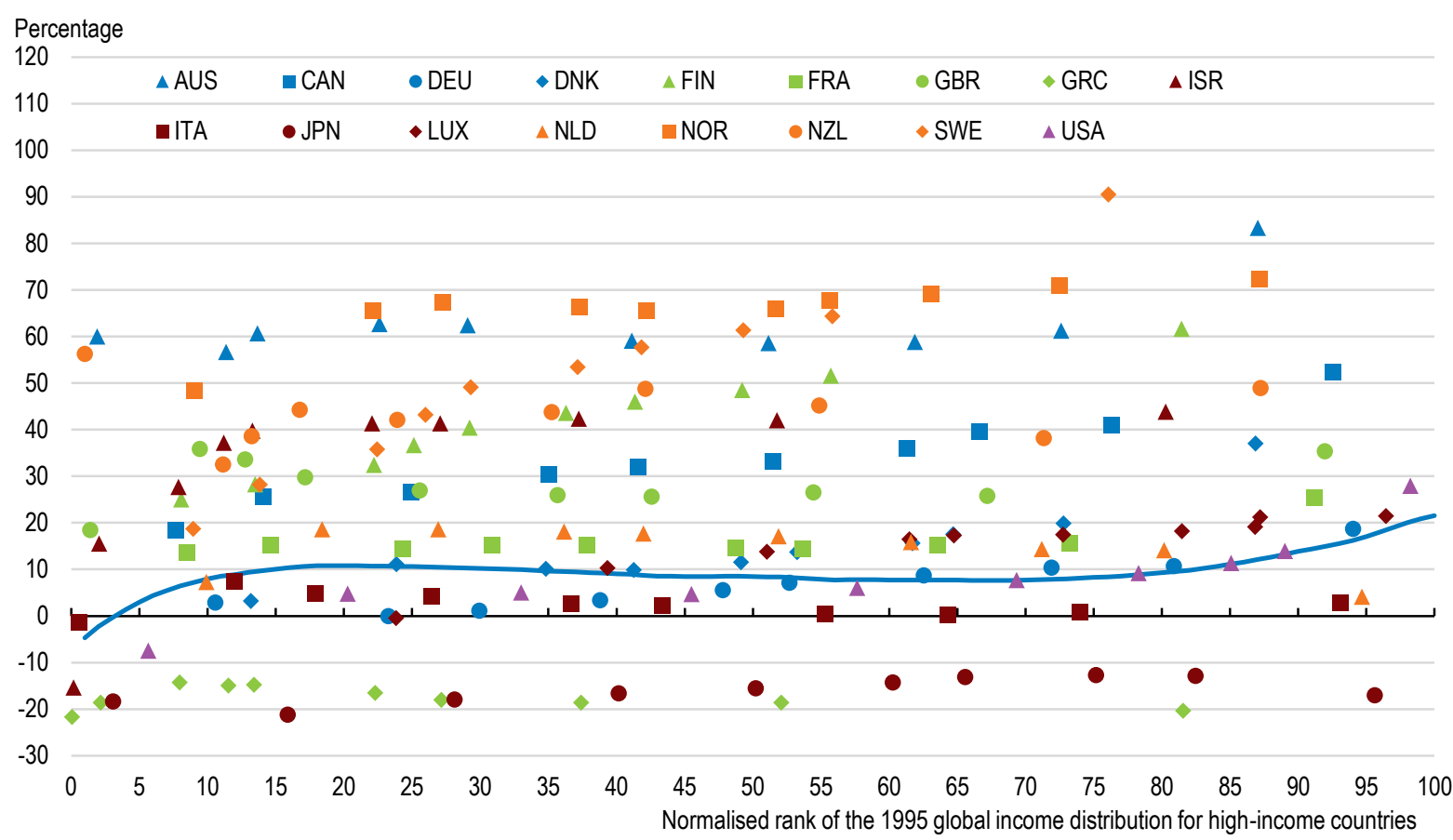

B. Anonymous and quasi non-anonymous growth incidence curves

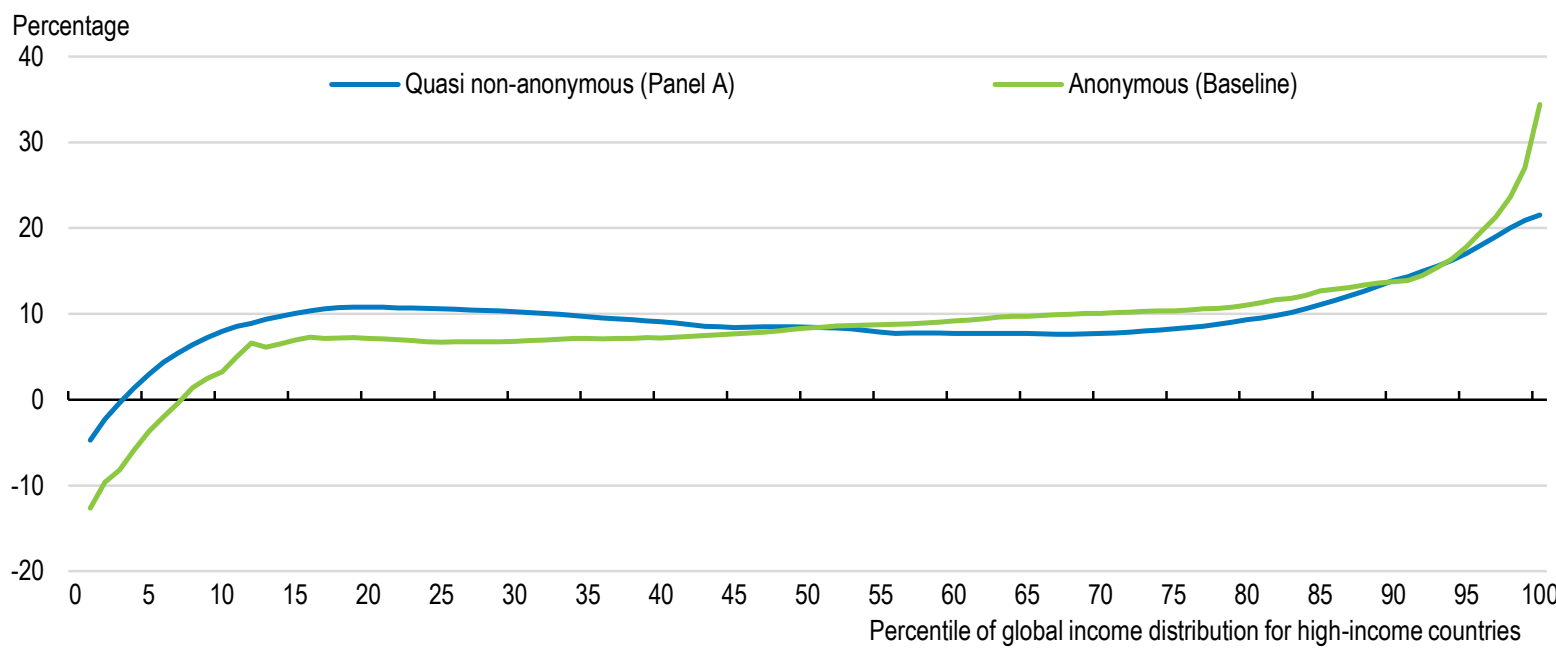

Note: Panel A reports the cumulative household disposable income growth for each country-decile from 1995 to 2013. Each countrydecile is placed at its position in the global income distribution for high-income countries in 1995. The solid line is the quasi nonanonymous growth incidence curve, obtained as the predicted value from a kernel-weighted local cubic polynomial regression. Panel $B$ reproduces the solid line from Panel A and the anonymous version from Figure 4. See Tables A1 and A2 in the Annex for country and year coverage.

Source: Author's calculations based on the OECD Income Distribution Database. 
33. The quasi non-anonymous growth incidence curve for the period 1995-2013 is presented in Figure 8, Panel A. The curve is obtained in the following way: i) household income growth for each country-decile is computed, for instance incomes in the $10^{\text {th }}$ decile in Canada grew by around 50 per cent from 1995 to 2013, as illustrated by the markers in Figure 8, Panel A; ii) each country-decile is ranked according to its placement in the global income distribution for high-income countries in 1995, which determines the placement of the markers on the horizontal axis in Figure 8, Panel A; iii) the quasi nonanonymous growth incidence curve is obtained from a population-weighted kernel regression of income growth on the rank in the initial 1995 distribution. ${ }^{23}$ The growth incidence curve is non-anonymous because the ranking of each country-decile is now the same between the two years for which growth rates are computed, but "quasi" since individual households need not belong to the same country-decile in both years (see Lakner and Milanovic, 2016). The overall shape turns out to be very similar to the anonymous version in Figure 4, which can be seen in Figure 8, Panel B that replicates both curves. Still, income growth has been higher in the lower-half of the distribution according to the non-anonymous curve and lower or the same in the upper-half relative to the anonymous curve, implying a smaller rise in inequality than found above.

\subsection{Sensitivity to the most populous countries: Japan and the United States}

34. The United States composes 37\% and Japan 16\% of the combined population of the 17 highincome countries included in the analysis (average across 1995-2013). To test their influence on the overall development, Figure 9 presents the global growth incidence curve for 1995-2013 with the two countries separately excluded. The dominance of the United States at the top is evident: the most affluent households only experienced cumulative real income growth around $17 \%$ when the United States is excluded; not that far from the $10 \%$ growth experienced by the bulk of the global distribution for high-income countries. In terms of the Gini index, the increase is 1.4 Gini points without the United States, half of the overall increase. It is thus clear that a substantial part of the increase in global inequality among high-income countries is driven by the United States.

35. The impact on inequality from excluding Japan is negligible, whereas it has a substantial negative influence on the level of growth across the global income distribution for high-income countries. From the $5^{\text {th }}$ to the $95^{\text {th }}$ percentile the difference is around 5 percentage points relative to the baseline growth incidence curve from Figure 4. The finding of very low household income growth for a large majority of the global income distribution for high-income countries is thus to some extent modified by excluding the effect of Japan. However, cumulative real income growth around $15 \%$ over almost two decades is still relatively low in historical perspective (corresponding to about $0.8 \%$ average annual growth).

23. The raw data, i.e. without the lognormal fitting, is applied in this subsection to facilitate illustration of cross-country performance. Results are qualitatively unchanged if the quasi non-anonymous growth curve is constructed for country-percentiles based on the disaggregated data (available upon request). 
Figure 9. The relative importance of the United States and Japan for global income growth among highincome countries

Cumulative growth rates for household disposable incomes 1995-2013, based on 17 high-income countries

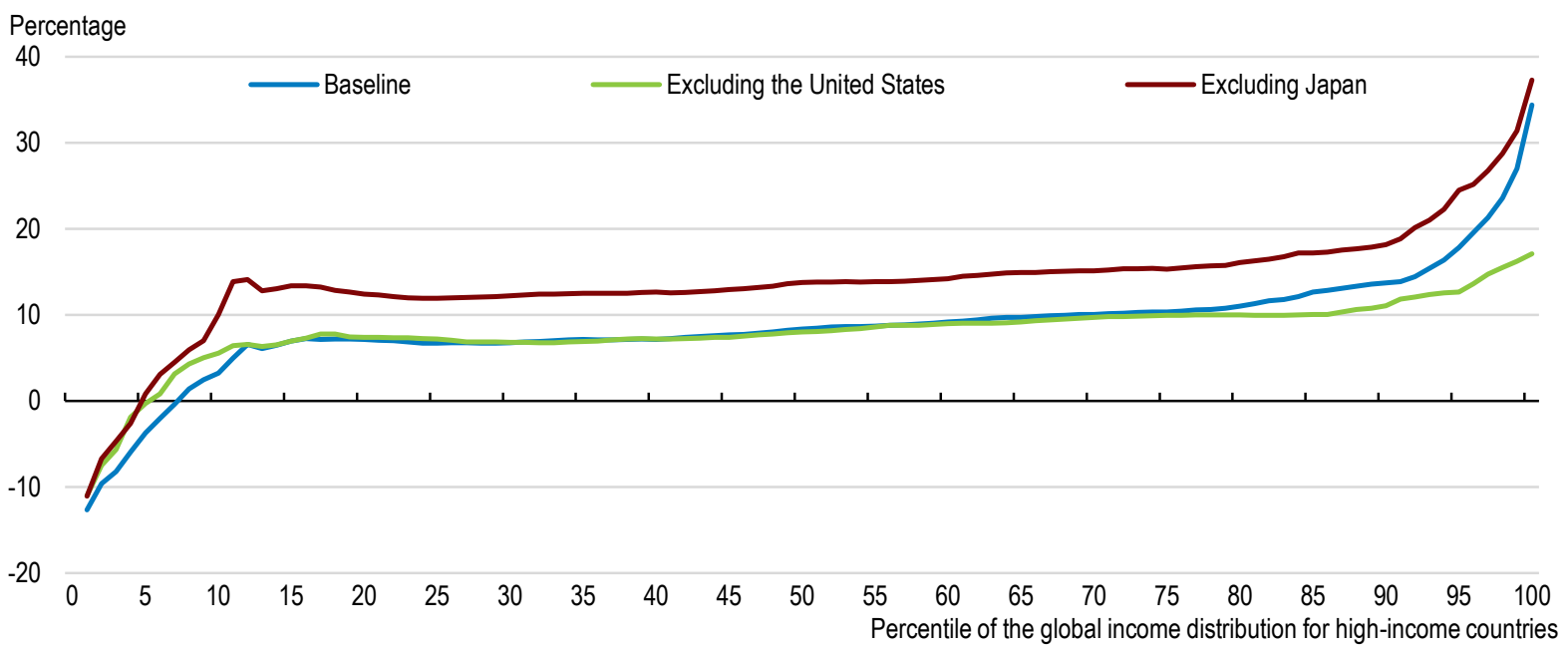

Note: The baseline curve is replicated from Figure 4, Panel A. The two other curves are constructed in a similar way for 16 highincome countries, but without the United States and Japan, respectively. See Tables A1 and A2 in the Annex for country and year coverage.

Source: Author's calculations based on the OECD Income Distribution Database.

\subsection{Scaling incomes to comply with national accounts means and adding social transfers in-kind}

36. The global inequality literature has often scaled household incomes from surveys to national account means, typically GDP or consumption per capita, to improve cross-country comparability (Anand and Segal, 2008; 2015). The reason is that national income surveys can differ substantially, some measure income others consumption expenditure, some are gross-of-taxes others net-of-taxes and some record cash items only while others include certain items of income-in-kind. By scaling, it is ensured that the highly harmonised series from national accounts govern cross-country differences and growth rates at the average, while the micro-based survey data are left to determine the relative within-country distribution and inequality level.

37. In the case of high-income countries such comparability issues are much less of a problem, especially since this paper relies on the highly harmonised OECD Income Distribution Database (see Section 3.1). However, scaling to national account means is relevant as a robustness check for other reasons. First, social transfers in-kind (STiK, e.g. healthcare and educational services) are not included in the micro-based household income concept. Yet STiK are often sizeable and with important cross-country differences (Figure 10): according to the national accounts measure of STiK, citizens in the Nordic countries on average received public services valued at around USD 8,000 annually, corresponding to around 25 per cent of the micro-based average household disposable income; this is more than twice than citizens of e.g. the United States and Switzerland receive, both in terms of absolute spending and relative to cash incomes. Second, scaling can address concerns of rising divergence between micro- and macrobased figures, emerging for a number of reasons, including measurement issues such as underreporting of top incomes, and more fundamental differences such as different developments in price deflators. While such scaling has no implications for relative inequality measures within countries, and thus cannot address the fundamental problems of inequality measurement related to e.g. missing top incomes, it can ensure that 
all resources recorded at the aggregate level are consistently allocated to the household sector in all countries.

Figure 10. Spending on social transfers in-kind according to the national accounts

STiK expenditure in 2013 or latest available year

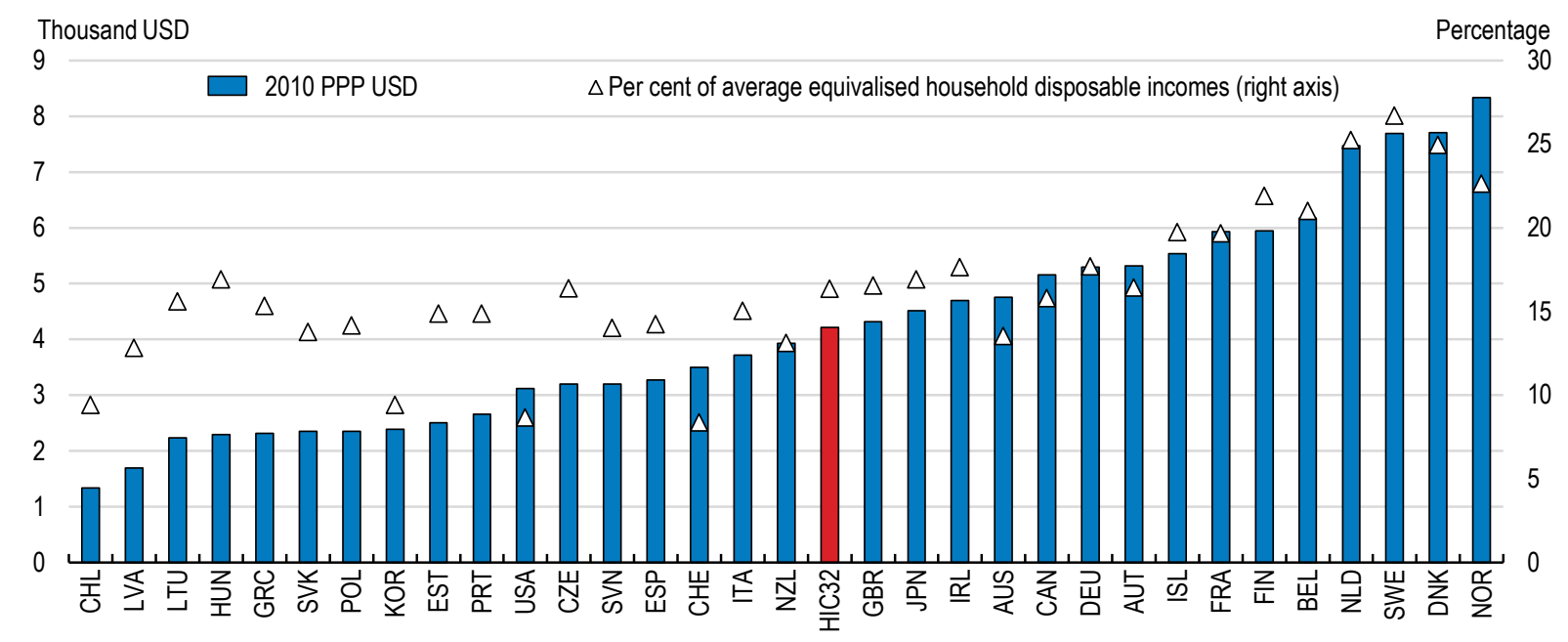

Note: Measured in 2010 USD using the price index and PPPs for actual individual consumption. HIC32 refers to a simple crosscountry average across the 32 high-income countries. Data for Israel and Luxembourg are not available.

Source: OECD National Accounts; OECD Income Distribution Database.

38. For the purpose of this paper, scaling by four different measures from the national accounts are considered, supplemented by a fifth tentative adjustment that allocates the total amount of STiK spending equally between all households for each country and year (see Table 4 for details of the adjustments). The national accounts provide measures for household disposable income per capita (HDI) and adjusted household disposable income per capita (AHDI), which are the most relevant items in this context. The former comes closest to the micro-based income measure, while the latter, by adding the value of STiK, generally is viewed as the best available measure of households' living standards for cross-country comparison (Stiglitz et al., 2009). ${ }^{24}$ In addition, the usual candidates applied in the global inequality literature, GDP per capita and household final consumption expenditure per capita (CON), are also included for reference. In each case the relevant price index and PPP are used for the scaled series (see Table 4); for instance in the case of AHDI, prices and PPPs for actual individual consumption, covering the household, government and NPISH sectors, are applied to account for the price development of STiK (e.g. healthcare).

24. It is beyond the scope of this paper to discuss the differences in the underlying income definitions and why micro- and macro-based measures differ. See Fesseau et al. (2013); Nolan et al. (2016); OECD (2016a, Chapter 3). For HDI an important difference to the micro-based series is the inclusion of the value of owner-occupied housing (recorded in "operating surplus" in national accounts), which is not included in the micro-based measure for household disposable income in the IDD. 
Table 4. Household income adjustments to national account measures

\begin{tabular}{|c|c|c|c|}
\hline National accounts measure & Adjustment & Price index & PPP \\
\hline $\begin{array}{l}\text { Household disposable income per } \\
\text { capita (HDI) }\end{array}$ & $y_{i c t}^{H D I}=y_{i c t} \cdot H D I_{c t} / \overline{y_{c t}}$ & $\begin{array}{l}\text { Consumer price } \\
\text { index }\end{array}$ & $\begin{array}{l}\text { Private } \\
\text { consumption }\end{array}$ \\
\hline $\begin{array}{l}\text { Adjusted household disposable } \\
\text { income per capita (AHDI) }\end{array}$ & $y_{i c t}^{A H D I}=y_{i c t} \cdot A H D I_{c t} / \overline{y_{c t}}$ & $\begin{array}{l}\text { Actual individual } \\
\text { consumption }\end{array}$ & $\begin{array}{l}\text { Actual individual } \\
\text { consumption }\end{array}$ \\
\hline GDP per capita (GDP) & $y_{i c t}^{G D P}=y_{i c t} \cdot G D P_{c t} / \overline{y_{c t}}$ & GDP deflator & GDP \\
\hline $\begin{array}{l}\text { Household final consumption } \\
\text { expenditure per capita (CON) }\end{array}$ & $y_{i c t}^{C O N}=y_{i c t} \cdot C O N_{c t} / \overline{y_{c t}}$ & $\begin{array}{l}\text { Final consumption } \\
\text { expenditure }\end{array}$ & $\begin{array}{l}\text { Private } \\
\text { consumption }\end{array}$ \\
\hline $\begin{array}{l}\text { Equal allocation of social transfers } \\
\text { in-kind (STiK) } \\
\text { (equivalised household } \\
\text { disposable incomes + STiK } \\
\text { spending per capita) }\end{array}$ & $y_{i c t}^{S T i K}=y_{i c t}+S T i K_{c t}$ & $\begin{array}{l}\text { Actual individual } \\
\text { consumption }\end{array}$ & $\begin{array}{l}\text { Actual individual } \\
\text { consumption }\end{array}$ \\
\hline \multicolumn{4}{|c|}{$\begin{array}{l}\text { Note: } y_{i c t} \text { refer to equivalised household disposable income for person i in country c in year t available from the (lognormal-fitted) } \\
\text { microdata; } \bar{y}_{c t} \text { refer to average equivalised household disposable income in country c in year t. The price index and PPP for actual } \\
\text { individual consumption covers goods and services for the household, government and non-profit institutions serving households } \\
\text { (NPISH) sectors. The last row applies different equivalence scales for cash income }\left(y_{i c t} \text { from microdata applies the square root of }\right. \\
\text { household members) and non-cash income (STiK applies the actual number of household member since it is allocated on a per } \\
\text { capita basis). }\end{array}$} \\
\hline
\end{tabular}

39. Since national accounts components are measured in per capita terms, whereas micro-based household incomes are equivalised (see Section 3.2), scaling implicitly results in economies of scale within households to no longer be assumed for the scaled series. This also implies that the levels of the micro- and macro-based income series cannot be compared since the equivalised series will be mechanically higher than the per capita series. ${ }^{25}$ Nevertheless, it is still useful to compute ratios between the two averages and compare the cross-country differences (see Figure A8 in the Annex). For instance, scaling by HDI reduces incomes relative to the micro-based measure in most high-income countries as expected; for instance by more than 30 percent in most of the Nordic countries, whereas it raises household incomes in the United States by close to 10 per cent, thereby raising between-country inequality (see Figure A9 in the Annex for country positions within the scaled global income distributions for high-income countries). Part of this difference may be explained by the underreporting of top incomes in the survey-based microdata for the United States (Piketty and Saez, 2003; Ruiz and Woloszko, 2016), while such underreporting is almost absent from the register-based microdata for the Nordic countries.

40. Scaling by AHDI is a simple way to include STiK in household incomes. Still, it assumes that the value of such public services is distributed proportionally to household disposable incomes, i.e. that more affluent households have a higher tendency to receive public healthcare, education etc. for free or at reduced costs. In reality, STiK disproportionately benefit low-income households, e.g. elderly or households with children, and therefore reduces within-country inequality significantly (OECD, 2011). Available empirical evidence tends to find a relatively equal distribution of STiK spending across the income distribution for countries with available data (Zwijnenburg et al., 2017; OECD, 2011). Against this background, the polar case of an egalitarian distribution of STiK (fixed amount per individual) is also considered (last row in Table 4) ${ }^{26}$ This is clearly a strong simplification, among other ignoring cross-

25. Micro-based per capita series could be computed with access to the underlying microdata. This is however not possible based on the semi-aggregate data from the IDD.

26. STiK (primarily Medicare and Medicaid) are also allocated by a fixed amount per beneficiary in Piketty et al. (2016) for the construction of Distributional National Accounts for the United States. By contrast the 
country differences in the services covered by STiK, and should thus be taken as an illustrative exercise only.

41. With these caveats and limitations in mind, the resulting Gini coefficients for the global income distribution for high-income countries are reported in Table 5, while growth incidence curves are illustrated in Figure 11. The following main insights from scaling to national accounts means emerge:

- Scaling by HDI is found to have limited effects on global inequality for high-income countries compared to the baseline scenario: the Gini coefficient is slightly higher and it increases by around $1 / 2$ percentage point more from 1995 to 2013; reflecting higher and increasing betweencountry inequality according to the MLD index. The most striking finding is substantially higher household disposable income growth according to the HDI measure, visualised by the growth incidence curve located around 5 percentage points above the baseline across most of the distribution. Since price indices and PPPs are the same, this could indicate that part of the lowgrowth malaise is due to increasing gaps in the micro-based sources. ${ }^{27}$

- Overall the picture for GDP per capita and household final consumption expenditure per capita is similar to the one for HDI: differences in inequality levels and changes are minor relative to the baseline scenario, while growth rates are substantially higher, in the case of consumption by more than 15 percentage points across most of the global income distribution for high-income countries. In this case, different deflators and different PPPs drive part of the differences (see Table 4). ${ }^{28}$

- The results for inclusion of STiK depends, as expected, on the allocation method, but the two methods also produce some common findings:

- Both allocations of STiK reduce between-country inequality and raises average household income growth substantially. The former is a likely reflection of relatively low STiK spending in the United States (Figure 12), which has the highest average household disposable income (Table 3). The latter may to some extent be driven by rising healthcare spending (OECD, 2016b).

- Scaling by AHDI yields a Gini coefficient and change over 1995-2013 in line with the baseline scenario, whereas growth rates are more than 10 percentage points higher than the baseline growth across the distribution, corresponding to an average annual growth rate around $1 \%$ at the median.

authors apply proportional allocation for collective public consumption (e.g. defence, infrastructure etc.) and educational spending.

27. Structural changes in household structure may explain part of the difference since micro-based income growth is based on equivalised incomes, whereas the distributions scaled by national accounts means are in per capita terms. For instance, the trend increase in the share of single households, observed in a number of high-income countries (OECD, 2011), works as a drag on income growth because it reduces economies of scale over time.

28. For instance, real GDP grew at a faster pace than AHDI over the period 1996-2013 in the majority of OECD countries (Ribarsky et al., 2016). A large part of the divergence can be explained by differences in price developments, with prices for consumers growing at a faster pace than those faced by producers. Exceptions are commodity-exporting countries, benefitting from terms of trade improvements (Australia, Canada, New Zealand and Norway). 
- Adding STiK in equal amounts across national income distributions lowers within-country inequality significantly, and since this constitute the vast majority of global inequality for high-income countries, the global Gini coefficient is reduced by more than 4 percentage points in all the years considered. More important, this also reduces the trend increase in inequality to 2.1 percentage point; a result of higher growth in STiK over the period considered relative to household incomes. Finally, the allocation of a fixed amount to all individuals has a distinct effect at the very bottom of the distribution, which is lifted from negative growth rates in the baseline case to above 10 per cent. Nevertheless, this is subject to the caveat that poor households are likely to value STiK less than one-to-one with cash income since such services cannot be exchanged to e.g. food or other basic goods, they are more likely to be in need of.

42. Summing up, the national accounts robustness checks leave the results for inequality levels and changes for high-income countries qualitatively unchanged. By contrast, the exercise questions the result of very sluggish growth in household incomes for the vast majority of people living in high-income countries. The micro-based analysis showed cumulative household disposable income growth around $10 \%$ from 1995 to 2013 for the global middle class in high-income countries. Scaling incomes to the most comprehensive income measure to track household living standards in the national accounts, adjusted household disposable incomes, indicates that the cumulative growth rate could be twice as high, reflecting especially rising healthcare spending. 
ECO/WKP(2017)34

Table 5. Inequality trends for household incomes adjusted to national accounts means

Household income distributions 1995-2013, based on 15 high-income countries

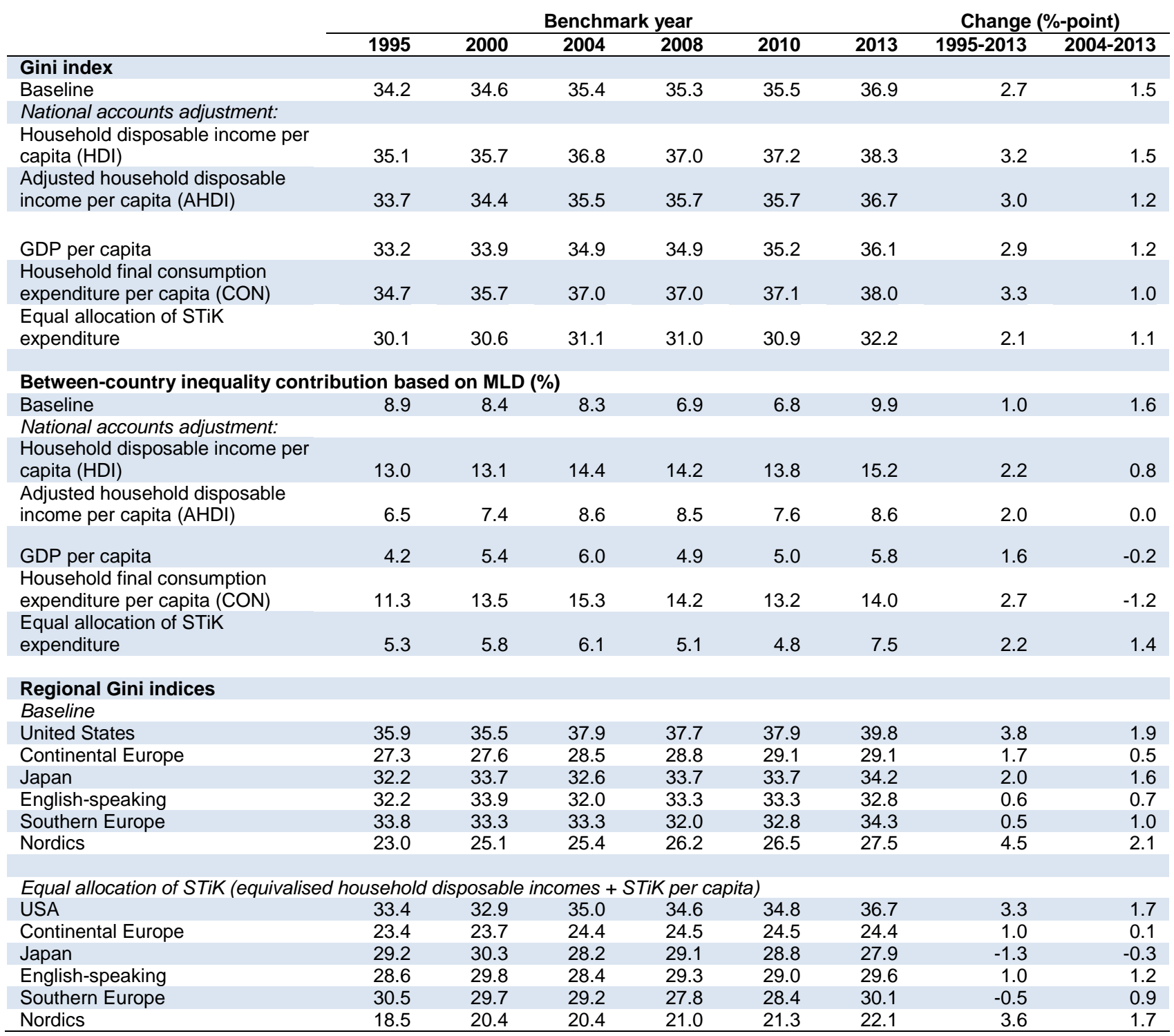

Note: See Table 4 for construction of the series and deflators and PPPs applied. The baseline scenario is the results from Table 3 , but based on 15 countries only. Israel and Luxembourg are excluded because of missing data.

Source: Author's calculations based on the OECD Income Distribution Database and OECD National Accounts. 
Figure 11. Growth incidence curves for incomes scaled to national accounts measures

Cumulative growth rates 1995-2013, based on 15 high-income countries

A. Scaling to national accounts means

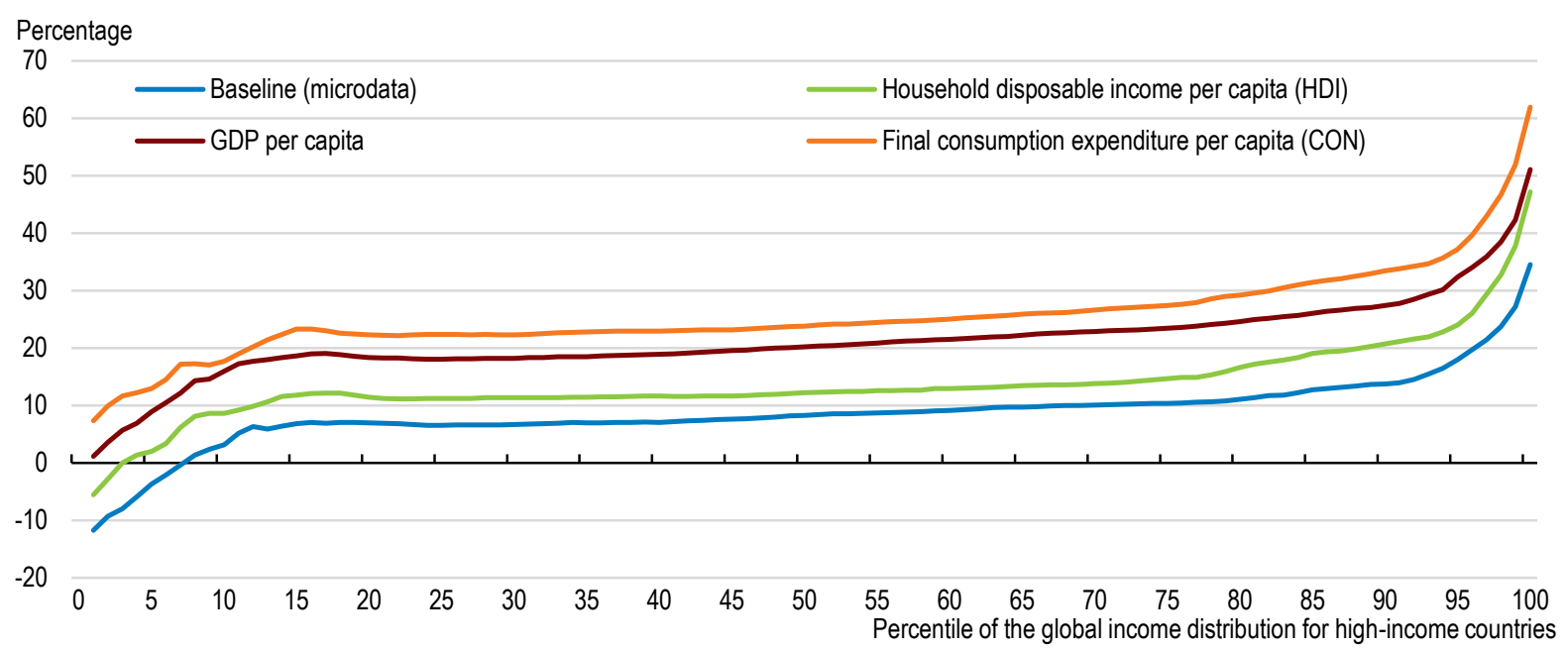

B. Including STiK by scaling to AHDI or allocating spending equally

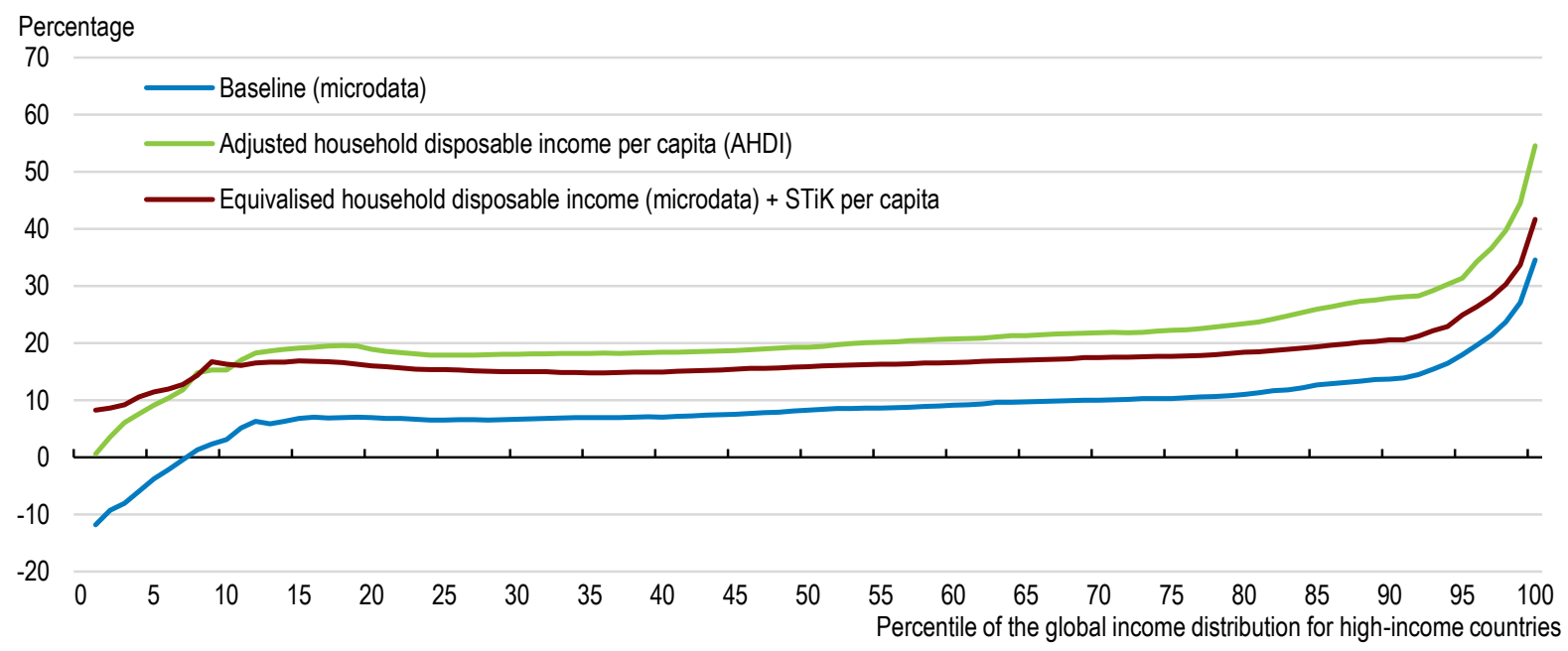

Note: See Table 4 for construction of the series and deflators and PPPs applied. The baseline curve is the growth incidence curve from Figure 4, but based on 15 countries only. Israel and Luxembourg are excluded because of missing data.

Source: Author's calculations based on the OECD Income Distribution Database and OECD National Accounts.

\subsection{Alternative Purchasing Power Parity exchange rates}

43. The analysis in this paper has applied 2010 PPP exchange rates for private consumption (from OECD sources). Figure 12 presents the global growth incidence curve for three alternative base years 2005, 2000 and 1995. Overall the choice of base year has little impact, which should be no surprise since PPPs have no effect on within country inequality and the paper has shown that this is the main driver of changing global inequality among high-income countries. Applying 1995 instead of 2010 PPPs results in a slightly steeper growth incidence curve and thus a larger increase in global inequality. Quantified by the global Gini for high-income countries, the rise from 1995 to 2013 becomes 3.2 Gini points compared to 2.7 points found above with 2010 PPPs. This is almost entirely driven by Japan for which the PPP exchange 
rate appreciates by almost 40\% from 1995 to 2010, thereby placing Japanese households lower in the global income distribution for high-income countries when applying 1995 instead of 2010 PPPs. In this alternative figuration, the deterioration of Japanese household incomes over the two decades turns out to have a slightly higher impact on global inequality for high-income countries.

\section{Figure 12. Robustness to the choice of base year PPP: Global growth incidence curve for high-income countries}

Cumulative growth rates for household disposable incomes 1995-2013, based on 17 high-income countries

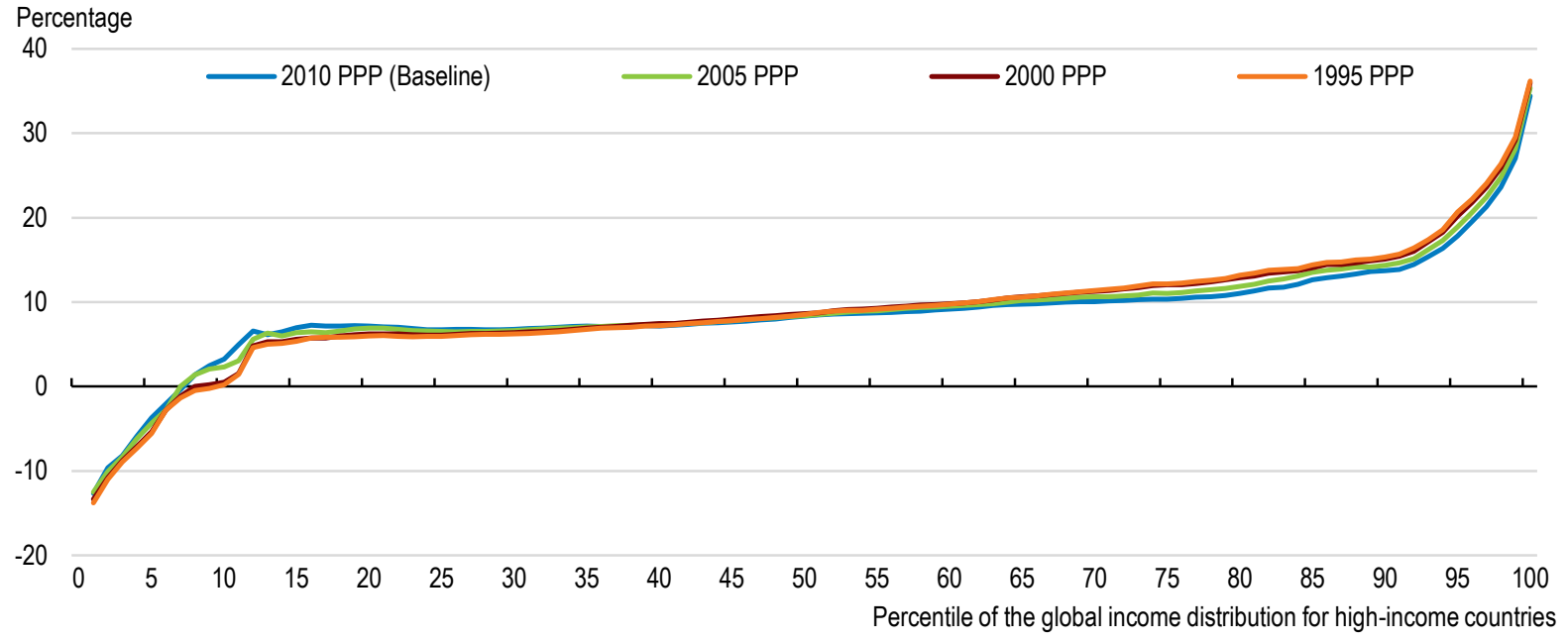

Note: See Tables $\mathrm{A} 1$ and $\mathrm{A} 2$ in the Annex for country and year coverage.

Source: Author's calculations based on the OECD Income Distribution Database.

\subsection{Alternatives to lognormal fitted income distributions}

44. The household income data used in the analysis are only available in the form of mean incomes by deciles, as explained in Section 3.1. To approximate the actual household income distribution for each country and each year, the available ten data points have been fitted to a lognormal distribution. ${ }^{29}$ Figure 13 presents the growth incidence curve for two alternatives to disaggregate the data; a parametric estimation of the Lorenz curve (Beta Lorenz curve, see Datt, 1998) and the Singh-Maddala distribution (Singh and Maddala, 1976). ${ }^{30}$ This turns out to have practically no impact on the shape of the growth incidence curve; in both cases it deviates very little from the baseline produced on the basis of lognormal distributions. This is to some extent a result of the requirement that the mean income by deciles of the estimated distributions should equal the mean of the raw data available from the IDD (following Shorrocks and Wan, 2008). As a result, only variation in the distribution of incomes within deciles is allowed. Note that the disaggregation is not designed to account for the underreporting of top incomes; combining disaggregation with methods to adjust for missing top incomes could make the results more sensitive to the choice of parametric or non-parametric estimation of income distributions. That is however beyond the scope of this paper.

\footnotetext{
29. See footnote 10 for details.

30. For simplicity only distributional forms available from the Stata "ungroup" command, used to produce the lognormal distributions, have been considered.
} 


\section{Figure 13. Robustness to lognormal fitted income distribution: Global growth incidence curves for high-} income countries

Cumulative growth rates for household disposable incomes 1995-2013, based on 17 high-income countries

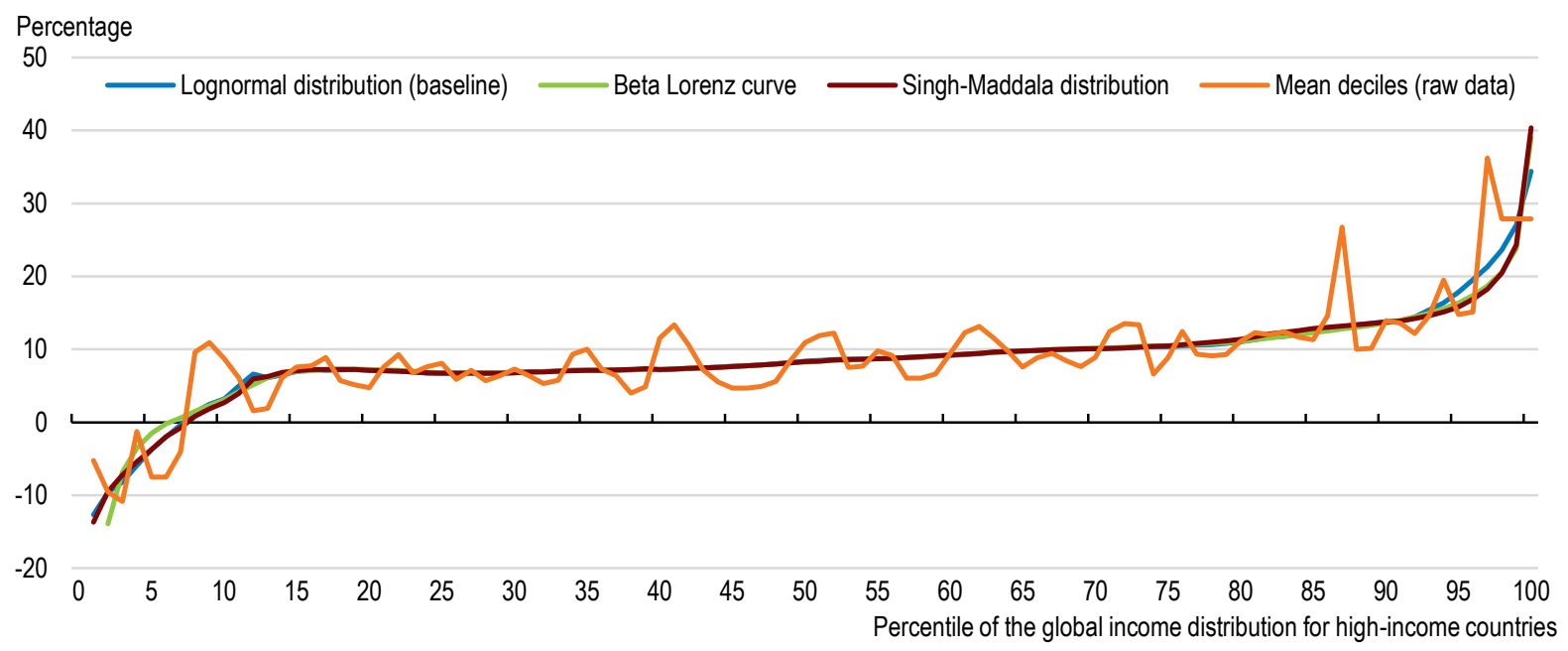

Note: See Tables $\mathrm{A} 1$ and $\mathrm{A} 2$ in the Annex for country and year coverage.

Source: Author's calculations based on the OECD Income Distribution Database.

45. In the literature on global income inequality it is also common to work directly with the grouped data, i.e. to assume that the distribution of incomes within each country-decile is egalitarian (e.g. Bourguignon and Morrison, 2002; Lakner and Milanovic, 2016). This alternative is also presented in Figure 13. Although it is more volatile, the overall shape is the same and the corresponding rise in the Gini is also 2.7 points as for the baseline case assuming lognormal distributions. ${ }^{31}$ In sum, the results do not appear to be sensitive to the method used to disaggregate the data.

\section{Conclusion}

46. This paper is the first to deliver an assessment of the global income distribution for the developed world as a whole. In doing so it relies on the OECD Income Distribution Database, which has not been applied before in the field of global income distributions. Global inequality for high-income countries is found to have increased by almost 3 Gini points from 1995 to 2013; in contrast to global inequality at the world level estimated to have fallen by more than 2 Gini points from 1988 to 2008 (Lakner and Milanovic, 2016). While both results are of interest, the group of high-income countries may be a more relevant reference in addressing growing concern for the impact of globalisation among job-losers and low-skilled workers in advanced countries.

47. The increase in inequality among high-income countries as a whole was a result of incomes at the top growing more than middle and lower incomes and incomes at the bottom falling behind, and the poorest even becoming poorer in real terms. Between the poles a very broad middle class experienced a strikingly similar development in household disposable incomes. As a result, there is little indication of an eroding middle-class among high-income countries as a whole, at least when focusing on household disposable incomes. Still, the global middle-class across high-income countries has experienced relatively

31. The global income distributions are constructed by percentiles (groups of 1\%) to ensure comparability with the other alternatives shown in Figure 11. When working directly with country-decile data it is, however, common to use larger groups (e.g. ventiles of 5\%) to obtain a smoother curve, see e.g. Figure 1, Panel B. 
low real income growth over the past two decades. This reflects foremost the impact of the 2008-09 crisis, but is also sensitive to the inclusion of Japan, which experienced a substantial decline in real incomes. Furthermore, robustness checks using national accounts aggregates indicate that adding social transfers inkind to household disposable incomes may lift household income growth substantially, albeit not above $1 \%$ per year on average across two decades around the median.

48. Decomposing the rise in global inequality for high-income countries into within- and betweencountry contributions shows that the bulk of the increase was due to the well-known increase in withincountry inequality in the majority of high-income countries. In fact, the rise in inequality within the United States, accounting for more than a third of the population in the applied sample of high-income countries, causes almost half of the overall increase in global inequality for high-income countries. 


\section{REFERENCES}

Abdelkrim, A. and J.-Y. Duclos (2007), "DASP: Distributive Analysis Stata Package”, PEP, World Bank, UNDP and Université Laval.

Acemoglu, D. (2002), "Technical Change, Inequality and the Labor Market", Journal of Economic Literature 40, pp. 7-72.

Anand, S. and P. Segal (2015), “The Global Distribution of Income”, in A.B. Atkinson and P. Bourguignon (eds.), Handbook of Income Distribution, Vol. 2A, North-Holland, Amsterdam, pp. 937-979.

Autor, D., D. Dorn and G. Hanson (2013), "The China Syndrome: Local Labor Market Effects of Import Competition in the United States", American Economic Review, Vol. 103/6, pp. 2121-2168.

Bourguignon, F. (2011), "Non-Anonymous Growth Incidence Curves, Income Mobility and Social Welfare Dominance", Journal of Economic Inequality, Vol. 9, pp. 605-627.

Bourguignon, F. and C. Morrison (2002), "Inequality among World citizens: 1820-1992", American Economic Review, vol. 92/4, pp. 727-744.

Causa, O. and M. Hermansen (2017), "The effectiveness of tax and transfer systems in reducing income inequality across OECD countries", OECD Economics Department Working papers, forthcoming.

Chotikapanich, D., R. Valenzuela and D. Rao (1997), "Global and Regional Inequality in the Distribution of Income: Estimation with Limited and Incomplete Data", Empirical Economics, Vol. 22, pp. 533546.

Datt, G. (1998), "Computational Tools for Poverty Measurement and Analysis", IFPRI Food Consumption and Nutrition Division Discussion Paper, No. 50, International Food Policy Research Institute.

Davies, J. and A. Shorrocks (1989), “Optimal Grouping of Income and Wealth Data”, Journal of Econometrics, Vol. 42, pp. 97-108.

Duclos, J.-Y., J. Esteban and D. Ray (2004), "Polarization: Concepts, Measurement, Estimation", Econometrica, Vol. 72/6, pp. 1737-1772.

Esping-Andersen, G. (1990), The Three Worlds of Welfare Capitalism, Polity Press.

Ferger, H. (2007), "Welfare Regimes in Central and Eastern Europe: Incorporating Post-Communist Countries in a Welfare Regime Typology", Contemporary Issues and Ideas in Social Sciences, Vol. 3/2, pp. 1-30.

Ferrera, M. (1996), “The 'Southern Model' of Welfare in Social Europe”, Journal of European Social Policy, Vol. 6/1, pp. 17-37.

Fesseau, M., F. Wolff and M. Mattonetti (2013), "A Cross-country Comparison of Household Income, Consumption and Wealth between Micro Sources and National Accounts Aggregates", OECD Statistics Working Papers, No. 52, http://dx.doi.org/10.1787/5k3wdjrnh7mv-en. 
Foster, J. and M. Wolfson (2010), "Polarization and the Decline of the Middle Class: Canada and the U.S.”, Journal of Economic Inequality, Vol. 8, pp. 247-273.

Frederiksen, K. (2012), "Income Inequality in the European Union", OECD Economics Department Working Papers, No. 952, OECD Publishing, Paris, http://dx.doi.org/10.1787/5k9bdt47q5zt-en.

Gasparini, L. and L. Tornarolli (2015), "A Review of the OECD Income Distribution Database”, Journal of Economic Inequality, Vol. 13, pp. 579-602.

Hammar, O. and D. Waldenström (2017), “Global Earnings Inequality, 1970-2015: Evidence from a New Database", mimeo.

Lakner, C. and B. Milanovic (2016), "Global Income Distribution: From the Fall of the Berlin Wall to the Great Recession”, World Bank Economic Review, Vol. 30/2, pp. 203-232.

Milanovic, B. (2016), Global Inequality: A New Approach for the Age of Globalization, Princeton University Press.

Minoiu, C. and S. Reddy (2014), "Kernel Density Estimation on Grouped Data: The Case of Poverty Assessment", Journal of Economic Inequality, Vol. 12, pp. 163-189.

Nolan, B., M. Roser and S. Thewissen (2016), "GDP per Capita Versus Median Household Income: What Gives Rise to Divergence over Time?”, INET Oxford Working Papers, No. 2016-03.

OECD (2017a), “Making Globalisation Work: Better Lives for All”, Ministerial Council Meeting 2017 Theme Paper.

OECD (2017b), Economic Policy Reforms 2017: Going for Growth, OECD Publishing, Paris, http://dx.doi.org/10.1787/growth-2015-en.

OECD (2016a), Economic Policy Reforms 2016: Going for Growth Interim Report, Chapter 3, OECD Publishing, Paris, http://dx.doi.org/10.1787/growth-2016-en.

OECD (2016b), "Social Expenditure Update 2016: Social spending stays at historically high levels in many OECD countries".

OECD (2015a), In It Together: Why Less Inequality Benefits All, OECD Publishing, Paris, http://dx.doi.org/10.1787/9789264235120-en.

OECD (2015b), OECD Economic Surveys: Japan 2015, OECD Publishing, http://dx.doi.org/10.1787/eco_surveys-jpn-2015-en

OECD (2011), Divided We Stand: Why Inequality Keeps Rising, OECD Publishing, http://dx.doi.org/10.1787/9789264119536-en.

Piketty, T. and E. Saez (2003), "Income Inequality in the United States, 1913-1998”, Quarterly Journal of Economics, Vol. 118/1, pp. 1-39.

Piketty, T., E. Saez and G. Zucman (2016), "Distributional National Accounts: Methods and Estimates for the United States", NBER Working Paper Series, No. 22945. 
Pinkovskiy, M. (2013), "World Welfare is Rising: Estimation using Nonparametric Bounds on Welfare Measures", Journal of Public Economics, Vol. 97, pp. 176-195.

Pinkovskiy, M. and X. Sala-i-Martin (2009), "Parametric Estimations of the world Distribution of Income", NBER Working Paper Series, No. 15433.

Ravallion, M. (2014), "Income Inequality in the Developing World", Science, Vol. 344/6186, pp. 851-855.

Ribarsky, J., C. Kang and E. Bolton (2016), "The Drivers of Differences between Growth in GDP and Household Adjusted Disposable Income in OECD Countries", OECD Statistics Working Papers, No. 71, OECD Publishing, Paris, http://dx.doi.org/10.1787/5jlz6qj247r8-en.

Ruiz, N. and N. Woloszko (2016), "What Do Household Surveys Suggest about the Top 1\% Incomes and Inequality in OECD Countries?", OECD Economics Department Working Papers, No. 1265, http://dx.doi.org/10.1787/5jrs556f36zt-en.

Shorrocks, A. and G. Wan (2008), "Ungrouping Income Distributions: Synthesising Samples for Inequality and Poverty Analysis Creation Date", in: K. Basu and R. Kanbur (eds.), Arguments for a Better World: Essays in Honor of Amartya Sen: Volume I: Ethics, Welfare and Measurement, Oxford University Press.

Singh, S. and G. Maddala (1976), “A Function for Size Distribution of Incomes”, Econometrica, vol. 44, pp. 963-970.

Song, J., D. Price, F. Guvenen, N. Bloom and T. von Wachter (2015), "Firming Up Inequality", NBER Working Paper, No. 21199.

Stiglitz, J., A. Sen and J.-P. Fitoussi (2009), Report by the Commission on the Measurement of Economic Performance and Social Progress, www.stiglitzsenfitoussi.fr/documents/rapport_anglais.pdf.

UNECE (2011), Canberra Group Handbook on Household Income Statistics, Second Edition, United Nations Publishing, Geneva.

Zwijnenburg, J., S. Bournot and F. Giovannelli (2017), "Expert Group on Disparities in a National Accounts Framework: Results from the 2015 Exercise”, OECD Statistics Working Papers, 2016/10, OECD Publishing, Paris, http://dx.doi.org/10.1787/2daa921e-en. 
ECO/WKP(2017)34

ANNEX A1.

Table A1. High-income countries and population shares

A. Sample for $\mathbf{2 0 1 3}$ or latest available year

B. Sample available from mid-1990s Population share

\begin{tabular}{|c|c|c|c|c|c|}
\hline & Populati & share ${ }^{1}$ & & Populati & share $^{2}$ \\
\hline & Sample & $\begin{array}{l}\text { All high-income } \\
\text { countries }\end{array}$ & & Sample & $\begin{array}{l}\text { All high-income } \\
\text { countries }\end{array}$ \\
\hline Australia & 2.2 & 2.0 & Australia & 2.5 & 1.8 \\
\hline Austria & 0.8 & 0.7 & Canada & 4.0 & 2.9 \\
\hline Belgium & 1.0 & 1.0 & Denmark & 0.7 & 0.5 \\
\hline Canada & 3.3 & 3.0 & Finland & 0.7 & 0.5 \\
\hline Chile & 1.6 & 1.5 & France & 7.9 & 5.7 \\
\hline Czech Republic & 1.0 & 0.9 & Germany & 10.3 & 7.4 \\
\hline Denmark & 0.5 & 0.5 & Greece & 1.4 & 1.0 \\
\hline Estonia & 0.1 & 0.1 & Israel & 0.9 & 0.6 \\
\hline Finland & 0.5 & 0.5 & Italy & 7.3 & 5.2 \\
\hline France & 6.2 & 5.6 & Japan & 16.0 & 11.5 \\
\hline Germany & 7.7 & 7.0 & Luxembourg & 0.1 & 0.0 \\
\hline Greece & 1.0 & 0.9 & Netherlands & 2.0 & 1.5 \\
\hline Hungary & 0.9 & 0.8 & New Zealand & 0.5 & 0.4 \\
\hline Iceland & 0.0 & 0.0 & Norway & 0.6 & 0.4 \\
\hline Ireland & 0.4 & 0.4 & Sweden & 1.1 & 0.8 \\
\hline Israel & 0.8 & 0.7 & United Kingdom & 7.6 & 5.5 \\
\hline Italy & 5.6 & 5.1 & United States & 36.6 & 26.4 \\
\hline Japan & 11.9 & 10.8 & & & \\
\hline Korea & 4.7 & 4.3 & & & \\
\hline Latvia & 0.2 & 0.2 & & & \\
\hline Lithuania & 0.3 & 0.3 & & & \\
\hline Luxembourg & 0.1 & 0.0 & & & \\
\hline Netherlands & 1.6 & 1.4 & & & \\
\hline New Zealand & 0.4 & 0.4 & & & \\
\hline Norway & 0.5 & 0.4 & & & \\
\hline Poland & 3.6 & 3.2 & & & \\
\hline Portugal & 1.0 & 0.9 & & & \\
\hline Slovak Republic & 0.5 & 0.5 & & & \\
\hline Slovenia & 0.2 & 0.2 & & & \\
\hline Spain & 4.4 & 4.0 & & & \\
\hline Sweden & 0.9 & 0.8 & & & \\
\hline Switzerland & 0.8 & 0.7 & & & \\
\hline United Kingdom & 6.0 & 5.5 & & & \\
\hline United States & 29.6 & 26.9 & & & \\
\hline Total & 100.0 & 91.1 & Total & 100.0 & 72.1 \\
\hline
\end{tabular}

1. Population shares computed for 2013 for all countries.

2. Average across 1995-2013.

Source: World Development Indicators, World Bank.

Table A2. Benchmark years

A. Sample for 2013 or latest available year

\begin{tabular}{ll} 
Year applied & Countries \\
\hline 2012 & Japan, New Zealand. \\
2013 & Austria, Belgium, Canada, Chile, Czech Republic, Denmark, Estonia, France, Germany, Greece, Iceland, \\
& Ireland, Italy, Latvia, Lithuania, Luxembourg, Norway, Poland, Portugal, Slovak Republic, Slovenia, Spain, \\
& Sweden, Switzerland, the United Kingdom, the United States. \\
2014 & Australia, Finland, Hungary, Israel, Korea, the Netherlands, the United States. \\
\hline
\end{tabular}




\begin{tabular}{|c|c|c|c|c|c|c|c|c|c|c|c|c|c|c|c|c|c|c|c|c|c|}
\hline & 1994 & 1995 & 1996 & 1997 & 1998 & 1999 & 2000 & 2001 & 2002 & 2003 & 2004 & 2005 & 2006 & 2007 & 2008 & 2009 & 2010 & 2011 & 2012 & 2013 & 2014 \\
\hline Australia & & $x$ & & & & & $x$ & & & & $x$ & & & & $x$ & IP & $\mathrm{x}$ & IP & $\mathrm{x}$ & IP & \\
\hline Canada & & $x$ & & & & & $x$ & & & & $x$ & & & & $x$ & $x$ & $x$ & $x$ & $x$ & $x$ & \\
\hline Denmark & & $x$ & & & & & $x$ & & & & & $x$ & & & $x$ & $x$ & $x$ & $x$ & $x$ & $x$ & \\
\hline Finland & & $x$ & & & & & $x$ & & & & $x$ & & & & $x$ & $x$ & $x$ & $x$ & $x$ & $x$ & \\
\hline France & & & $x$ & & & & $x$ & & & & & $x$ & & & $x$ & $x$ & $x$ & $x$ & $x$ & $x$ & \\
\hline Germany & & $x$ & & & & & $x$ & & & & $x$ & & & & $x$ & $x$ & $x$ & $x$ & $x$ & $x$ & \\
\hline Greece & $x$ & & & & & $x$ & & & & & $x$ & & & & $x$ & $x$ & $x$ & $x$ & $x$ & $x$ & \\
\hline Israel & & $x$ & & & & & $x$ & & & & & $x$ & & & $x$ & $x$ & $x$ & $x$ & $x$ & $x$ & \\
\hline Italy & & $x$ & & & & & $x$ & & & & $x$ & & & & $x$ & $x$ & $x$ & $x$ & $x$ & $x$ & \\
\hline Japan & & $x$ & & & & & $x$ & & & $x$ & & & & & IP & $x$ & IP & IP & $x$ & EP & \\
\hline Luxembourg & & & $x$ & & & & & $x$ & & & $x$ & & & & $x$ & $x$ & $x$ & $x$ & $x$ & $x$ & \\
\hline Netherlands & & $x$ & & & & & $x$ & & & & & $x$ & & & $x$ & $x$ & $x$ & $x$ & $x$ & $x$ & \\
\hline Norway & & $x$ & & & & & $x$ & & & & $x$ & & & & $x$ & $x$ & $x$ & $x$ & $x$ & $x$ & \\
\hline Sweden & & $x$ & & & & & $x$ & & & & $x$ & & & & $x$ & $x$ & $x$ & $x$ & $x$ & $x$ & \\
\hline $\begin{array}{l}\text { United } \\
\text { Kingdom }\end{array}$ & $\mathrm{x}$ & & & & & & $\mathrm{x}$ & & & & $\mathrm{x}$ & & & & $\mathrm{x}$ & $\mathrm{x}$ & $\mathrm{x}$ & $\mathrm{x}$ & $x$ & $x$ & \\
\hline United States & & $x$ & & & & & $x$ & & & & & $\mathrm{x}$ & & & $x$ & $x$ & $x$ & $x$ & $x$ & $x$ & \\
\hline
\end{tabular}

Note: Benchmark years applied are 1995, 2000, 2004 and 2008-13. Country-year observations available in the OECD Income Distribution Database are marked by a blue cell. The series contain a break around 2011 for most countries (update of the terms of reference, see http://www.oecd.org/els/soc/lDD-Metadata.pdf). This is addressed by scaling incomes for each decile by the ratio of the corresponding deciles in a year for which the series before and after the break overlap. An " $x$ " marks the country-year observation applied for a given benchmark year, while "IP" ("EP") indicates that the observation has been linearly interpolated (extrapolated).

Source: OECD Income Distribution Database, 2015-16 version of 12 October, 2016 
ECO/WKP(2017)34

Figure A1. Density of high-income countries' global income distribution: OECD Income Distribution data vs Lakner-Milanovic data

Benchmark year 2008

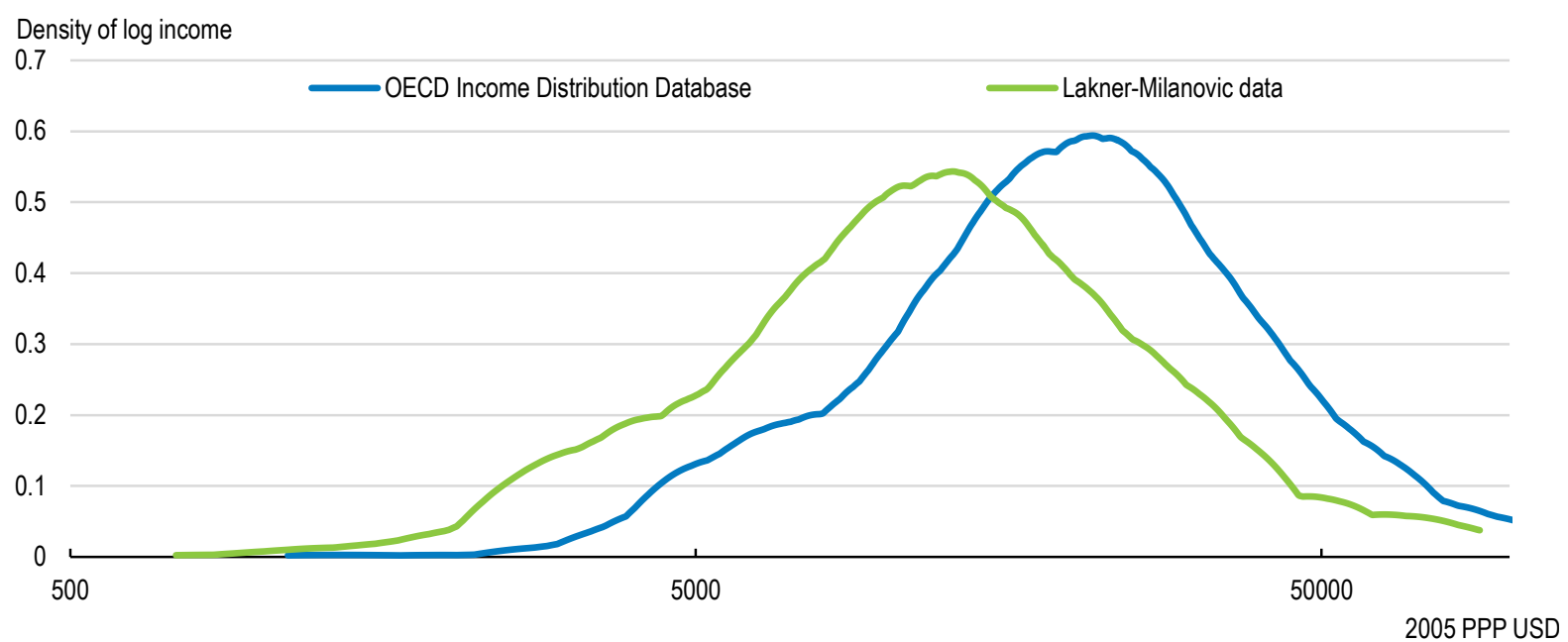

Note: Kernel density estimates based on log mean household disposable income by deciles (see Lakner and Milanovic (2016) for details). Data from the OECD Income Distribution database comprise 34 high-income countries. Household disposable income is equivalised, i.e. economies of scale within the household is assumed by dividing the combined household income by the square root of the number of household members. Data from Lakner and Milanovic (2016) comprise 38 high-income countries. Household income is not equivalised, i.e. the combined household income is divided by the number of household members, assuming no economies of scale.

Source: Authors' calculations based on data from Lakner and Milanovic (2016) and OECD Income Distribution Database. 
Figure A2. The global income distribution for high-income countries based on decile data and lognormal-fitted income distributions

Global income distribution for high-income countries, 2013

A. Based on mean income by country-deciles

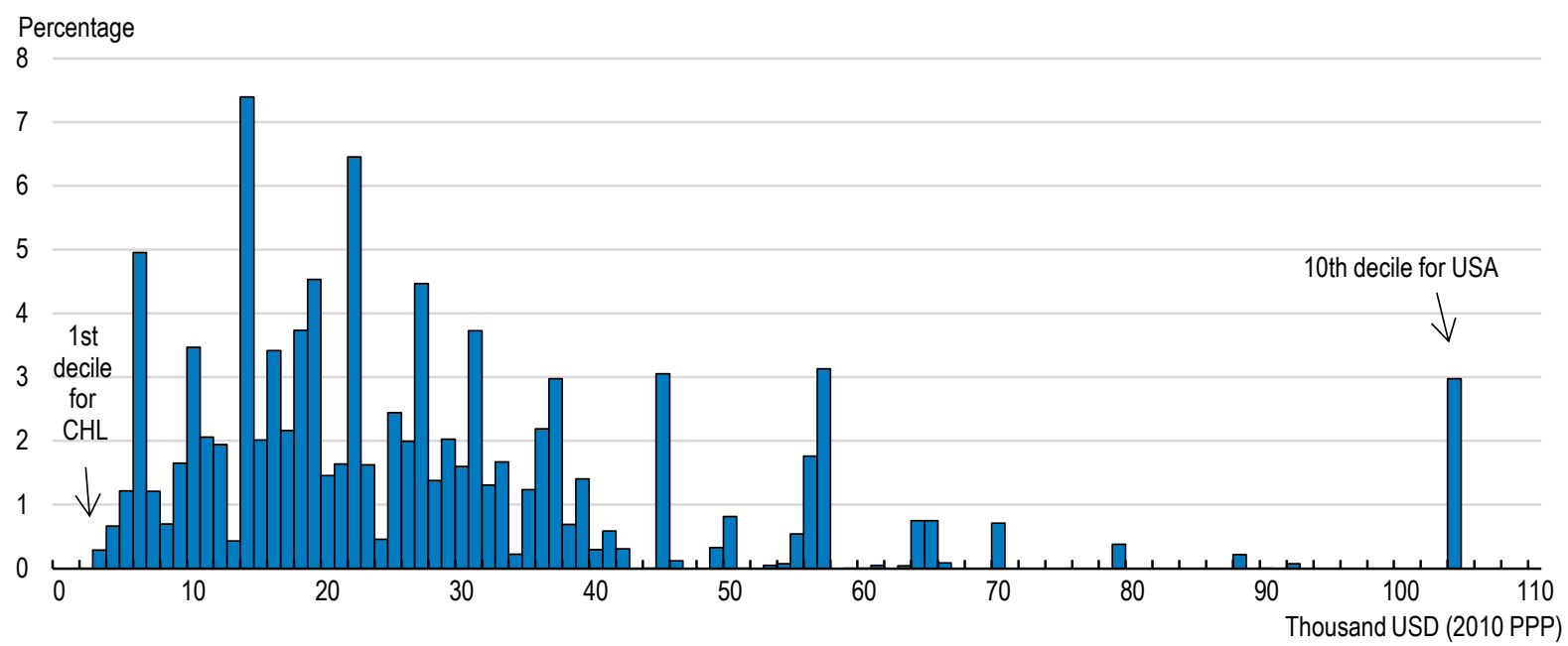

B. Based on lognormal-fitted income distributions at the country level

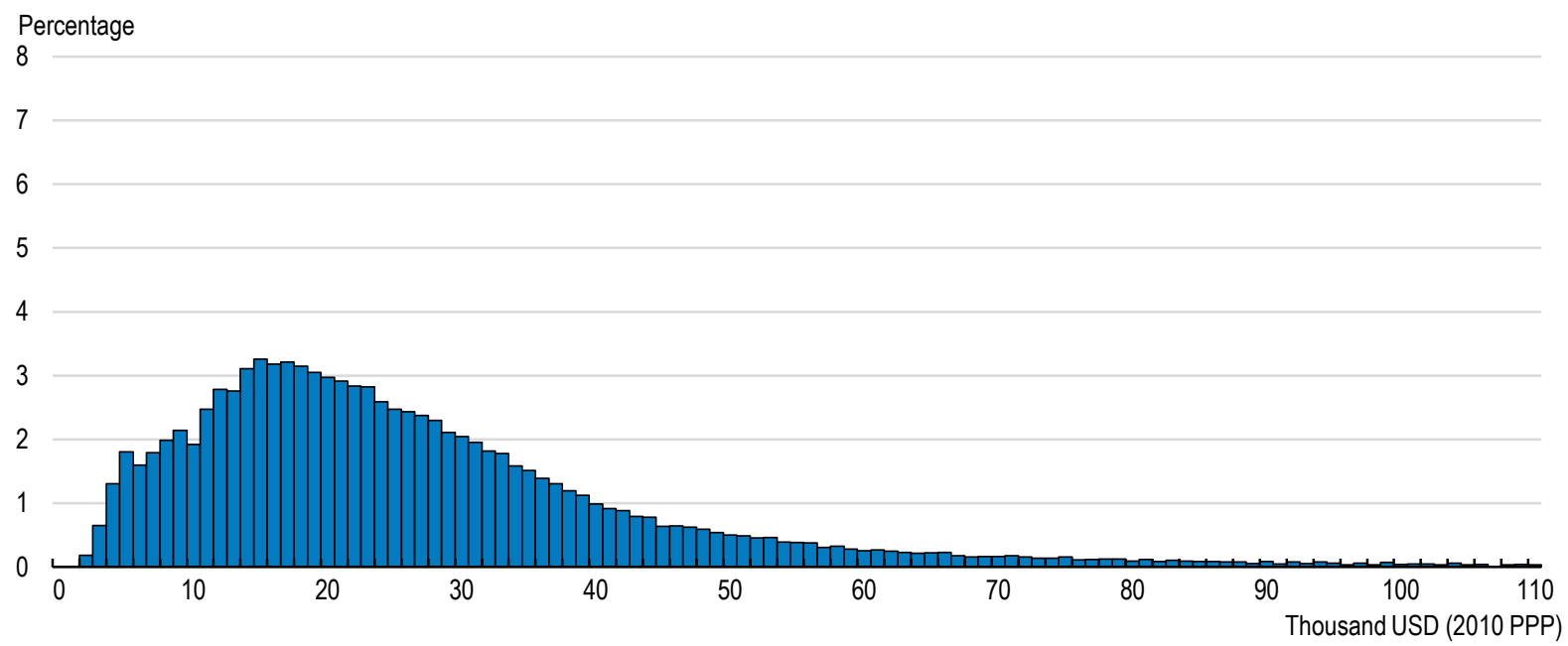

Note: Based on household disposable incomes for 34 high-income countries (see Table A1). Panel A shows the global income distribution for high-income countries based on population-weighted mean incomes by country-deciles (i.e. 34 x 10 data points). Panel B shows the same global income distribution for high-income countries based on fitted lognormal income distributions at the country level (applying the "ungroup" command in the DASP package (Abdelkrim and Duclos, 2007).

Source: Author's calculations based on the OECD Income Distribution Database. 
Figure A3. Composition of the global income distribution for 17 high-income countries

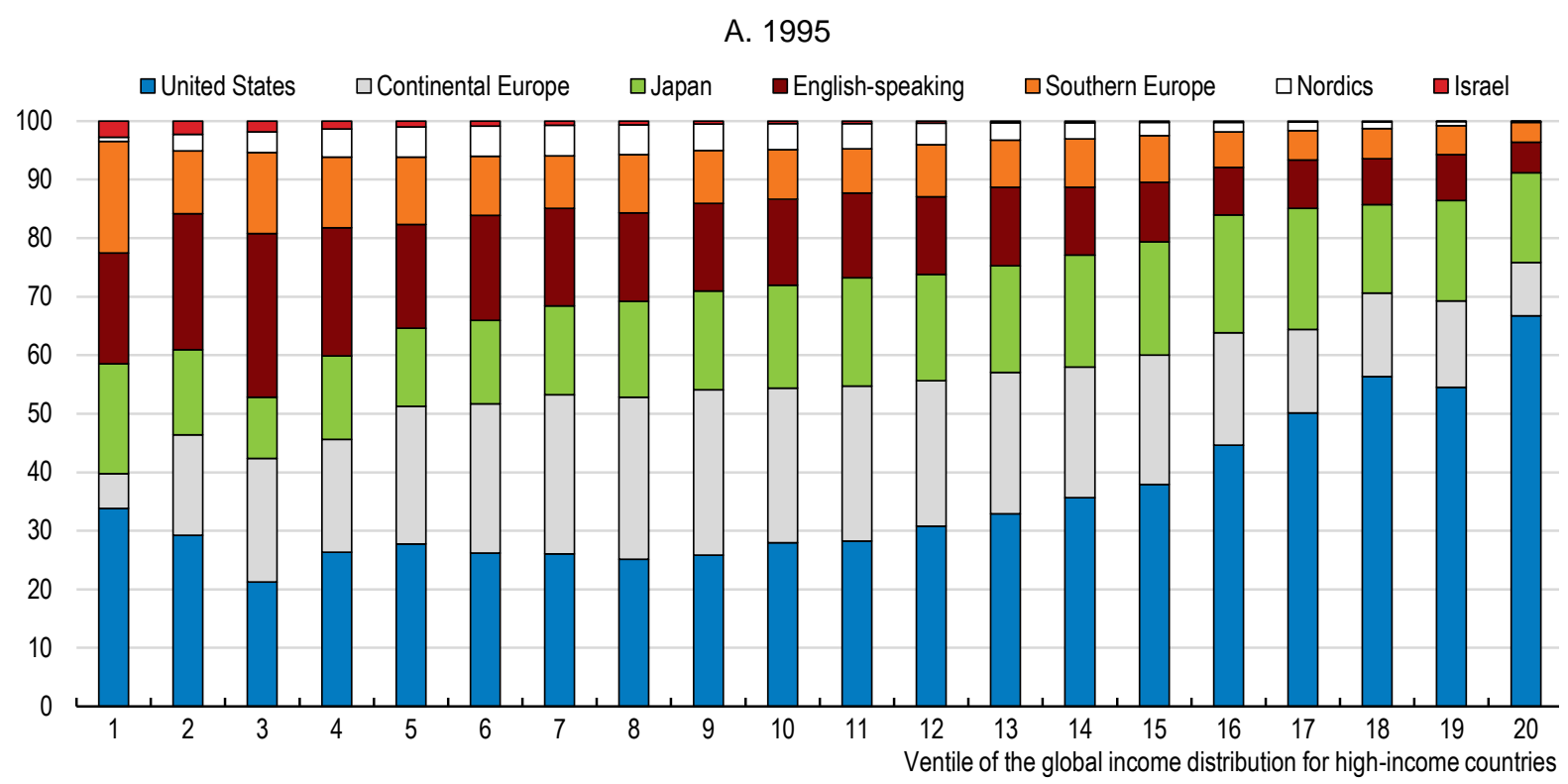

B. 2013

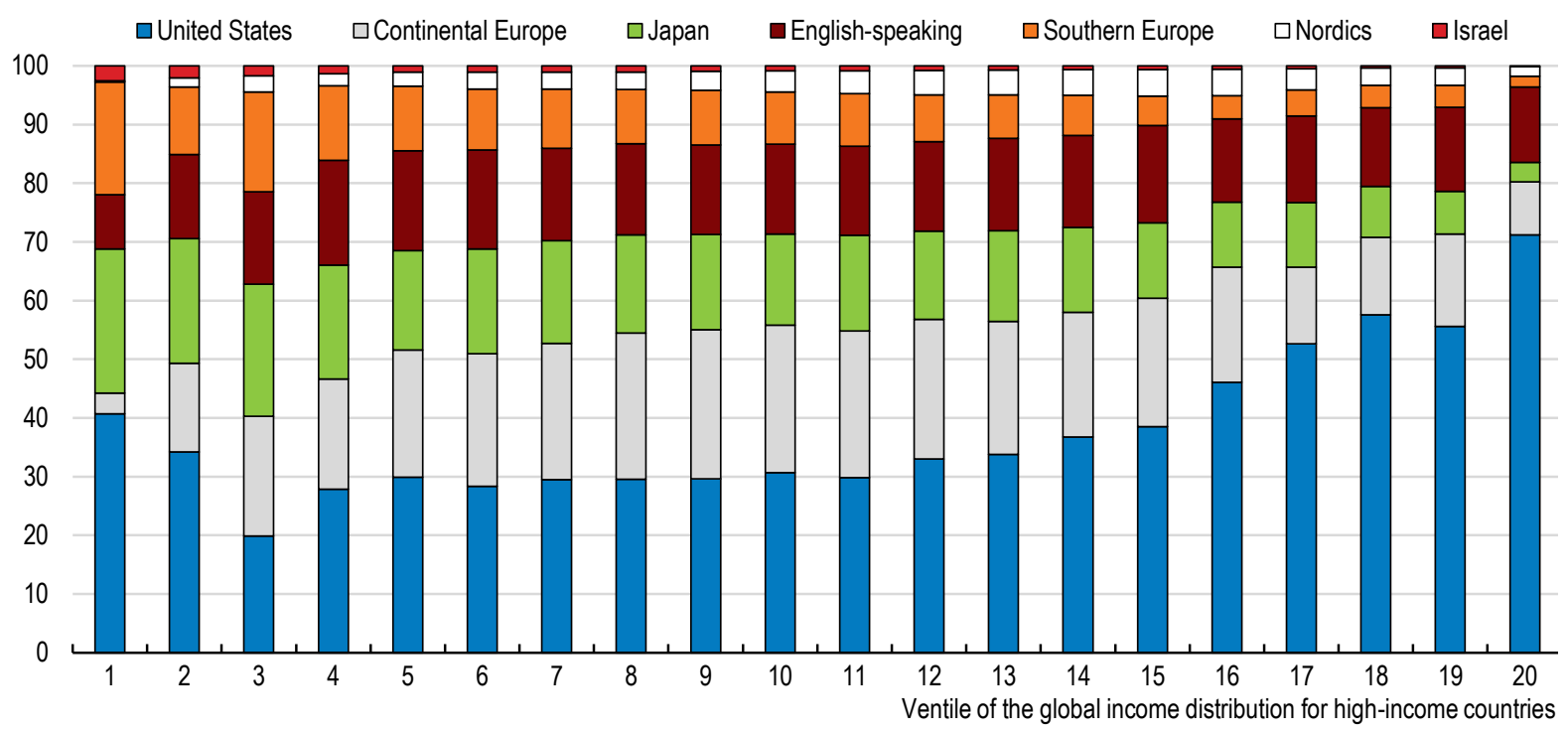

Note: Based on 17 high-income countries (see Tables A1 and A2) and using lognormal-fitted income distributions at the country level (see Section 3.1). Continental Europe refer to France, Germany, Luxembourg and the Netherlands; English-speaking refer to Australia, Canada, New Zealand and the United Kingdom; Southern Europe refer to Greece and Italy; Nordics refer to Denmark, Finland, Norway and Sweden.

Source: Author's calculations based on the OECD Income Distribution Database. 
Figure A4. Decomposing the global growth incidence curve for high-income countries into within and between-country profiles: subperiods
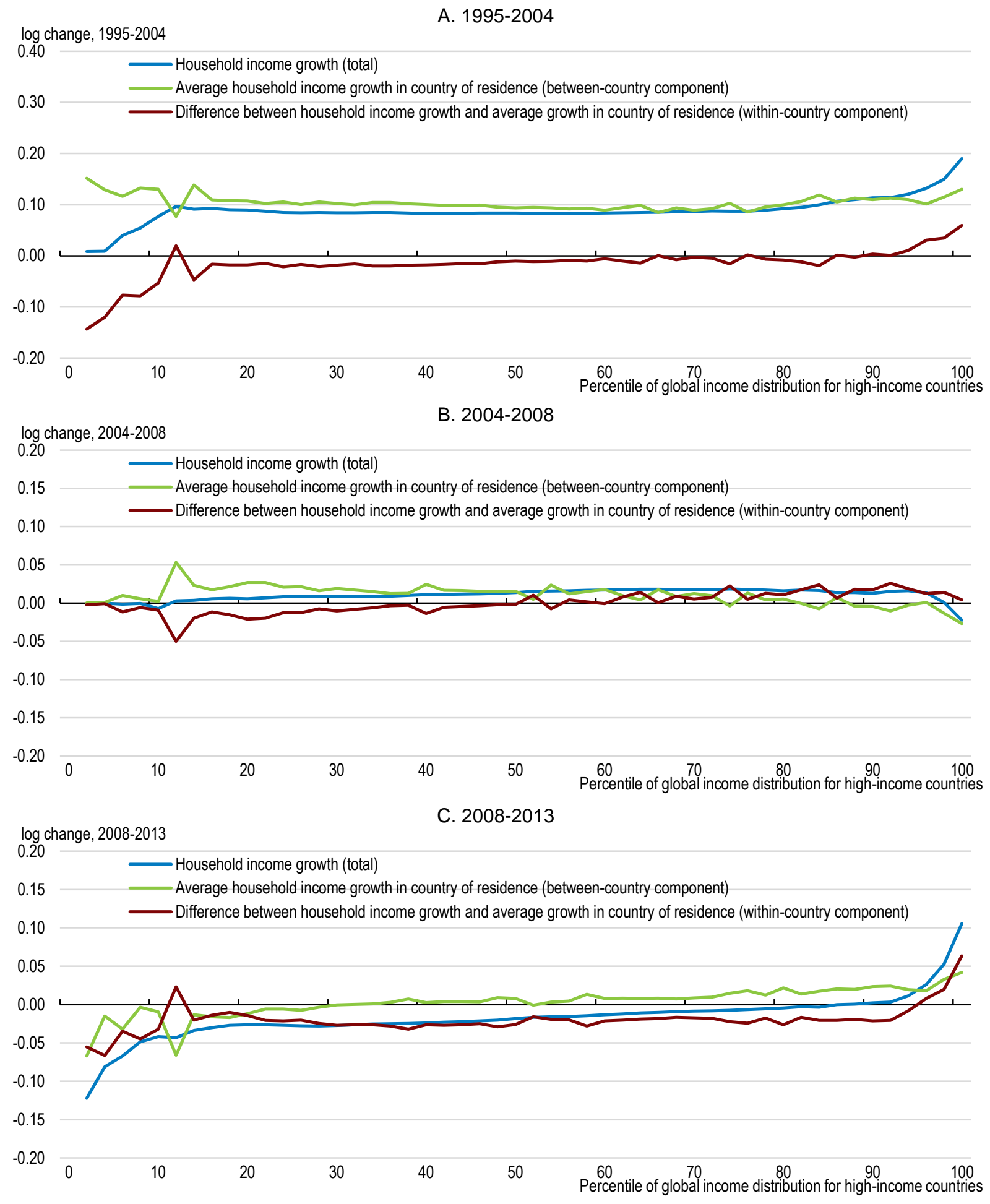

Note: Based on 17 high-income countries. See Tables A1 and A2 in the Annex for country and year coverage.

Source: Author's calculations based on the OECD Income Distribution Database. 
Figure A5. Decomposing the global growth incidence curve from Lakner and Milanovic (2016) into within and between-country components

Log change in household incomes across, 1988 to 2008

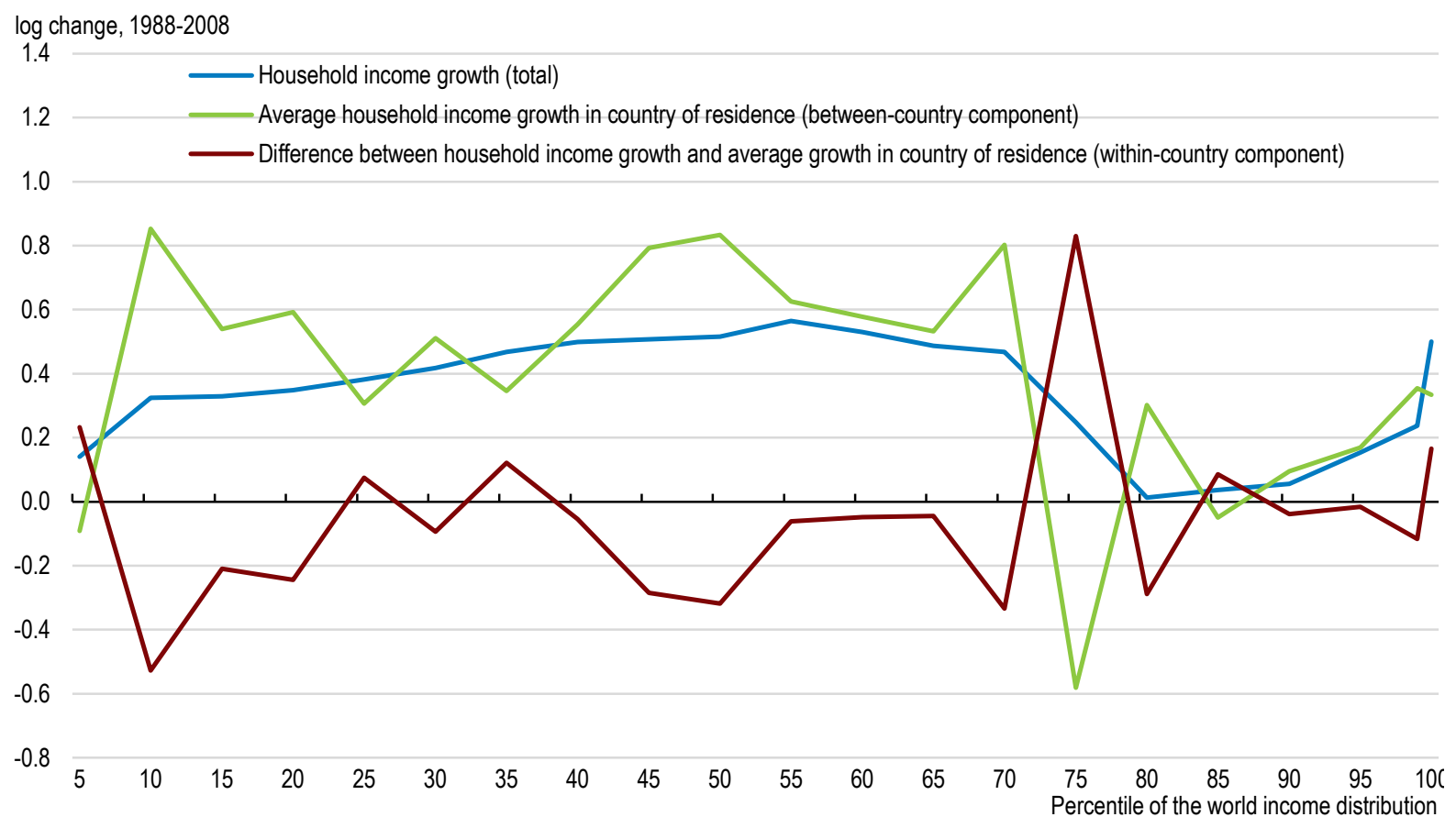

Note: See Section 4.2 for details on the calculations.

Source: Author's calculations based on data from Lakner and Milanovic (2016). 
Figure A6. Movements of individual countries within the global income distribution for high-income countries

Household disposable incomes 1995-2013, based on 17 high-income countries Australia

Canada

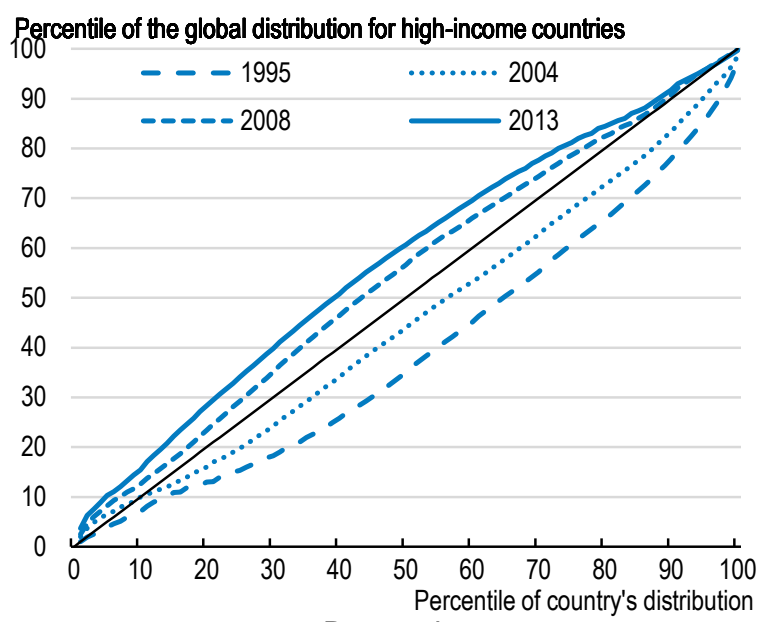

Denmark

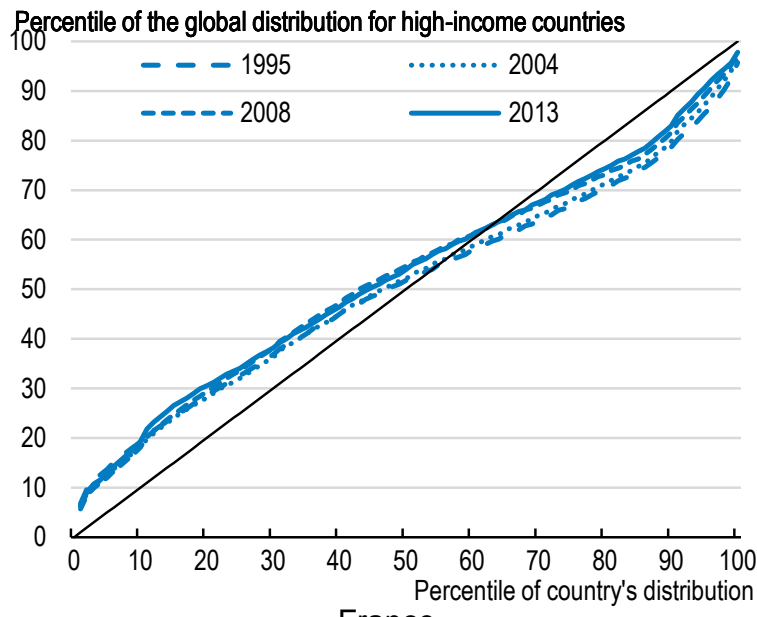
France

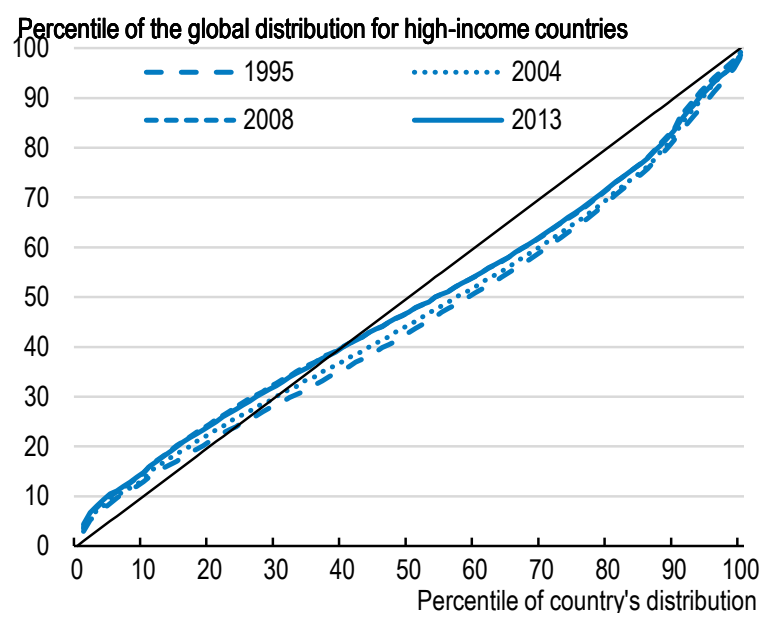

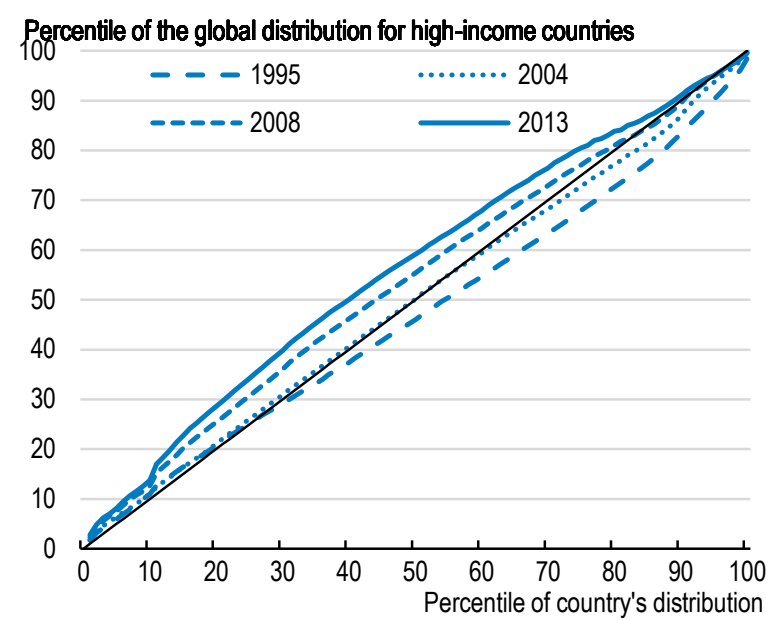

Finland

Percentile of the global distribution for high-income countries

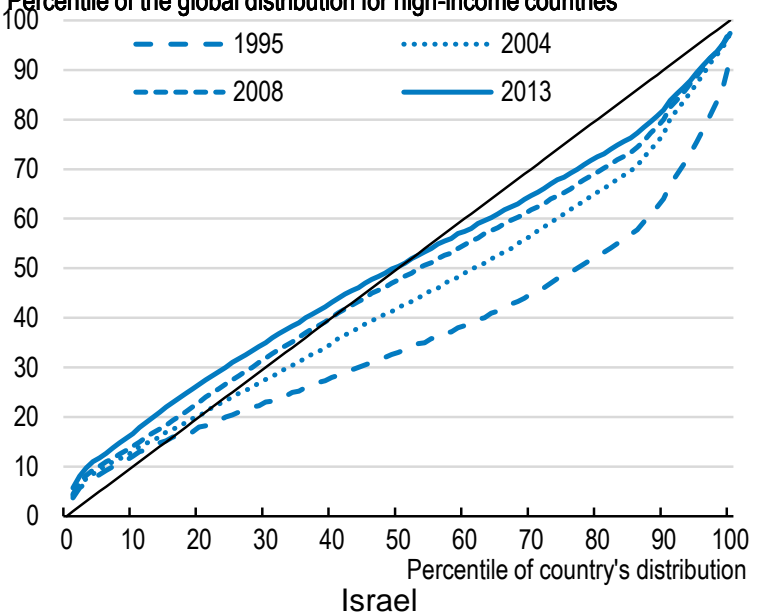

Percentile of the global distribution for high-income countries

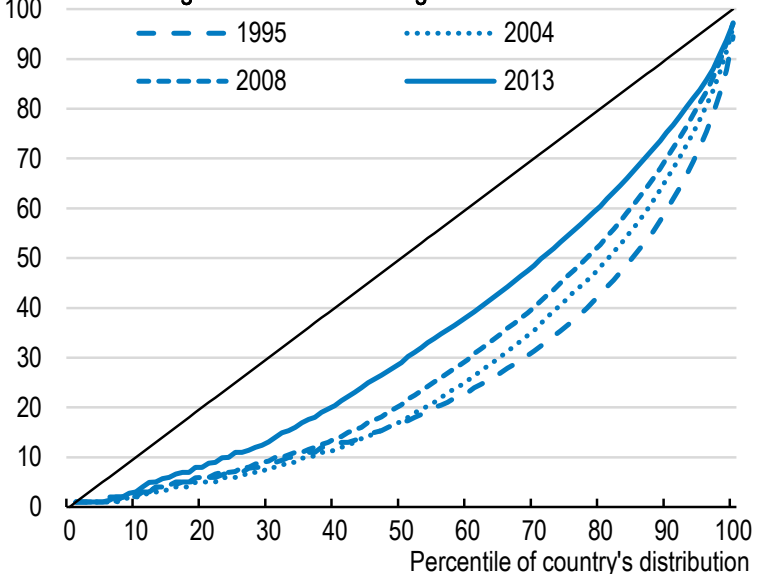


Italy

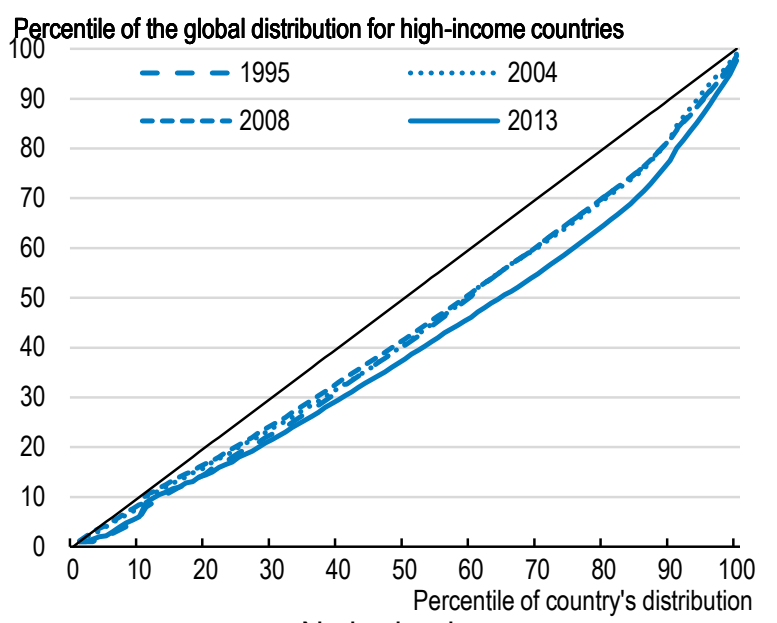

Netherlands
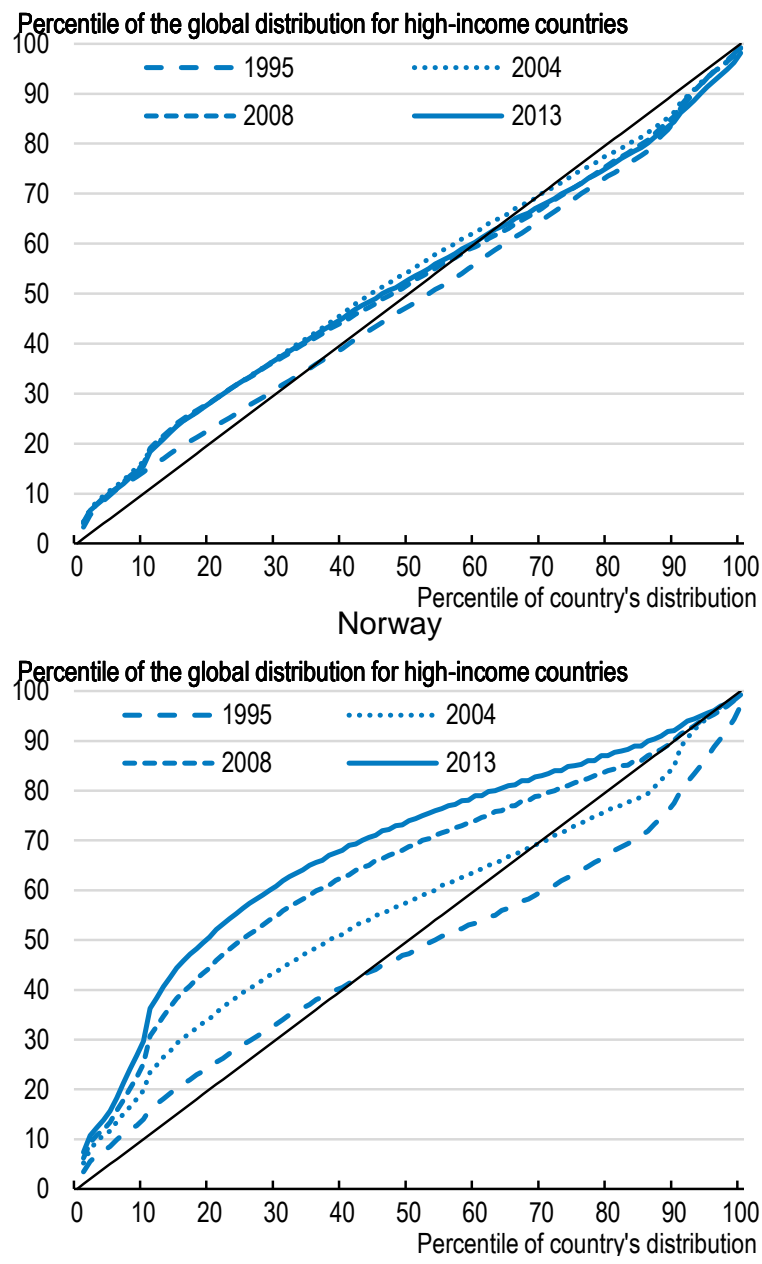

Luxembourg

Percentile of the global distribution for high-income countries

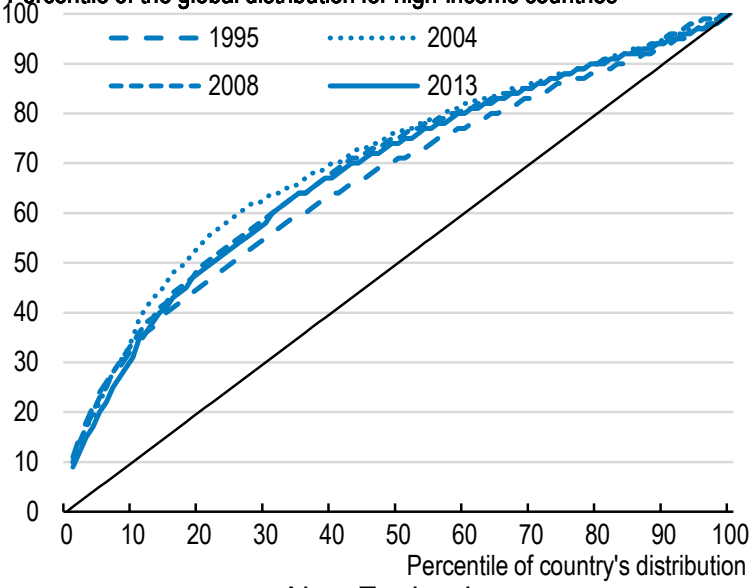

New Zealand

Percentile of the global distribution for high-income countries

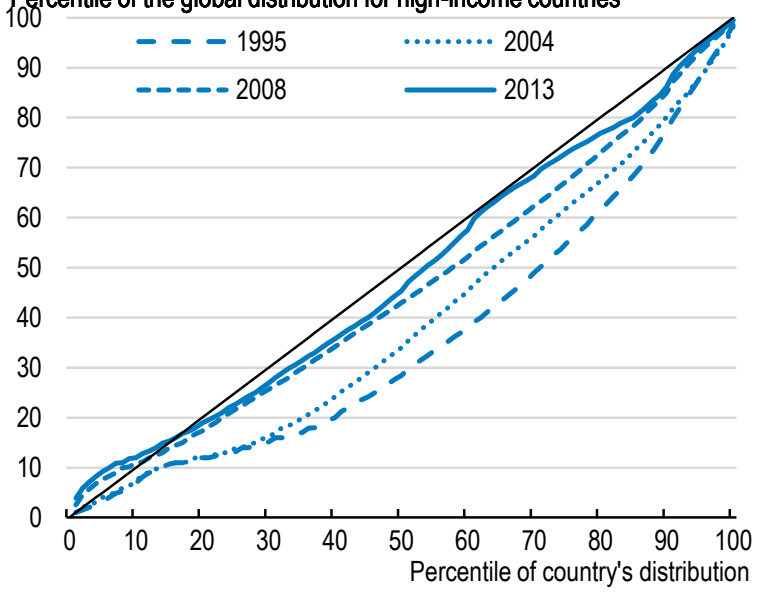

Note: Years shown refer to the global income distribution for high-income countries, for some countries the nearest available year is applied, see Table A2.

Source: Author's calculations based on the OECD Income Distribution Database. 
Figure A7. Quasi non-anonymous global growth incidence curves for high-income countries

Cumulative growth rates for household disposable incomes, based on 17 high-income countries

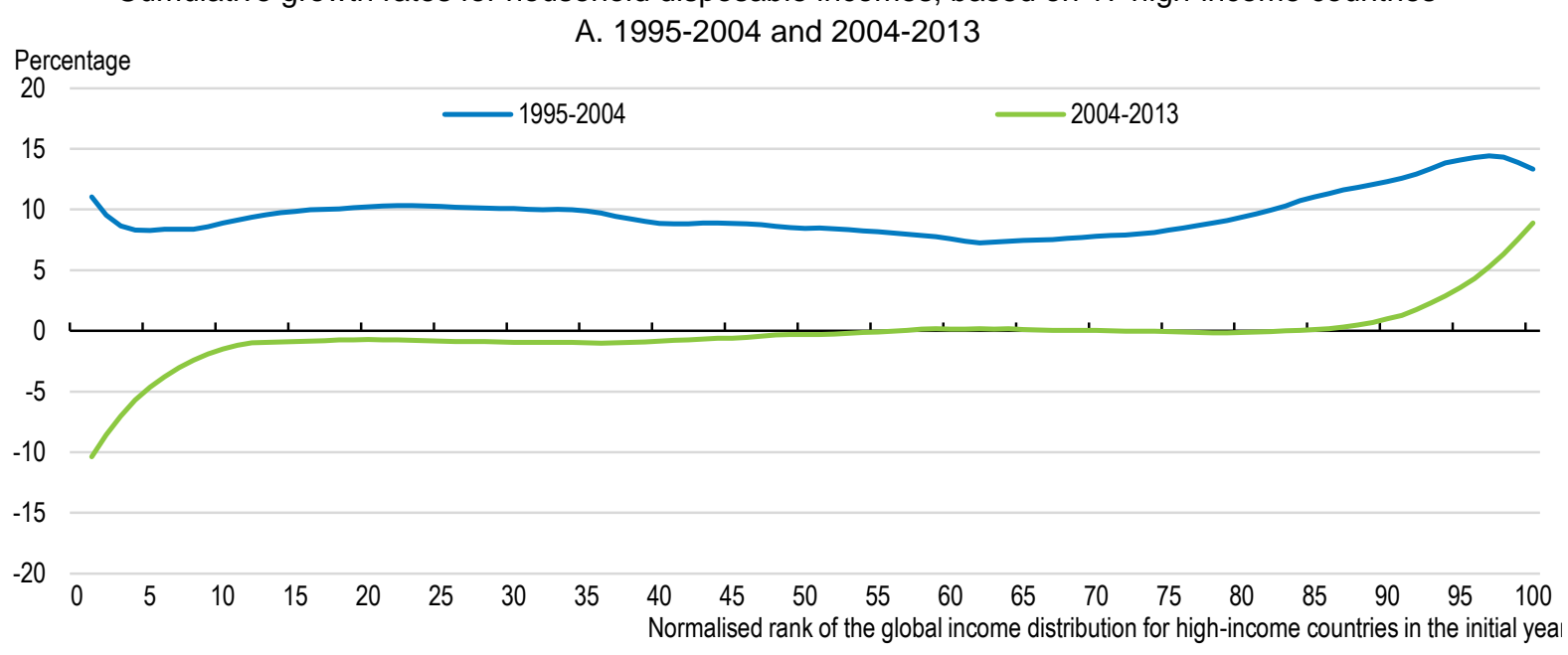

Note: Quasi non-anonymous growth incidence curves are obtained as the predicted value from a kernel-weighted local cubic polynomial regression. In each case country-deciles are placed in the global income distribution for high-income countries according to the initial year. See Tables A1 and A2 in the Annex for country and year coverage.

Source: Author's calculations based on the OECD Income Distribution Database. 


\section{Figure A8. Micro-based household incomes versus national accounts means}

Difference between per capita measures from national accounts and average equivalised household disposable income from microdata, 2013 or latest available year

A. Household disposable income and adjusted household disposable income per capita
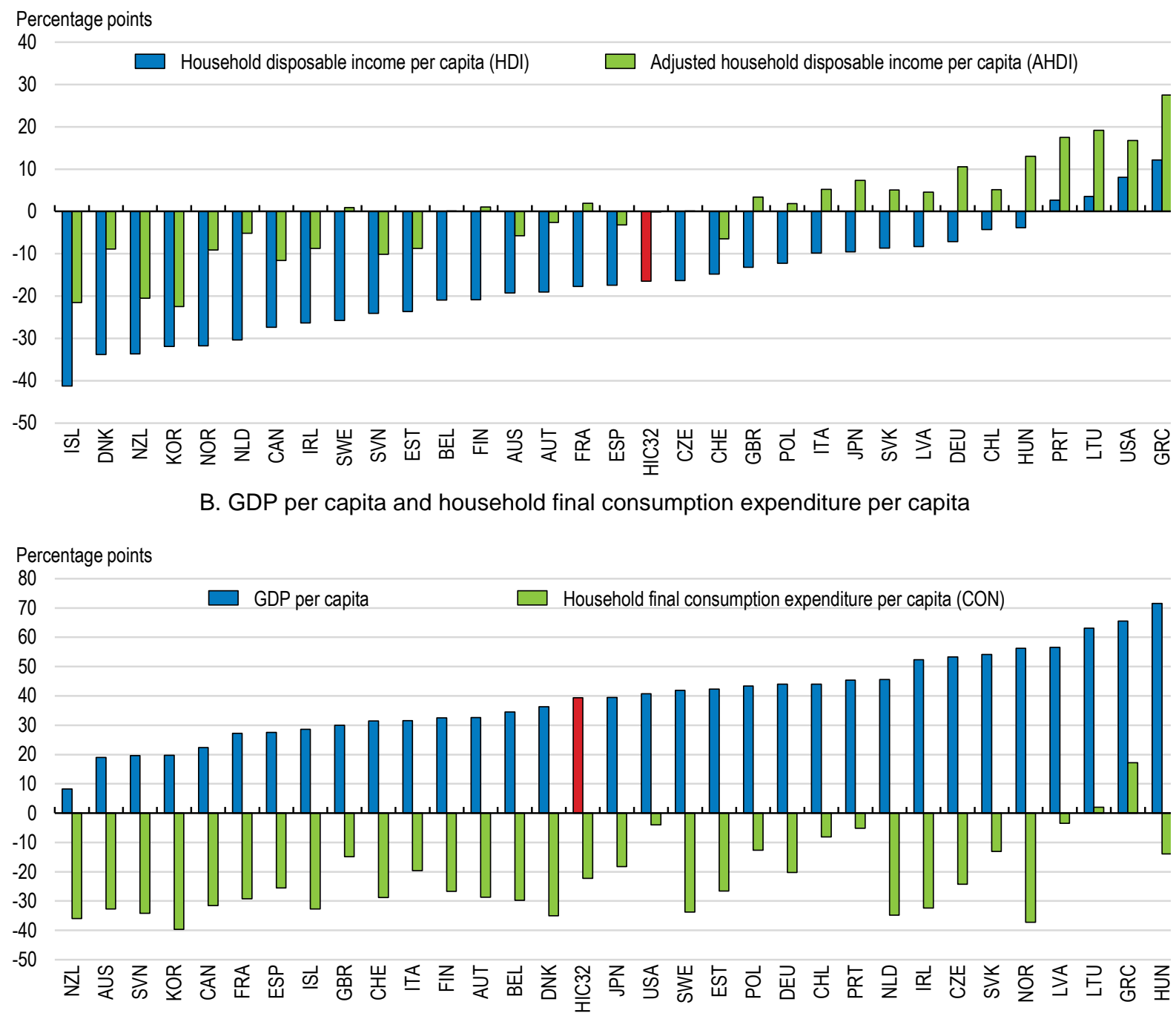

Note: The figure reports the difference between each national accounts mean and average household disposable income from microdata, in per cent of the latter. The four national accounts measures are expressed in per capita terms (no economies of scale), while household disposable incomes from microdata are equivalised to account for economies of scale within households (see Section 3.1). Equivalised household disposable incomes are thus mechanically higher relative to national accounts means. Hence, levels are not comparable, while cross-country differences can be compared.

Source: OECD National Accounts; OECD Income Distribution Database. 
Figure A9. Country positions within the global income distribution for high-income countries for different adjustments to national accounts aggregates

Australia

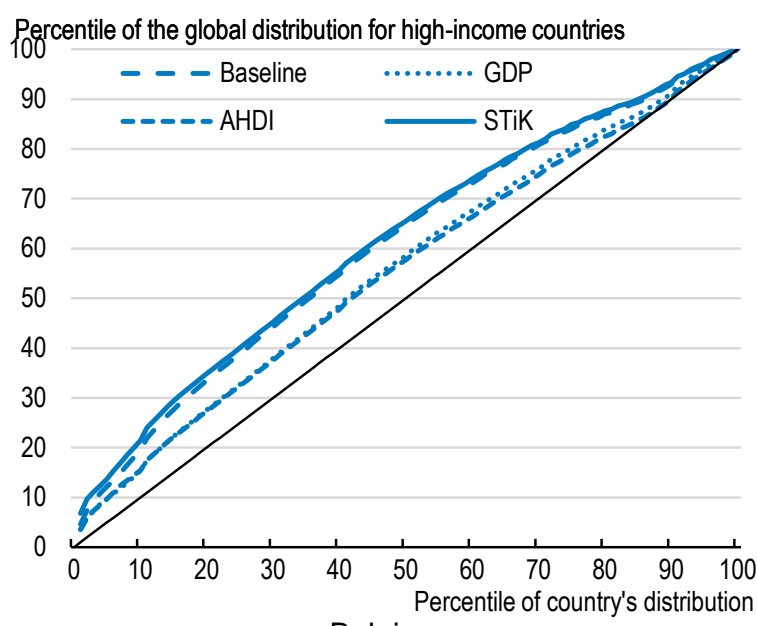

Belgium

Percentile of the global distribution for high-income countries

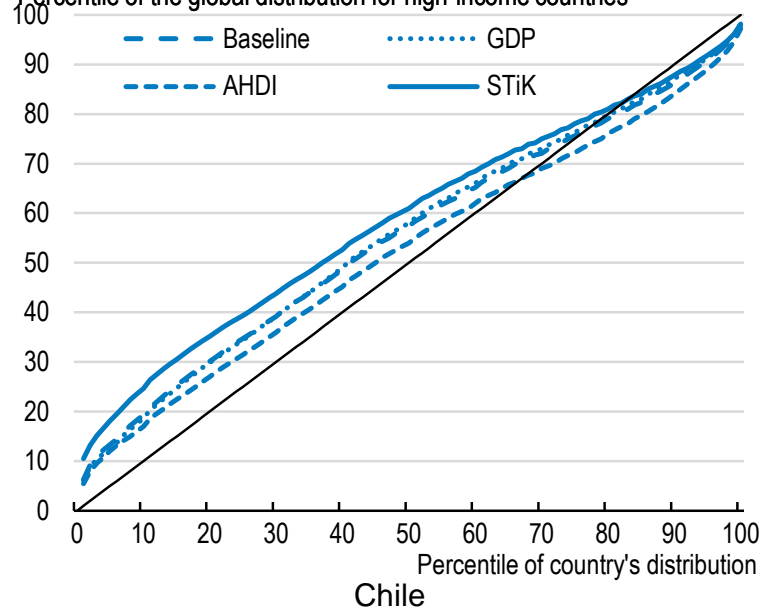

Percentile of the global distribution for high-income countries

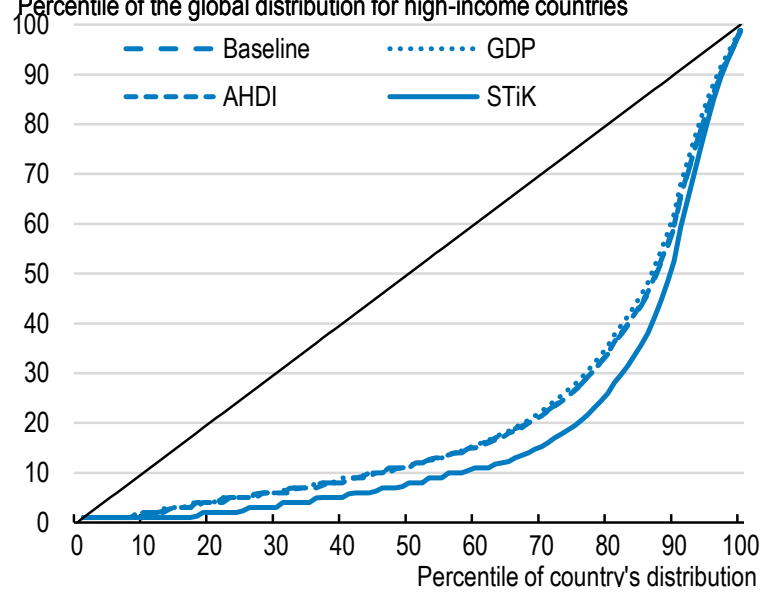

Austria

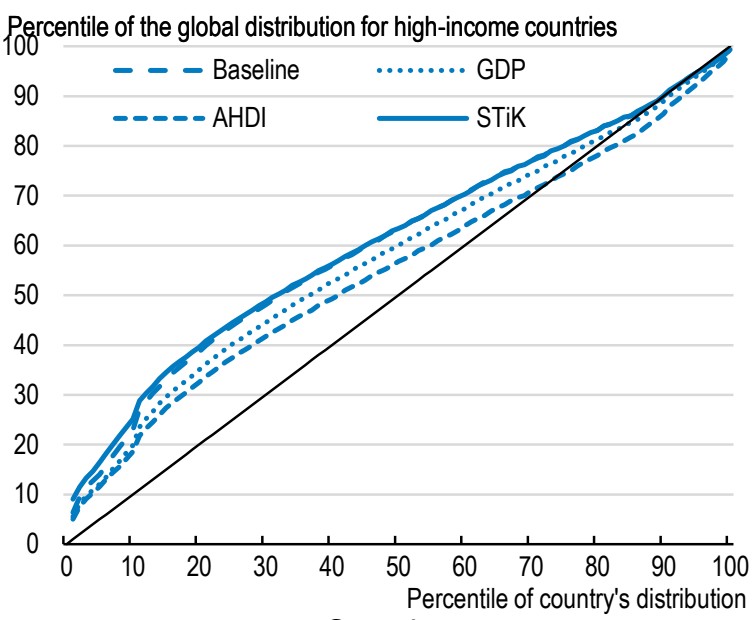

Canada

Percentile of the global distribution for high-income countries

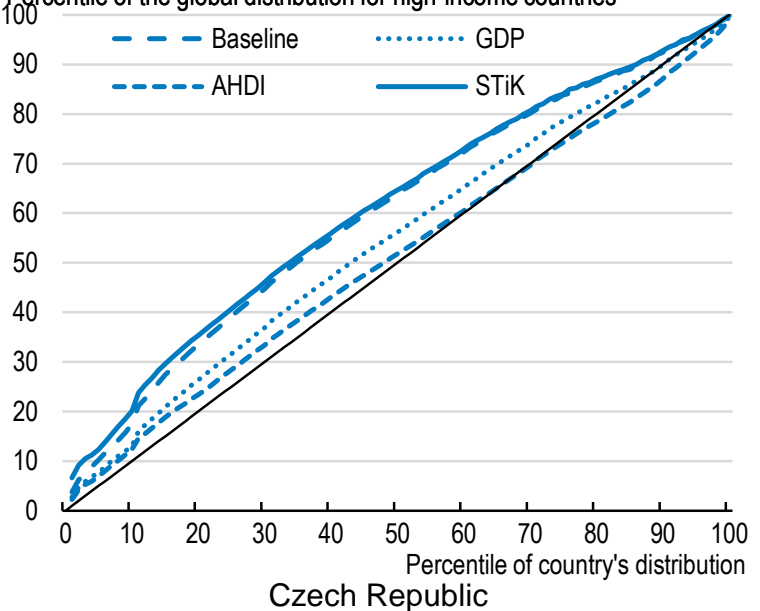

Percentile of the global distribution for high-income countries

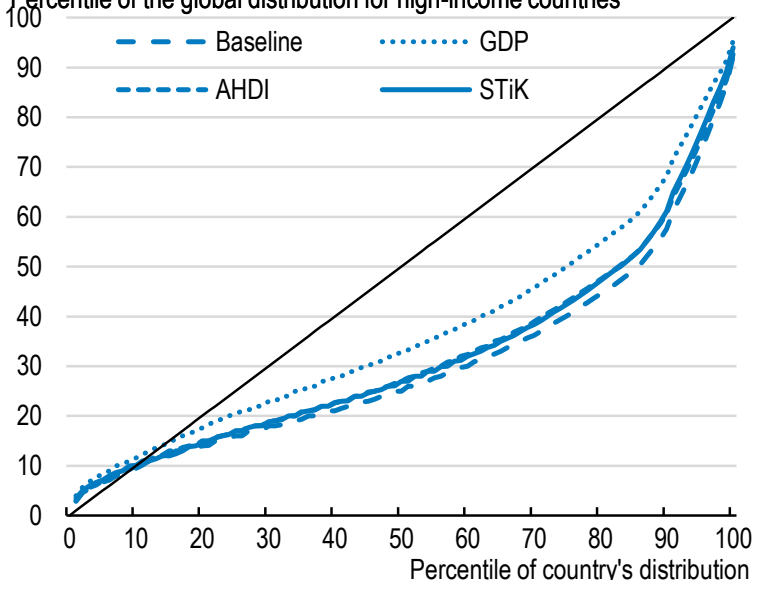


Denmark

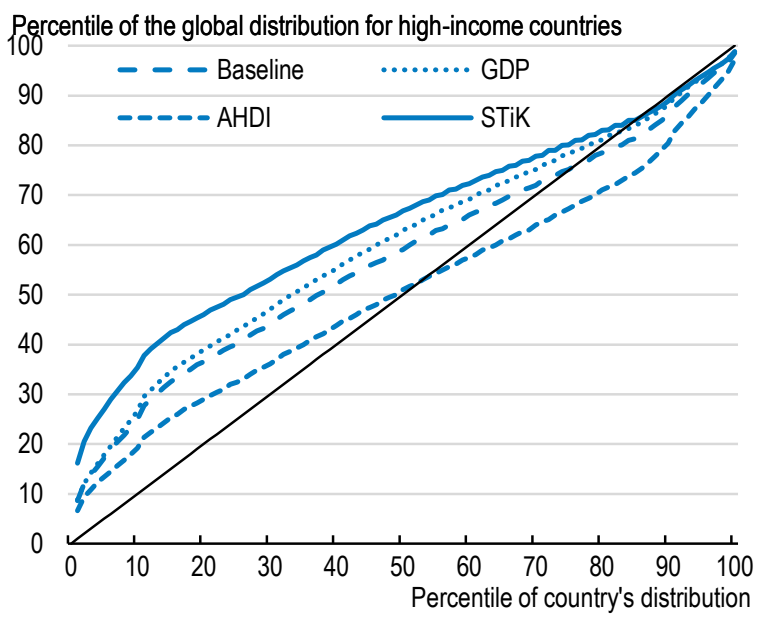

Finland

Percentile of the global distribution for high-income countries
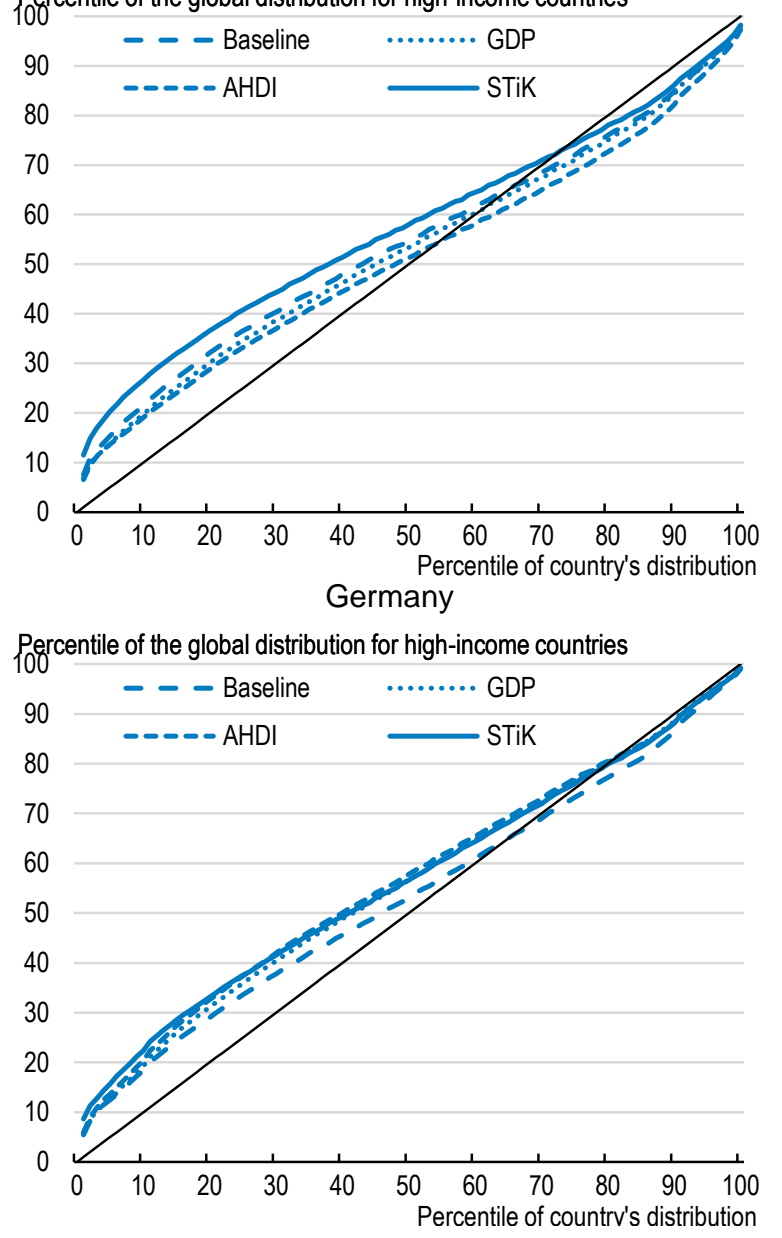

Estonia

Percentile of the global distribution for high-income countries

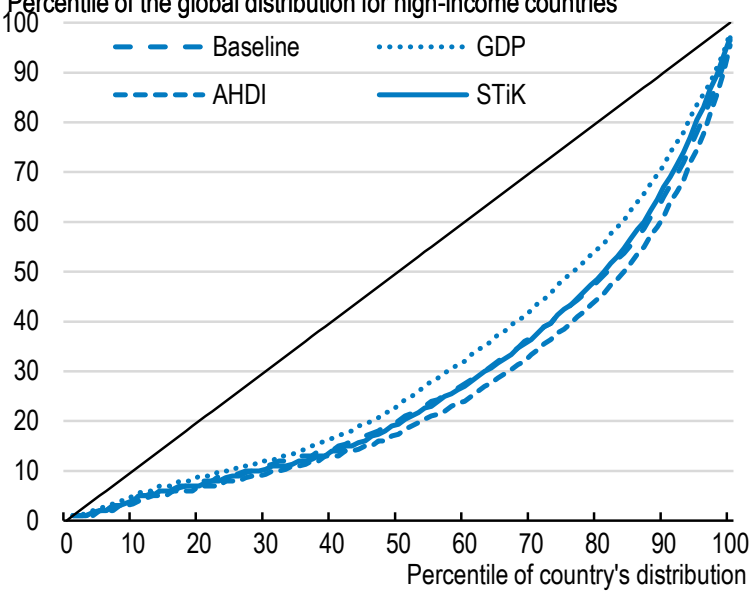

France

Percentile of the global distribution for high-income countries

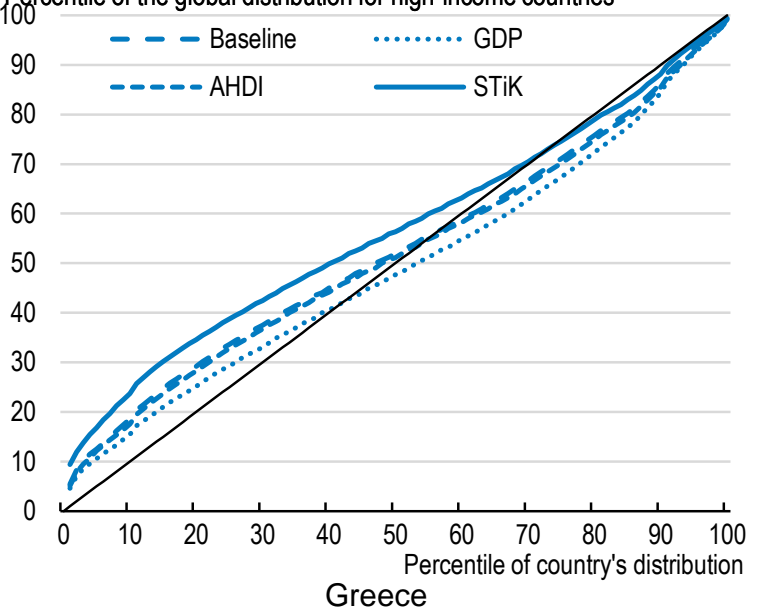

Percentile of the global distribution for high-income countries

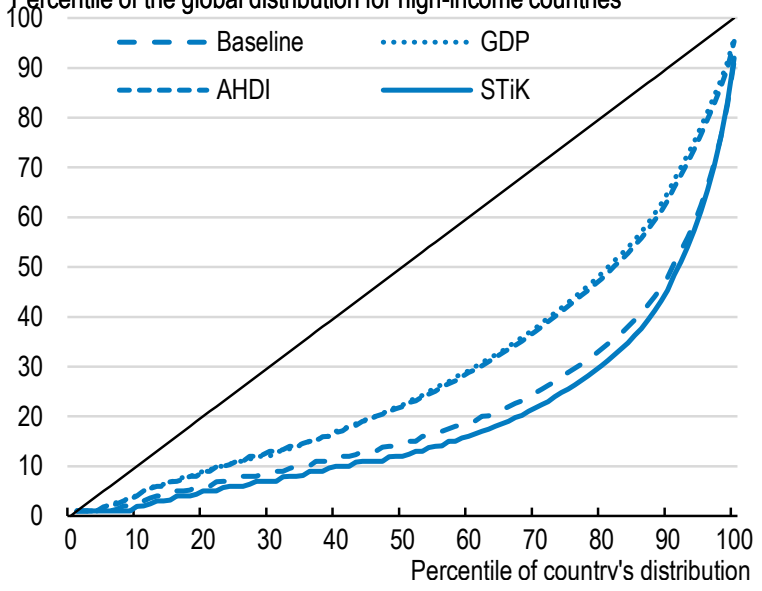


Hungary

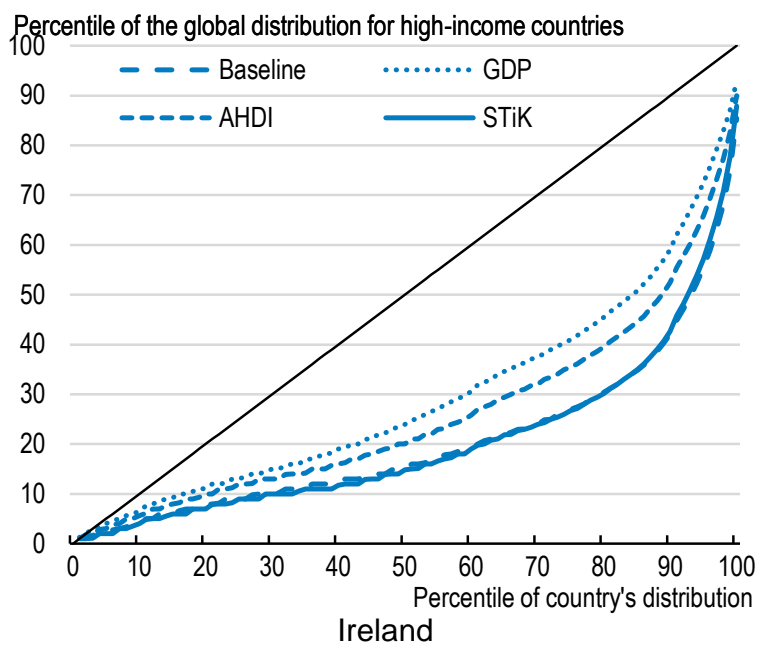

Percentile of the global distribution for high-income countries
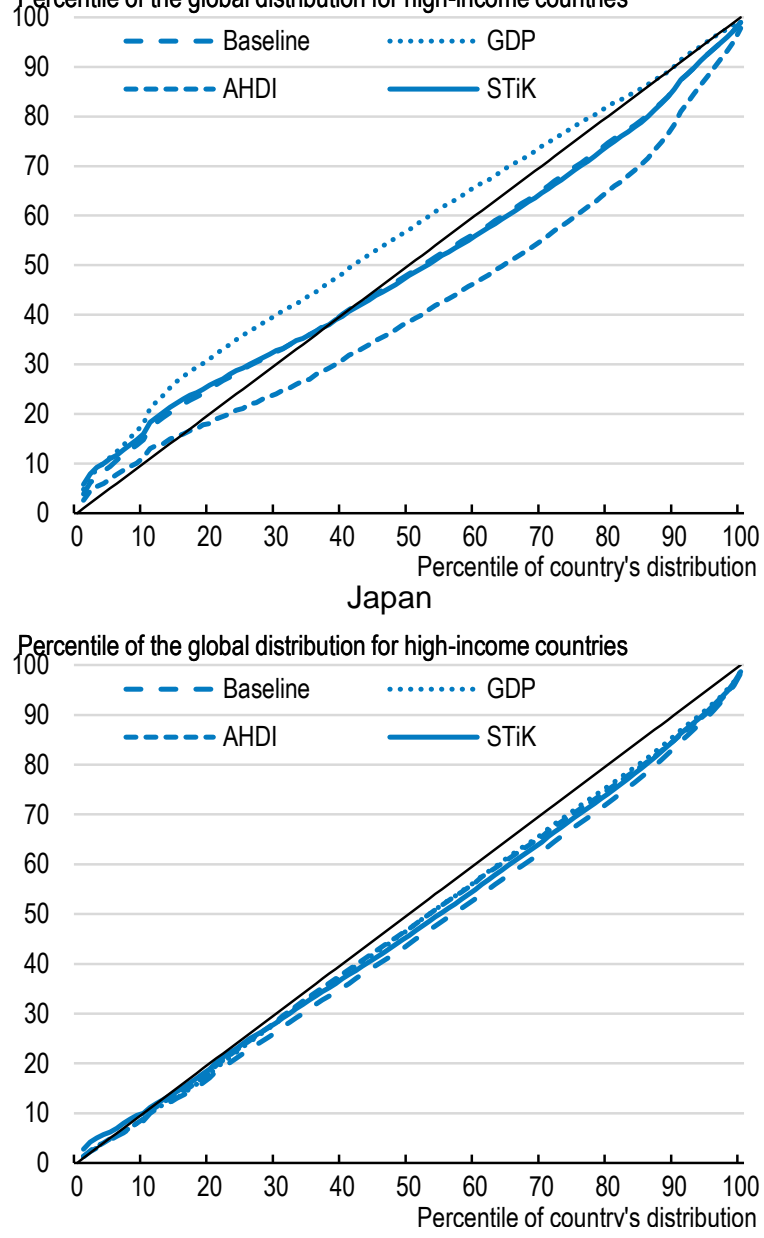

Iceland

Percentile of the global distribution for high-income countries

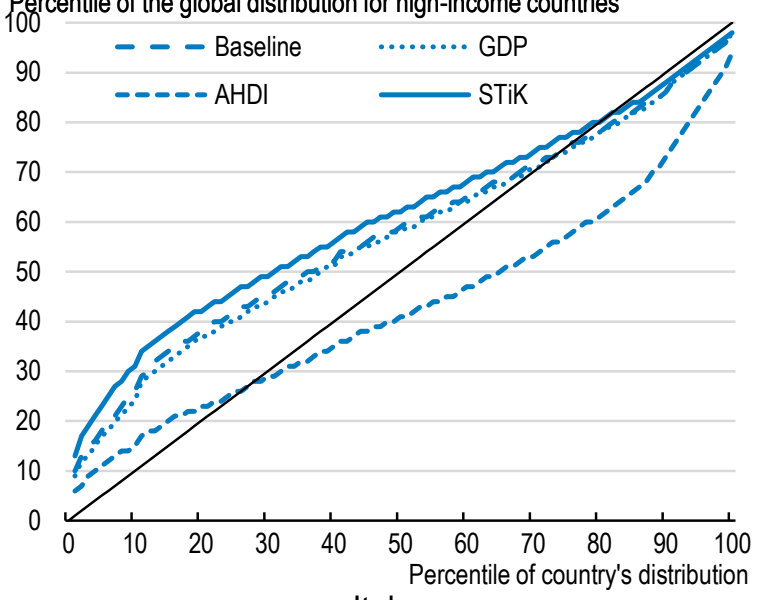
Italy

Percentile of the global distribution for high-income countries

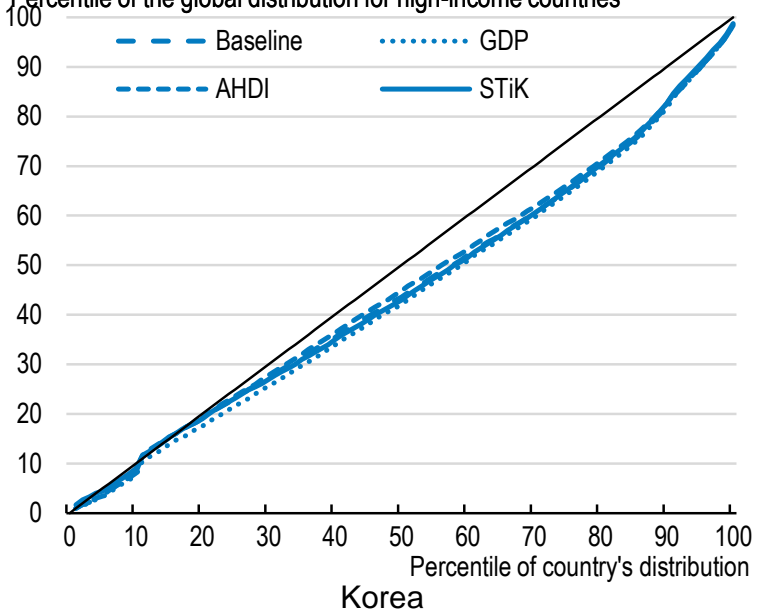

Percentile of the global distribution for high-income countries

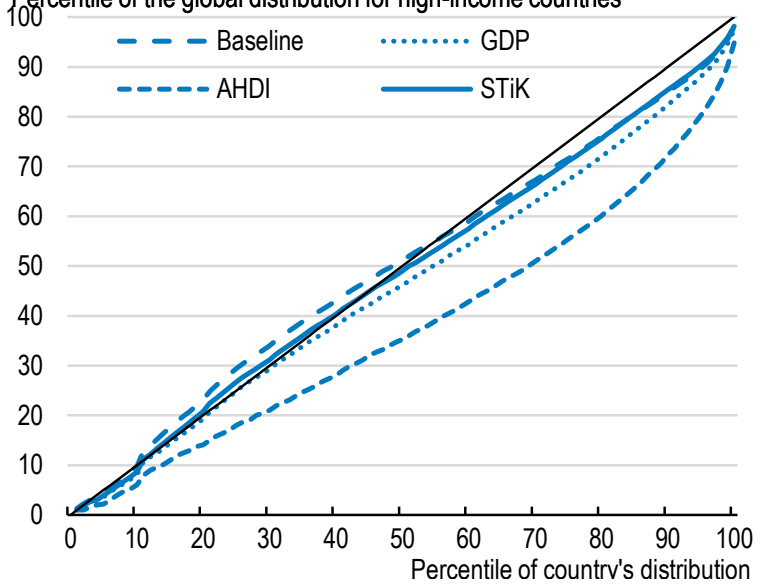


Latvia

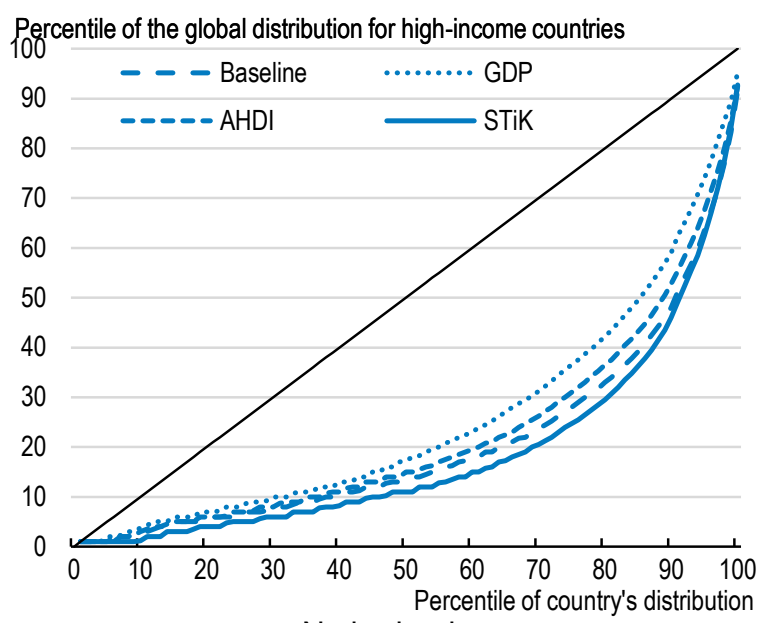

Netherlands
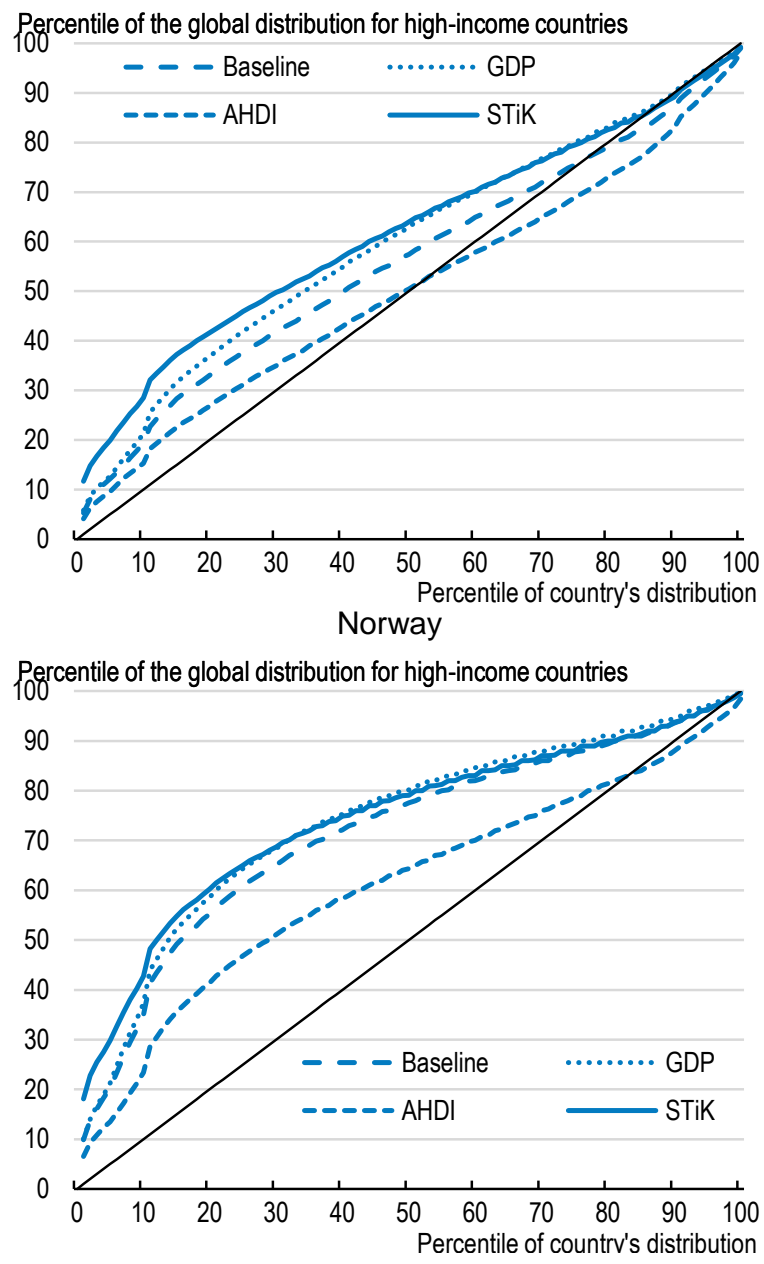

Lithuania

Percentile of the global distribution for high-income countries

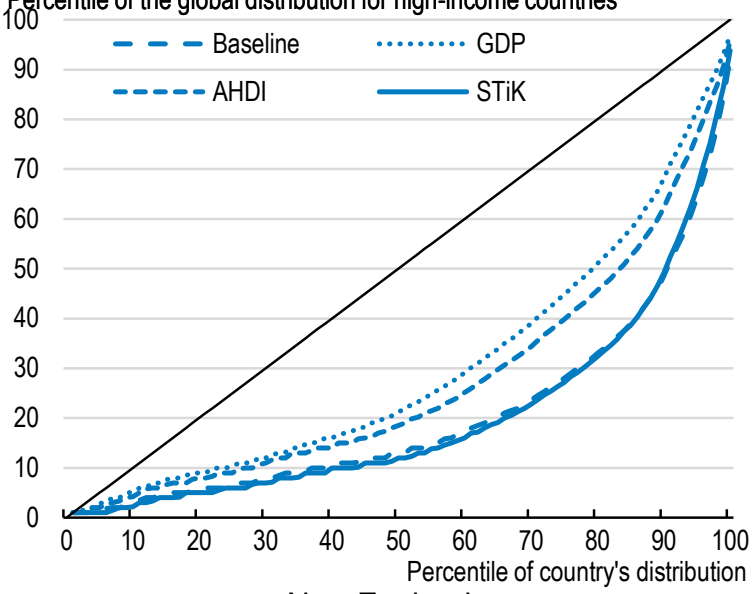

New Zealand

Percentile of the global distribution for high-income countries

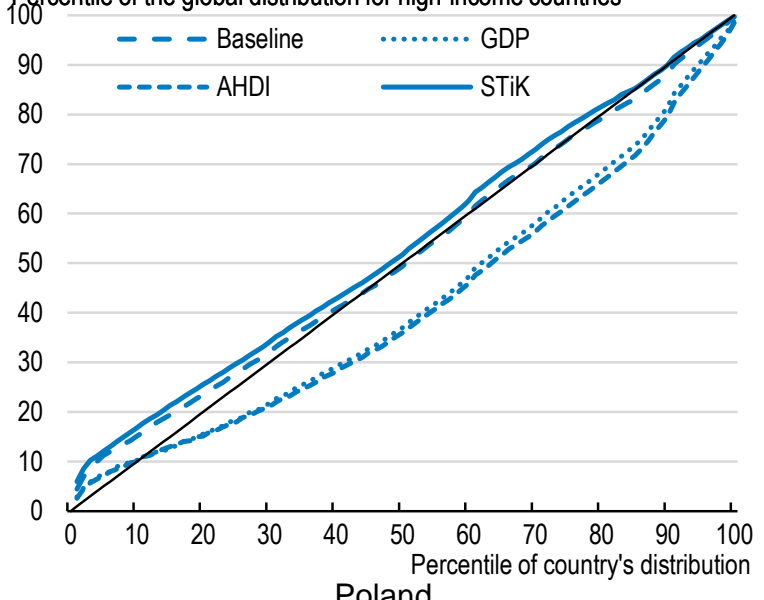
Poland

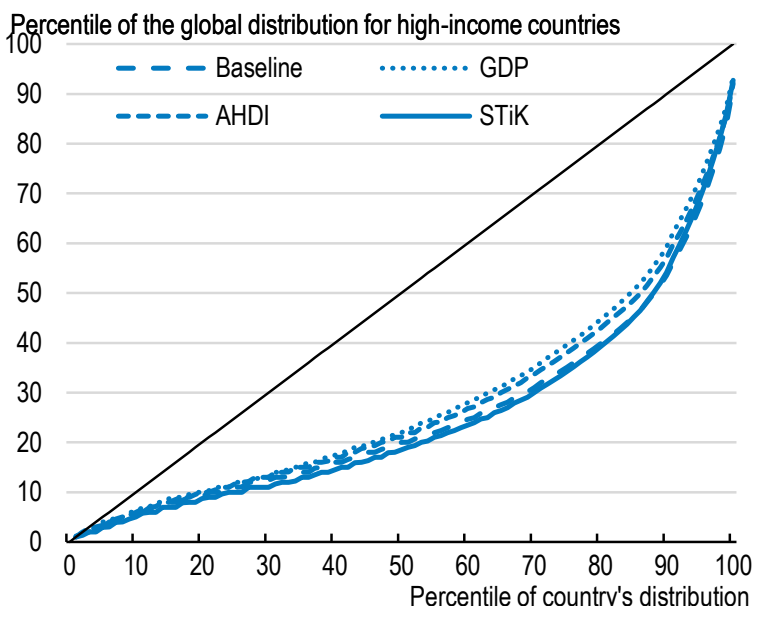


Portugal

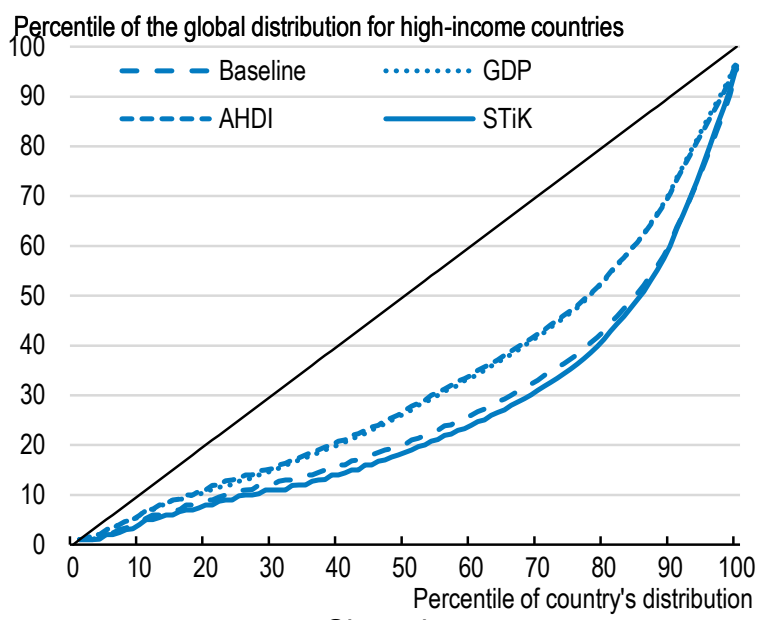

Slovenia
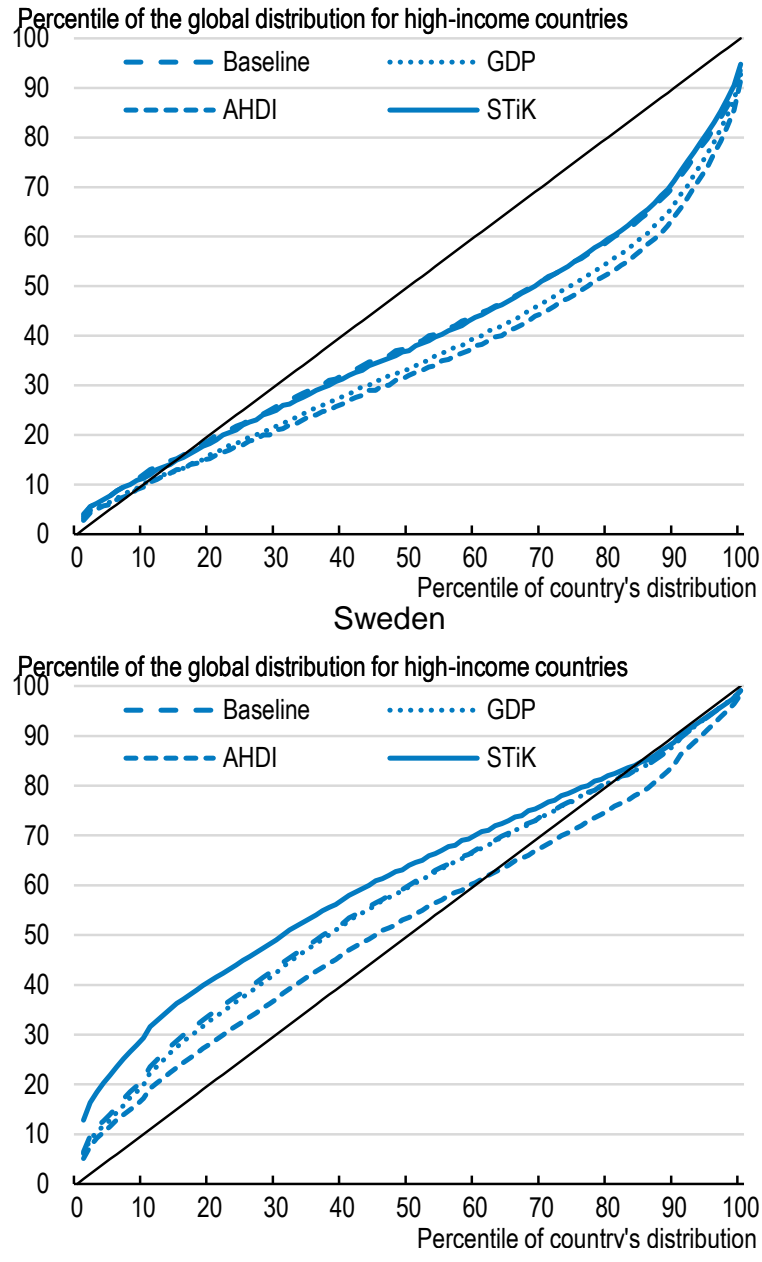

Slovak Republic

Percentile of the global distribution for high-income countries

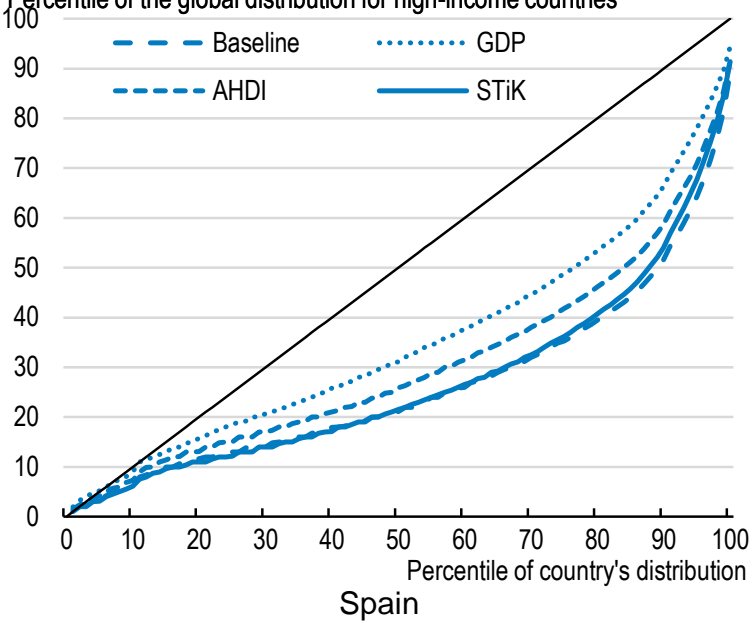

Percentile of the global distribution for high-income countries

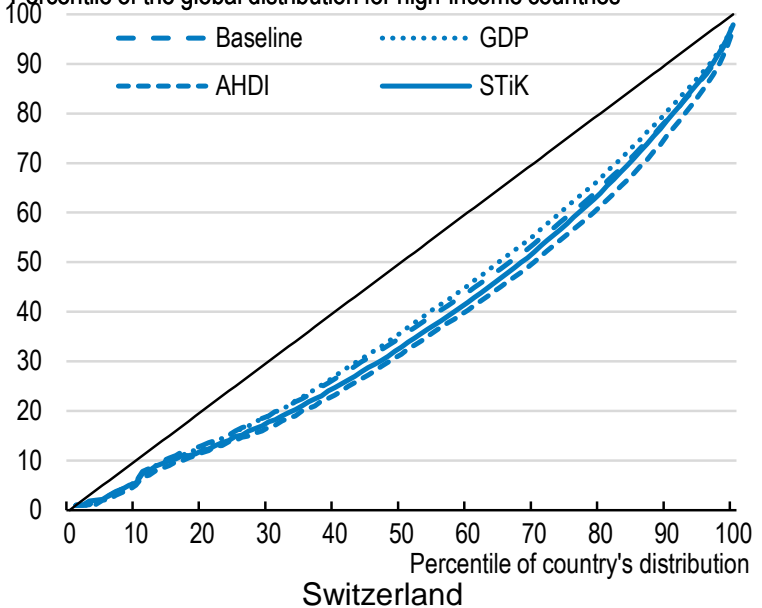

Percentile of the global distribution for high-income countries

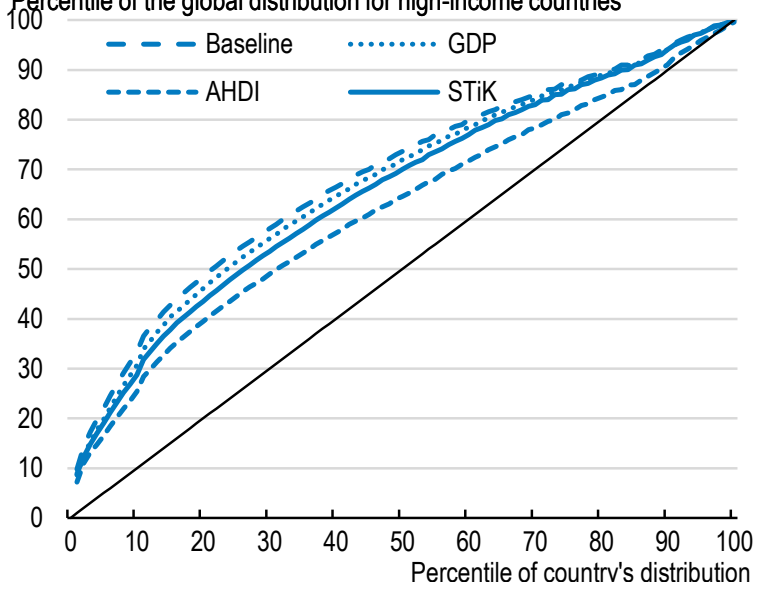


United Kingdom

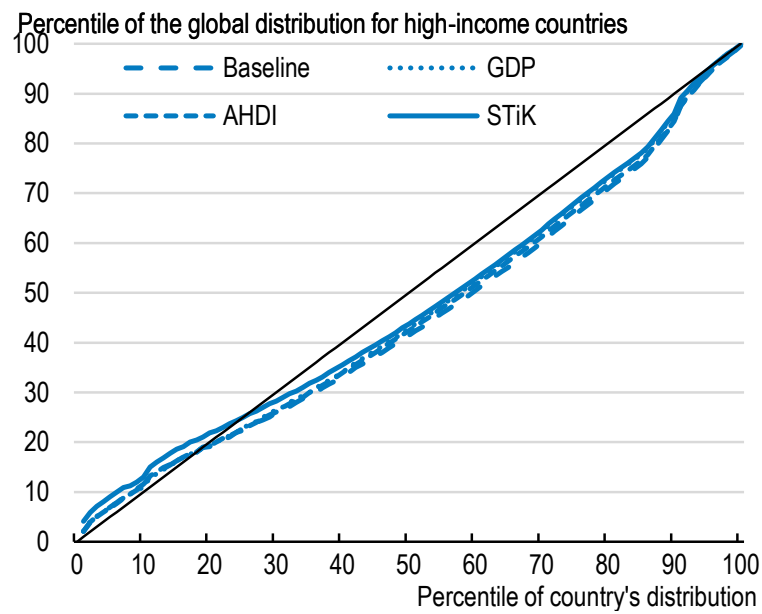

United States

Percentile of the global distribution for high-income countries

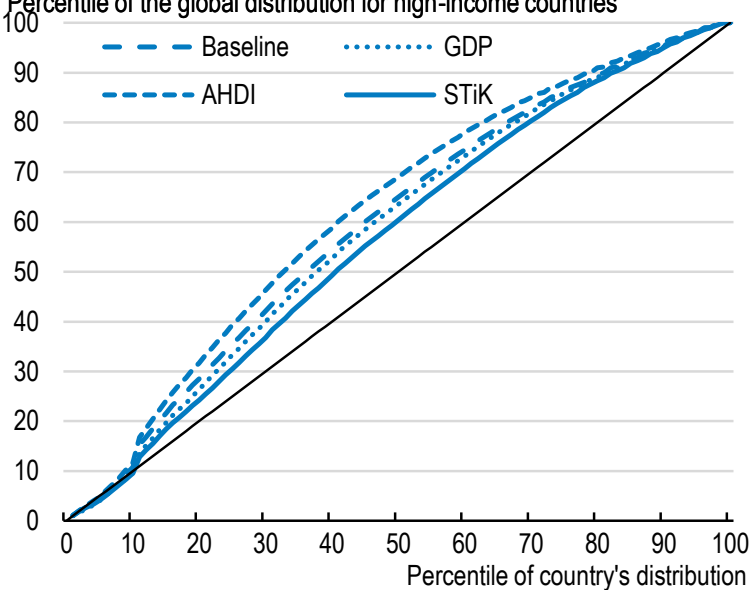

Note: Baseline refers to the distribution based on microdata; GDP refers to scaling by GDP per capita; AHDI refers to scaling by adjusted household disposable income per capita; STiK refers to equal allocation of STiK per capita spending. See Table 4 for construction of the series and deflators and PPPs applied. Israel and Luxembourg are excluded because of missing data.

Source: Author's calculations based on the OECD Income Distribution Database. 